\title{
A Realistic Greenland Ice Sheet and Surrounding Glaciers and Ice Caps Melting in a Coupled Climate Model
}

\author{
Marion Devilliers ( $\square$ marion.devilliers@u-bordeaux.fr ) \\ University of Bordeaux, CNRS https://orcid.org/0000-0002-3929-2747
}

\section{Didier Swingedouw}

Universite de Bordeaux, CNRS

\section{Juliette Mignot}

Sorbonne Universite Campus Pierre et Marie Curie, CNRS

\section{Julie Deshayes}

Sorbonne Universite Campus Pierre et Marie Curie, CNRS

\section{Gilles Garric}

Mercator Ocean

\section{Mohamed Ayache}

Institut Mediteranéen d'Océanologie

\section{Research Article}

Keywords: Greenland melting, AMOC, subpolar gyre

Posted Date: April 13th, 2021

DOI: https://doi.org/10.21203/rs.3.rs-401895/v1

License: (1) This work is licensed under a Creative Commons Attribution 4.0 International License. 


\title{
A realistic Greenland ice sheet and surrounding glaciers and ice caps melting in a coupled climate model
}

\author{
Marion Devilliers • Didier Swingedouw • \\ Juliette Mignot • Julie Deshayes · Gilles \\ Garric • Mohamed Ayache
}

7 Received: date / Accepted: date

\begin{abstract}
Greenland ice sheet experienced an intensive melting in the last century, especially in the 1920s and over the last decades. The supplementary input into the ocean could disrupt the freshwater budget of the North Atlantic. Simultaneously, some signs of a recent weakening of the Atlantic Meridional Overturning Circulation (AMOC) have been reported. In order to better understand the possible impact of the increasing melting on the North Atlantic circulation, salinity and temperature trends, we construct an observation-based estimate of the freshwater fluxes spanning from 1840 to 2014. The estimate is based on runoff fluxes coming from Greenland ice sheet and surrounding glaciers and ice caps. Input from iceberg melting is also included and spatially distributed over the North Atlantic following an observed climatology. We force a set of historical simulations of the IPSL-CM6A-LR coupled climate model with this reconstruction from 1920 to 2014. The ten-member ensemble mean displays freshened and cooled waters around Greenland, which spread in the subpolar gyre, and then towards the subtropical gyre and the Nordic Seas. Over the whole period, the convection is reduced in the Labrador and Nordic Seas, while it is slightly enhanced in the Irminger Sea, and the AMOC is weakened by $0.32 \pm 0.35 \mathrm{~Sv}$ at $26^{\circ} \mathrm{N}$. The multi-decadal trend of the North Atlantic surface temperature obtained with the additional freshwater forcing is slightly closer to observations than in standard historical simulations, although the two trends are only different at the $90 \%$ confidence level. Slight improvement of the Root Mean Square Error with respect to observations in the
\end{abstract}

M. Devilliers and D. Swingedouw and M. Ayache

UMR CNRS 5805 EPOC - OASU - Universit de Bordeaux Alle Geoffroy Saint-Hilaire - CS 50023 - 33615 PESSAC CEDEX - FRANCE Fax : 0 (33) 5400033 16UMR EPOC Tel.: +33(0)-540-003-316

E-mail: marion.devilliers@u-bordeaux.fr

J. Mignot and J. Deshayes

UMR CNRS 7159 LOCEAN IRD - Universit Pierre et Marie Curie/MNHN. Institut Pierre Simon Laplace. Bote 100 - 4, place Jussieu 75252 PARIS Cedex 05.

Tel.: +33(0)-144-273-248

G. Garric

Mercator Ocan 8-10 rue Herms 31520 Ramonville Saint-Agne France Tel.: +33(0)-561-393-800 
subpolar gyre region suggests that part of the surface temperature variability over the recent decades may have been forced by the release of freshwater from Greenland and surrounding regions since the 1920s. Finally, we highlight that the AMOC decrease due to Greenland melting remains modest in these simulations and can only explain a very small amount of the $3 \pm 1 \mathrm{~Sv}$ weakening suggested in a recent study.

Keywords Greenland melting · AMOC · subpolar gyre

\section{Introduction}

Since the mid-1990s, ice sheet melting and glacier discharge have increased, thereby changing the freshwater budget of the Arctic and the North Atlantic (Rignot and Kanagaratnam 2006; Böning et al. 2016; Bamber et al. 2018). Several recent analysis have addressed the physical and biogeochemical impact of the increased freshwater fluxes (FWF) from Greenland Ice Sheet (GrIS) (Böning et al. 2016; Gillard et al. 2016; Marsh et al. 2010; Yang et al. 2016; Carmack et al. 2016). Most of these studies focus on the possible modification of Atlantic Meridional Overturning Circulation (AMOC), along with temperature and salinity changes, and how they can be related to the recent freshwater release.

The AMOC indeed plays an important role in the Earth climate system (Buckley and Marshall 2016). Warm surface and thermocline waters are transported northward, compensated by a deep southward return flow of cold waters. The AMOC drives a significant part of the meridional heat transport and storage in the ocean and influences the carbon cycle (Kostov et al. 2014; Romanou et al. 2017). A slow-down could induce a cooling of the North Atlantic Ocean, which would have a great impact on global climate (Stouffer et al. 2006; Swingedouw et al. 2009; Sgubin et al. 2017). The recent study of Caesar et al. (2018) uses a Sea Surface Temperature (SST) fingerprint to suggest a possible weakening of this circulation of $3 \pm 1$ Sverdrup (Sv) since the mid-1950s $\left(1 \mathrm{~Sv}=10^{6} \mathrm{~m}^{3} / \mathrm{s}\right)$. Such a weakening over the last 150 years has also been suggested from sortable silt, a proxy record of deep current intensity, and may be unprecedented over the last 1,500 years (Thornalley et al. 2018). Rahmstorf et al. (2015) also presented some evidence of a weakening the AMOC after 1975 is an unprecedented event in the past millennium. However, the proxies used in these studies have considerable uncertainties and direct AMOC observations are only available for the last fifteen years. In other studies (e.g. Böning et al. 2016), the authors concluded that up to now, the weakening of the AMOC can not be detected. The lack of a warming trend in North Atlantic SST observations since the beginning of the twentieth century, denoted as a "warming hole" (Marshall et al. 2015; Gervais et al. 2018), have been related to a weakening AMOC in many studies (Wunsch 2002; Drijfhout et al. 2012; McCarthy et al. 2015a; Robson et al. 2016; Friedman et al. 2017). A slowdown of the circulation could indeed lead to a decrease in heat transport in this region. Nevertheless, considerable variability in the North Atlantic SST may limit the robustness of these results.

Along with these signs of a slowing AMOC, Friedman et al. (2017) suggest a long term (1896-2016) subpolar surface freshening in the North Atlantic and a low-latitude surface salinification trend. Over a more recent period (the last 
twenty years), Dukhovskoy et al. (2016) performed passive tracer experiments with three models. This study showed the propagation of Greenland meltwater into the subarctic seas, which may have contributed to a negative salinity trend. However the authors argued that the observed salinity does not show such a freshening over this period and in this area. The authors suggested that saltier waters coming from the Atlantic may have counteracted the freshening signal. Some other models have also exhibited saltier northward advection of Atlantic waters over the last half century (Pardaens et al. 2008).

To explain the possible signs of decreasing AMOC and salinity, Rahmstorf et al. (2015) hypothesized that the AMOC weakening over the twentieth century may be related to a freshening of North Atlantic waters coming from the increasing melting of GrIS. Paleo-climate studies indeed provided some evidence that during Last Interglacial, GrIS melting inhibited deep convection of the southern coast of Greenland, cooling the local climate and reducing the AMOC (Sánchez Goñi et al. 2012). An extensive discussion of the role the GrIS melting in the possibly slowing AMOC and modification of the convection activity in the North Atlantic over the twentieth century is provided in the chapter 6 of the recently released IPCC Special Report on the Ocean and Cryosphere in a Changing Climate ("SROCC" report, Pörtner et al. 2019). Yang et al. (2016) linked the observed variations of Labrador Sea water thickness since 1980 to the recent freshening due to GrIS melting and also suggested a possible impact on the AMOC. Robson et al. (2016) discussed the role of long-term freshening and observed upper ocean cooling since 2005 in the density variations in the deep Labrador Sea. Jackson et al. (2016) used a globalocean reanalysis product to suggest that the possible recent AMOC weakening may be mainly related to the large AMOC maximum in the 1990s, mainly forced by positive North Atlantic Oscillation conditions. Indeed, considerable variability in the North Atlantic prevents strong conclusions relying on observations only (McCarthy et al. 2015b). For instance, deep convection resumed in the Labrador Sea in 2014-2016 according to observations (Yashayaev and Loder 2016) while Greenland ice sheet melting have been accelerating (Bamber et al. 2018). Thus, the exact role of internal variability and GrIS melting concerning a potential AMOC weakening remains largely unknown.

To improve knowledge and understanding of the possible links between the observed trends in the North Atlantic, one needs to perform coupled model simulations with realistic GrIS melting. However climate models usually do not incorporate an interactive ice sheet component and have therefore a crude parameterization of the ice sheet melting. The observed melting data (either from runoff, basal melting or icebergs) from the GrIS is not yet included in the models, which is clear way towards improvement for climate modelling as discussed in the chapter 6.7.1.2 of Collins et al. (2019). One possibility to circumvent this issue is to add externally the observed freshwater fluxes from ice sheet melting. Idealized studies were made spreading a very high amount $(0.1 \mathrm{~Sv})$ of freshwater around Greenland over different periods (Stouffer et al. 2006; Swingedouw et al. 2013; Swingedouw et al. 2015). A weakening of the AMOC was observed in response to the large release of freshwater, as expected, but the amount of freshwater input in these studies was not realistic. In the case study of Lenaerts et al. (2015), a realistic meltwater runoff is added into a coupled climate model (Community Earth System Model or "CESM", version 1.1.2) with ocean medium-resolution $\left(\simeq 1^{\circ}\right)$, and one run was performed from 1850 to 2200 using two different emission scenarios 
(RCP8.5 and RCP2.6). The authors concluded that the inclusion of a realistic runoff has a small impact on AMOC fate: a slightly enhanced weakening $(-1.2 \mathrm{~Sv}$ at the end of the twenty-first century) is detected.

Other studies have used realistic amount of freshwater with Ocean General Circulation Models (OGCMs). The link between GrIS melting, North Atlantic freshening and AMOC weakening was not clearly established by Böning et al. (2016) and Dukhovskoy et al. (2016) in their OGCM simulations starting in 1990. However these studies usually only consider the last decades of the twentieth century, and therefore do not take into account the large melting suspected in the 1920s. Different reconstructions based on meteorological station records, ice cores, and regional climate model output (Box and Colgan 2013; Chylek et al. 2006; Box and Colgan 2013; Fettweis et al. 2017) indeed displayed a low surface mass balance of GrIS around the 1920s, which was presumably related to positive summer temperature anomalies. Furthermore, former studies using a realistic Greenland meltwater amount only included the contribution from GrIS and not the surrounding regions like Canadian Arctic Archipelago, Svalbard and Iceland. Including these regions and increasing the spatial resolution of their regional model led the authors from Bamber et al. (2012) to update their estimate of freshwater fluxes. The new estimations are presented in the study of Bamber et al. (2018), with a significantly larger freshwater release in the North Atlantic. The total cumulative anomaly for the period considered (1958-2016) is about twice as large as the value reported previously in Bamber et al. (2012). Dukhovskoy et al. (2019) included the updated dataset from Bamber et al. (2018) and their analysis revealed a strong freshening signal from 2010 onward. They performed a passive tracer experiment, using an OGCM, showing that Greenland melting was not sufficient to have caused such salinity decrease and possible contributions from Arctic freshwater export and local precipitation were suspected. Nevertheless, this study was limited to a very short period of time (1993-2004), neglecting the effects of long-term melting. Finally, realistic studies are generally performed using OGCM with atmospheric forcing and surface restoring (Böning et al. 2016; Gillard et al. 2016; Saenko et al. 2017), which may impact the effect of additional freshwater release. Coupled climate models have the advantage of avoiding surface restoring and enabling atmospheric feedback in response to the ice sheet melting. The disadvantage of climate models is that simulations are much more computationally expensive, so the use of lower oceanic resolution is generally required with these models, leaving out the resolution of small-scale processes. Therefore, a compromise must be made in relation to all these constraints.

To our knowledge, no ensemble of coupled climate model simulations over the last century with realistic melting, including meltwater runoff and solid ice discharge, have yet been performed. We propose to analyze the impact of an externally forced FreshWater Flux (FWF) from GrIS and surrounding glaciers and ice caps in an ensemble of ten members of a global $1^{\circ}$ resolution coupled climate model with recently updated anomalies and overall trends covering the period 1920 to 2014. We thereby wish to assess the potential impact of freshwater input from Greenland melting on surface salinity, temperature and circulation in the North Atlantic. This approach may also lead to a better understanding of the mechanisms involved in the supposed recent weakening of the AMOC. We compare the response to this FWF input in the model to the observed signals to try to assess the part that may be related to natural variability. This may help to evaluate the 
hypothesis raised by Rahmstorf et al. (2015) and Yang et al. (2016) that a freshening in the North Atlantic waters caused by an increase in meltwaters coming from GrIS could lead to a weaker AMOC. We wish to better attribute the impacts of FWF trends, although no proper detection-attribution in the statistical sense (Ribes et al. 2017) will be performed in this study, which focuses on the fingerprints and forced response.

In the first section, we describe the reconstruction of freshwater fluxes as well as the modelling protocol. The second section compares the ten-member ensemble mean of experiments including additional freshwater input (denoted as the Melting ensemble) to the ensemble mean of ten historical members, with the same initial conditions (the Historical ensemble). Results in terms of temperature and salinity modifications over the historical period are presented, as well as changes in oceanic convection and circulation. In the third section, we evaluate the multidecadal trends and anomalies in surface temperature and salinity and confront them against available observations. Variability of the trends within the members of the Melting and the Historical ensembles is presented. Finally, the link with a recent estimate of AMOC changes is discussed.

\section{Material and Methods}

In this study we are forcing a climate model with a reconstructed spatial and temporal dataset of meltwater fluxes coming from Greenland and surrounding regions over the past 170 years. This first section describes the reconstruction of these freshwater fluxes and the numerical experiments performed using this dataset.

\subsection{Construction of the dataset}

We are using the monthly values of FWF from the recent observation-based estimate of Bamber et al. (2018), in the vicinity of Greenland, which covers the period 1958-2016. The dataset has several components which differ in their nature: it combines high spatial and temporal resolution satellite observations of solid ice discharge and regional climate model output of surface tundra and ice runoff. The components are further described in the next subsection (section 1.1.1).

In Bamber et al. (2018) dataset, the melting of the icebergs, denoted as the "solid ice discharge" component, is located along the coasts. As we wish to include the possible drift of the icebergs, we proceed to a spatial redistribution of this component far from the coast. This step of the reconstruction is described in section 1.1.2.

Finally, we extend all the components of the FWF back to the year 1840 using the total ice sheet mass budget closure over the 1840-2010 period from Box and Colgan (2013) and a regression approach described in section 1.1.3.

\subsubsection{Description of the dataset of Bamber et al. (2018)}

Four out of the five components of the dataset from Bamber et al. (2018) are liquid runoff (monthly values). They are described as runoff from land ice ("ice 
runoff") on the one hand and snow melt on tundra on the other hand ("tundra runoff"). Both are given for two different regions: along the coast of Greenland and the coast of surrounding regions (Canadian Arctic Archipelago, Svalbard and Iceland). These runoff fluxes values were estimated from the outputs of a regional climate model (RACMO2.3p2) forced by atmospheric re-analysis (ERA-40 and ERA-Interim) for the period 1958-2016 (Noël et al. 2018). Errors are assumed to be systematic and evaluated at around $20 \%$ for ice runoff and $10 \%$ for tundra runoff.

The fifth component of the dataset is the solid ice discharge for GrIS only: it corresponds to the flux of ice crossing the grounding line of marine-terminating glaciers around the ice sheet. It is based on satellite-observations of ice surface velocity and a compilation of ice thickness (Morlighem et al. 2017) obtained from ice penetrating radar measurements. The dataset therefore has four different runoff fluxes and one flux of solid ice discharge. The components will be denoted as follow:

- Greenland ice runoff

- Outside of Greenland ice runoff

- Greenland tundra runoff

- Outside of Greenland tundra runoff

- Greenland solid ice discharge

All of these monthly fluxes are provided in Bamber et al. (2018) on a $5 \mathrm{~km}$ resolution grid and were interpolated on the eORCA1.2 mesh grid (Deshayes et al., in prep), using a nearest neighbour algorithm. The cumulative resulting annual global fluxes are presented in supplementary Figure S1. The total FWF is about $0.047 \mathrm{~Sv}$ (or $1456 \mathrm{~km}^{3} \cdot \mathrm{yr}^{-1}$ ), in average over the period 1958-2016.

\subsubsection{Spatial redistribution of the solid ice discharge}

The solid ice discharge related to icebergs from Bamber et al. (2018) is located at the coast of GrIS in the dataset. Solid ice fluxes (icebergs) are not generally included in a physically realistic manner in climate and ocean General Circulation Models (GCMs) (cf. Radic and Hock (2014) for a review): they are incorporated as liquid inputs at their source, along the edge of the ice sheet. This approach may lead to physical inaccuracy in surface property fields and mixed layer depths as in reality icebergs can drift thousands of kilometers from their original source (Marsh et al. 2015). In this study, we modify the spatial distribution of the solid ice discharge of Bamber et al. (2018), using satellite-based location of the icebergs from the Altiberg project (Tournadre et al. 2015), to account for the iceberg drift.

The Altiberg icebergs database project (Tournadre et al. 2015) provides a monthly spatial evolution of the icebergs around the North and the South Poles from 1993 to 2012. The data are available on the NEMO grid with eORCA025 configuration and were interpolated for our model configuration.

Let $I c e b^{A}(i, j, t)$ denote the Altiberg spatial and temporal evolution of the solid ice fluxes on the $2 \mathrm{D}$ grid $((i, j)$ being the indices of the grid cells), and $t$ the time variable.

Let $<I c e b^{A}(i, j, t)>_{t}$ denote the 1993-2012 time averaged 2D map of the flux that depends only on $(i, j)$. We normalize this quantity to obtain a 2D map of $[0-1]$ distribution coefficients. 
We multiply these distribution coefficients with the spatially integrated temporal evolution of the solid ice discharge estimation of Bamber et al. (2018), denoted as $L(i, j, t)$.

$$
\operatorname{Iceb}(i, j, t)=\frac{<\operatorname{Iceb}^{A}(i, j, t)>_{t}}{\sum_{i, j}<\operatorname{Iceb}^{A}(i, j, t)>_{t}} \sum_{i, j} L(i, j, t)
$$

The global monthly amount of $L(t)=\sum_{i, j} L(i, j, t)$ from Bamber et al. (2018) is maintained with this redistribution method, but icebergs drift is also considered. This simple parameterization of the iceberg fluxes does not resolve correctly the drifting of the icebergs, which would necessitate the use of an iceberg model. Yet it constitutes a reasonable compromise, considering the available data. The basal melting is also not included here since only solid ice that crosses the grounded line is taken into account as iceberg fluxes. Also, the thermal impact of iceberg melting is neglected.

The final spatial distributions of the fluxes (icebergs and runoffs) used for our study are shown in Figure 1, after the temporal extension step, which is described in the next section.
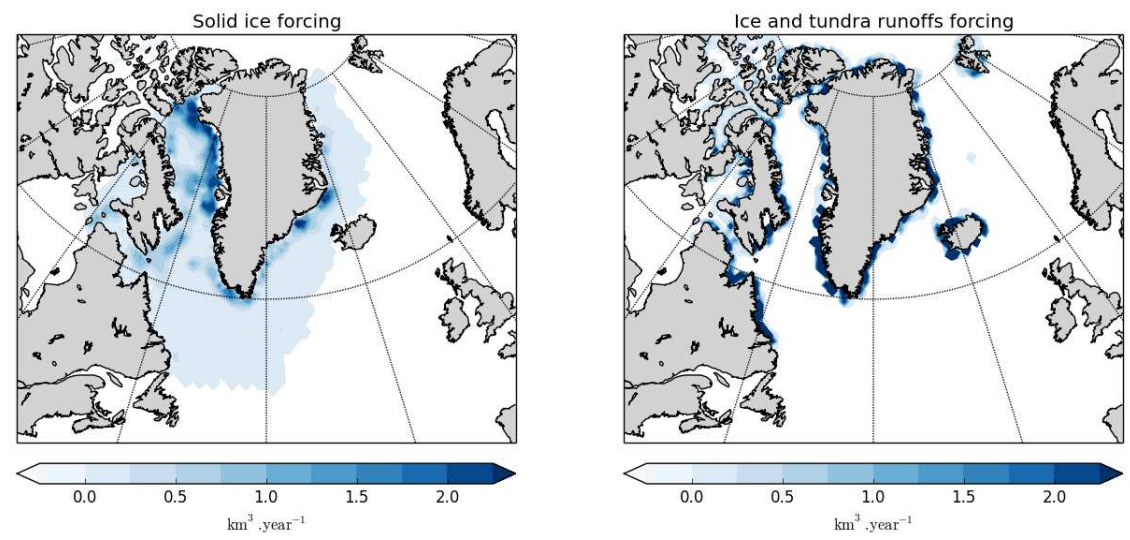

Fig. 1: Time averaged (1920-2014) spatial distribution of icebergs (left) and runoff (right) freshwater fluxes (in $\mathrm{km}^{3} \cdot \mathrm{yr}^{-1}$ )

1.1.3 Extension of the fluxes back to 1840

The FWF from Bamber et al. (2018) are available from 1958 to 2016. To account for the large melting event of the 1920s (Chylek et al. 2006; Box and Colgan 2013; Fettweis et al. 2017), we extend them several decades in the past by performing a linear regression against the yearly estimation of Greenland ice runoff from Box and Colgan (2013), that goes back to 1840 .

The study of Box and Colgan (2013) aimed at reconstructing GrIS mass balance subcomponents at the ice sheet scale. Marine ice loss, composed of iceberg calving and underwater melting (both liquid and solid fluxes), was related to the surface mass balance reconstruction in order to produce a total ice sheet mass budget closure over the 1840-2010 period. High correlation was obtained between 
Greenland marine ice loss and meltwater runoff with a smoothing of 13 years $(c f$. Figure 4 in the study of Box and Colgan 2013). Their resulting annual reconstruction of Greenland Ice Runoff (spatially averaged) from 1840 to 2012 is here denoted as GIR (Box and Colgan 2013, their Figure 5, red line) and is showed in our Figure 2 (red line).

The first step consists in performing a linear regression of all the components from Bamber et al. (2018) (cf. subsection 1.1.1) on GIR to obtain annual values from 1840 to 1957 . In the second step, monthly values for the period 1840-1957 are calculated using the annual time series obtained from the first step, and a climatological seasonal cycle. In the third step, we spread these values over Greenland region using a fixed $2 \mathrm{D}$ spatial distribution.

In Bamber et al. (2018), a smoothing of five years was applied to the solid ice discharge to account for the years with no observed discharge value: the authors fit a linear least squares regression over the ice runoff component of the previous four years. We choose to apply the same 5-year filter to every component of the dataset of Bamber et al. (2018) in order to use the same methodology for all the fluxes.

We first perform a linear regression between GIR and the 5-year smoothed spatially integrated Greenland Ice Runoff from Bamber et al. (2018), denoted $\left(\mathrm{GIR}_{b}\right)$ (blue line in Figure 2), over the period both data sets have in common: 1958-2012. We obtain the relation (in $\mathrm{km}^{3}$ per year):

$$
\mathrm{GIR}_{\mathrm{b}}=2.02 \mathrm{GIR}-178
$$

with a quite high correlation coefficient $\left(r^{2}=0.94, \quad p-\right.$ value $\left.\ll 0.001\right)$ between the two time series. We can notice that $\left(\mathrm{GIR}_{b}\right)$ is stronger than GIR by $27 \%$ which is $3.2 \mathrm{mSv}$ or $101 \mathrm{~km}^{3} \cdot \mathrm{yr}^{-1}$ on average over $1958-2012$. This is probably because the model used by Bamber et al. (2018) has a higher resolution (1 km grid instead of $5 \mathrm{~km}$ ) and it resolves much more of the ablation zone and smaller glaciers near the margin. Results obtained from Bamber et al. (2018) agree well with van den Broeke et al. (2016). The regression coefficients obtained are then used to extend Greenland ice runoff from Bamber et al. (2018) backwards over the 1840-1957 period. The extension is plotted in Figure 2 (green line). 


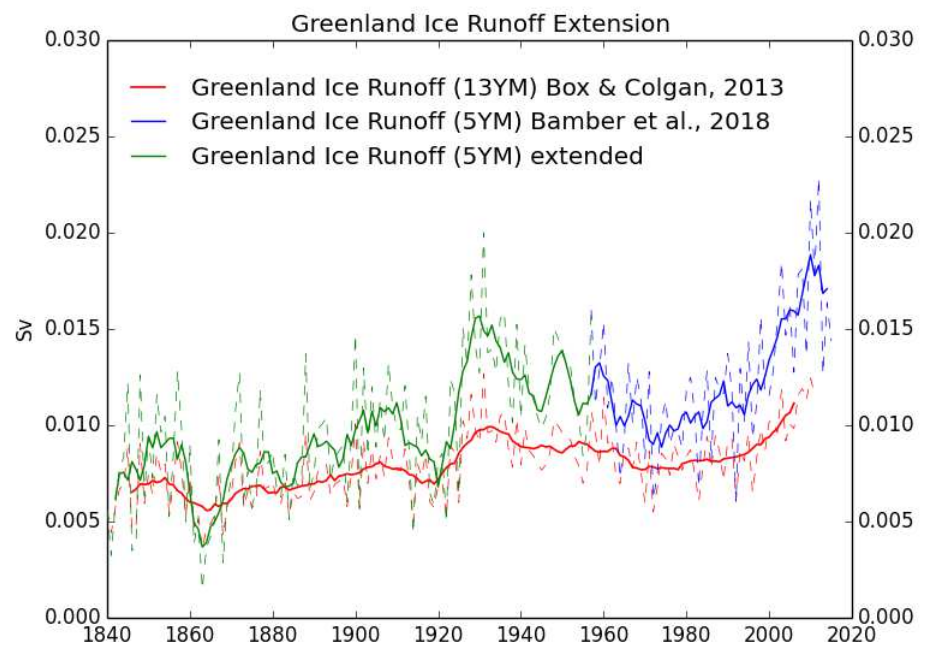

Fig. 2: Spatial annual sum of Greenland Ice Runoff (in Sv) for Raw (in blue, with a 5-year running mean) and Extended (in green, with a 5-year running mean) freshwater fluxes from Bamber et al. (2018) and Box and Colgan (2013) (in red, with a 13-year running mean).

The same method is applied to the other components of Bamber et al. (2018) data leading to a complete dataset of annual means for the period 1840 to 2016, which is shown in Figure 3. Correlation coefficients with GIR and associated pvalues for all fluxes are available in table 1. Ice runoff (from Greenland and from outside of Greenland) and solid ice fluxes are well correlated with GIR. These high coefficient values give enough confidence to extend these three fluxes in the past using a linear regression on GIR. Concerning the two tundra runoff fluxes, the correlation coefficients with GIR are very small. These values could therefore have been kept constant for the extension period (1840-1957). We chose nevertheless to apply the same method as the one used for the other fluxes and discuss this choice below.

Greenland tundra runoff fluxes from Bamber et al. (2018) averaged value over (1958-2016) is about $84.5 \mathrm{~km}^{3} \cdot \mathrm{yr}^{-1}$ (or $2.7 \mathrm{mSv}$ ), which is close to the averaged value of the reconstructed Greenland tundra runoff over the period 1840-1957: $83.9 \mathrm{~km}^{3} \cdot \mathrm{yr}^{-1}$ (or $2.6 \mathrm{mSv}$ ). This flux is not very strong as compared to the total freshwater flux average over $1958-2016\left(1456 \mathrm{~km}^{3} \cdot \mathrm{yr}^{-1}\right.$ or $\left.46 \mathrm{mSv}\right)$. It is almost constant over the period 1958-2016 (temporal standard deviation $\simeq 4.8 \mathrm{~km}^{3} \cdot \mathrm{yr}^{-1}$ or $0.15 \mathrm{mSv}$ ) and the flux obtained with the regression over the extended period (1840-1957) has a very small standard deviation also $\left(\simeq 1 \mathrm{~km}^{3} \cdot \mathrm{yr}^{-1}\right.$ or $0.03 \mathrm{mSv}$, c.f. green line in Figure 3). This is due to the fact that the correlation coefficients are small and the Greenland tundra fluxes over the period (1958-2016) do not present a large trend. We are therefore quite confident that using a constant value for this flux (the average of 1958-2016) would have led to similar results.

Outside of Greenland, the tundra runoff flux from Bamber et al. (2018) over (1958-2016) has a mean value of about $473 \mathrm{~km}^{3} \cdot \mathrm{yr}^{-1}(\simeq 15 \mathrm{mSv})$, with a large 
variability: its standard deviation is about $43.8 \mathrm{~km}^{3} \cdot \mathrm{yr}^{-1}(\simeq 1.4 \mathrm{mSv})$. Therefore, the choice of a constant flux for the extension period instead of the regression we used is not obvious. We believe that further analysis is needed in order to find the best method to extend this flux. With our approach, the average of the flux over the extension period (1840-1957) is about $530 \mathrm{~km}^{3} \cdot \mathrm{yr}^{-1}(\simeq 17 \mathrm{mSv})$ so using a constant values obtained by averaging the flux from Bamber et al. (2018) over the period (1958-2016) would have led to a mean difference over the (1840-1957) period of only $57 \mathrm{~km}^{3} \cdot \mathrm{yr}^{-1}(\simeq 1.8 \mathrm{mSv})$. Although this remains to be quantified, we believe that switching method should not have a large impact on our results. More generally, this low-frequency regression could be improved in future studies by the addition of random noise to take into account the uncertainties.

\begin{tabular}{|l|l|l|}
\hline Fluxes & Correlation Coefficients & p-values \\
\hline Greenland solid ice discharge & 0.93 & $\ll 0.001$ \\
Greenland tundra runoff & 0.3 & 0.35 \\
Outside Greenland tundra runoff & -0.09 & 0.80 \\
Greenland ice sheet runoff & 0.94 & $\ll 0.001$ \\
Glaciers and ice caps runoff & 0.85 & $\ll 0.001$ \\
\hline
\end{tabular}

Table 1: Correlation coefficients with GIR of each flux from Bamber et al. (2018) over the period (1958-2012). Degree of freedom $=(n-2) / 5$, and $n=51$ after applying a 5 -year moving mean.

After obtaining annual means, we perform a second step in order to calculate monthly values for each of the fluxes over the period 1840-1957. Monthly fluxes from Bamber et al. (2018) are averaged over the period 1958-1980 in order to construct a monthly climatology. The 1980-2016 period was excluded to avoid the large increase of the 1990s, probably related to the strong anomalies in summer temperature (Chylek et al. 2006; Fettweis et al. 2017). This climatology is then applied to the annual fluxes of the period 1840-1957 obtained in the first step. Monthly fluxes are calculated by weighting the climatology with the fluxes of a given year. The same method is used for every component except the solid ice discharge for which we chose to apply a climatology constructed with the data from the Altiberg project, over the period 1993-2012 (no available data before 1993).

Finally, a spatial redistribution of the monthly values for the period 18401957 is carried out. The 2D spatial distribution of the runoff components from the data set of Bamber et al. (2018), and the one calculated for the solid ice discharge in section 1.1.2, are averaged and normalized over the period 1958-1980. Monthly fluxes are multiplied to the constant 2D map of coefficients between 0 and 1 obtained (this method is the same as described in section 1.1.2). The final reconstructed dataset have monthly values of fluxes over a 2D map from 1840 to 1957.

Obviously, using a constant spatial distribution introduces some error in this reconstruction, and the same remark applies for the use of a climatology based on the period 1958-1980. However, since there is no spatial distribution evolution of the fluxes available in Box and Colgan (2013) reconstruction, we consider that this is a reasonable compromise given what is available. Other climatology and spatial reconstruction methods may lead to different results, and a systematic study may 
be needed to evaluate properly the different hypotheses chosen to perform the reconstruction. Nevertheless, we argue this might have a limited impact, notably given the coarse resolution of the ocean model used in this study.

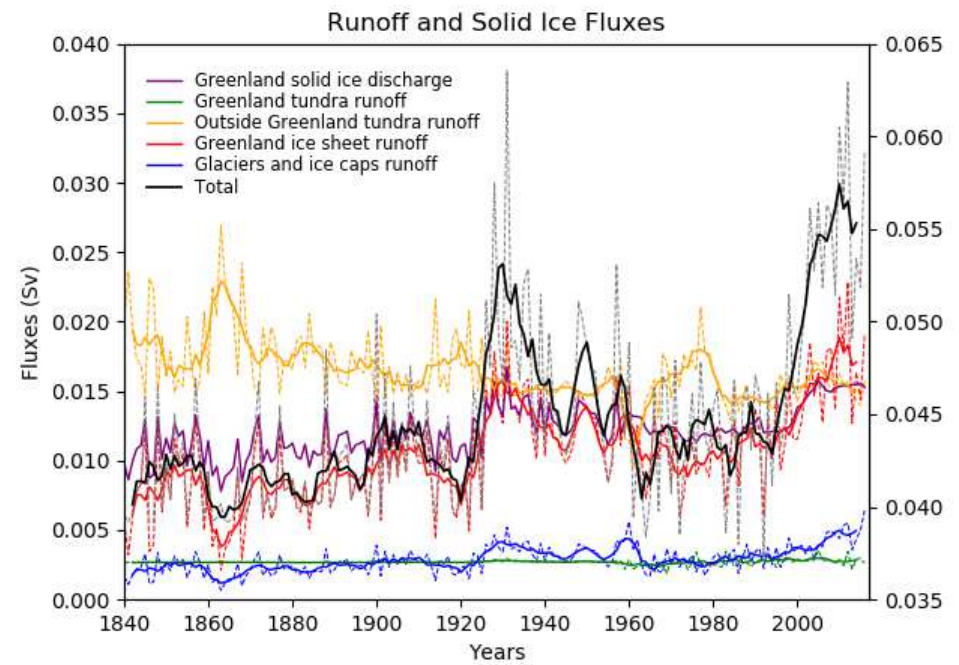

Fig. 3: Final dataset: initial and extended annual fluxes (in Sv) from Bamber et al. (2018), using a linear regression over the 1958-2012 ice runoff from Box and Colgan (2013) (GIR). Solid lines are 5-year running means, dashed lines are the mean annual values. The total flux from all sources is shown by the solid black line plotted against the right-hand $\mathrm{Y}$ axis (in Sv).

\subsection{Climate model simulations}

\subsubsection{Description of the IPSL-CM6A-LR model}

The ocean-atmosphere coupled model used in this study is the IPSL-CM6A model (Boucher et al. 2020) in its low resolution (LR) version as developed for CMIP6. Lurton et al. (2020) describes the implementation of the CMIP6 climate forcings. The atmospheric model is LMDZ6 (Hourdin et al. 2020), which is the updated version of LMDZ5B (Hourdin et al. 2013), with a $144 \times 142$ regular grid (horizontal resolution around $2.5^{\circ}$ in longitude and $1.5^{\circ}$ in latitude) and 79 vertical layers. The oceanic model is NEMO (Madec 2008) with the configuration NEMOv3.6STABLE using the eORCA1.2 grid: global ocean with a tripolar grid; one South Pole, one North Pole above Siberia and one North Pole above northern America. The nominal resolution is $1^{\circ}$ and decreases to $1 / 2^{\circ}$ in the tropical region. There are 75 vertical levels, with $1 \mathrm{~m}$ resolution near the surface, and $200 \mathrm{~m}$ in the abyss. It includes the LIM-3 sea ice model (Rousset et al. 2015) and the PISCES module (Aumont and Bopp 2006) for oceanic biogeochemistry.

Runoff fluxes are computed by the atmospheric component. Iceberg calving in the North Atlantic is included with a very simple scheme to represent the ice sheet 
water budget. Snow accumulates on land ice until the snowpack is capped to a value of $3000 \mathrm{~kg} / \mathrm{m}^{2}$. Any excess is sent to a buffer reservoir before returning to the ocean through a temporal smoothing of 10 years, to avoid any spurious lowfrequency variability in the freshwater input to the ocean ( $c f$. Marti et al. (2010) for more details). The released flux is equally distributed over the ocean above $40^{\circ} \mathrm{N}$. Therefore, although the processing for solid ice discharge related to icebergs in our study (section 1.1.2) is a rough representation of iceberg calving, it improves the actual parametrization used in IPSL-CM6A-LR. Note that the Lagrangian iceberg module of the model NEMO (Marsh et al. 2015) is not activated in this version of IPSL climate model.

\subsubsection{Historical and Melting Ensembles}

We consider a set of 10 members from the large ensemble of 30 historical simulations of the IPSL-CM6A-LR climate model from 1920 to 2014 (referred to as the Historical ensemble). External forcing is prescribed from 1850 (Lurton et al., in prep). Members are starting from different initial conditions, obtained from a preindustrial simulation, in order to sample internal variability.

In a second set of 10 historical simulations, with the same starting dates as the one selected for the Historical ensemble, runoff and solid ice discharge fluxes computed by the atmospheric model are overwritten before transmission to the ocean component, with the values presented in Figure 3. This second set will be reffered to as the Melting ensemble. A Student's t-test, presented in the next subsection, is used to investigate the statistical significance of the difference between the two ensemble means (Melting and Historical).

To clarify the description of the results in section 2, we define the ensemble mean of the Historical ensemble as the forced signal from external radiative forcing, while the difference between the Historical and Melting ensemble means is the forced signal from GrIS melting. The spread represents the amplitude of the internal variability, and can be compared to the forced signals to obtain a signal to noise ratio ( $c f$. section 3$)$.

\subsection{Descrition of the Student's t-test used to compare Melting and Historical} ensemble means

In order to test the difference between the two ensemble means relatively to the spread among their members, we perform the following Student's t-test. All members are first averaged over the period 1920-2014, so there is no time-dimension for this test. The number of members in each ensemble is $10(n=10)$. We use the equations for independent samples with similar variances. $X$ denotes the physical variable tested. 
$X_{M}^{i} \quad: X$ from the member $i$ of the Melting ensemble

$\overline{X_{M}}=\frac{1}{n} \sum_{i=1}^{n} X_{M}^{i} \quad \operatorname{Var}\left(X_{M}\right)=\frac{1}{n-1} \sum_{i=1}^{n}\left(X_{M}^{i}-\overline{X_{M}}\right)^{2}$

$X_{H}^{i} \quad: X$ from the member $i$ of the Historical ensemble

$\overline{X_{H}}=\frac{1}{n} \sum_{i=1}^{n} X_{H}^{i} \quad \operatorname{Var}\left(X_{H}\right)=\frac{1}{n-1} \sum_{i=1}^{n}\left(X_{H}^{i}-\overline{X_{H}}\right)^{2}$

$t=\frac{\overline{X_{M}}-\overline{X_{H}}}{\sqrt{\frac{\operatorname{Var}\left(X_{M}\right)}{n}+\frac{\operatorname{Var}\left(X_{H}\right)}{n}}} \quad$ degree of freedom $=2(n-1)$

Ice and tundra runoff values from Greenland and surrounding regions presented in Figure 3 are summed to obtain a total runoff time series. In the Melting ensemble, these runoff values are used to overwrite the monthly runoff values computed by the atmospheric component of the model in the area in blue in the top of the Figure 4 (denoted as forcing zone). Figure 4 (bottom) compares the runoff in the Melting ensemble (blue) and the Historical ensemble (black), cumulated over the region where they are overwritten. They are of the same order of magnitude. We are therefore more correcting a trend than a mean bias. The melting rate is indeed higher in our reconstructed observation-based dataset than it is in the model in the 1920s-1930s and from the 1990s. This may be related to the ice dynamics which is not accounted for in the model parametrization where a simple thermodynamical budget is used ( $c f$. Swingedouw et al. 2007). 


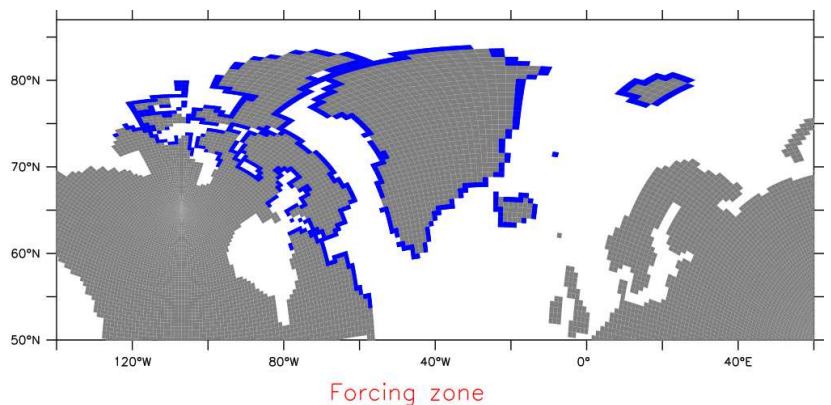

Historical ens. mean runoff Melting ens. mean runoff

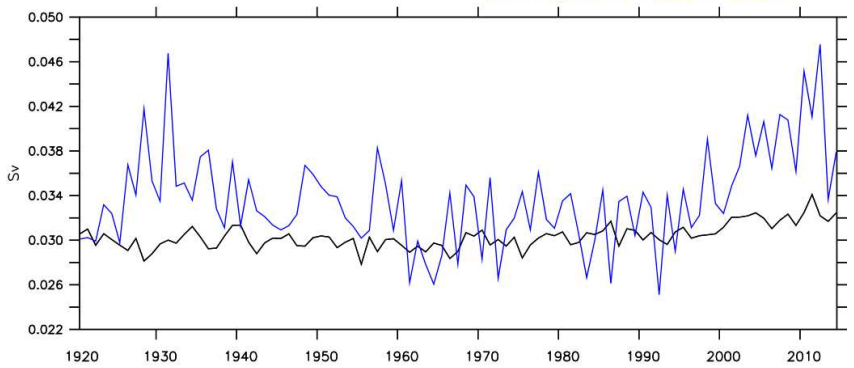

Fig. 4: Top panel shows the area around Greenland (denoted as "forcing zone", in blue) where runoff are replaced in the model. Bottom panel shows the mean annual runoff values (in Sv) in the two ensembles cumulated in the forcing zone: prescribed fluxes in the Melting ensemble (blue line) and computed fluxes in the Historical ensemble (black line).

The total amount of runoff is larger in the Melting ensemble where it is prescribed, than in the Historical ensemble, where it is diagnosed from the model. The average difference in runoff over the whole period is about $4.16 \mathrm{mSv}$ or $131.2 \mathrm{~km}^{3} \cdot \mathrm{yr}^{-1}$. Maximum values are reached during the periods $1926-1931(9.1 \mathrm{mSv})$ and $2006-2013(8.7 \mathrm{mSv})$. The historical mean of output runoff is about $30.3 \mathrm{mSv}$ so the Melting experiments lead to an increase of $13.7 \%$ of the runoff in the Greenland region. We choose not to compensate this supplementary water elsewhere and have more freshwater fluxes going into the ocean in this area in the Melting runs than in the Historical ones. By doing so we better represent the ice sheet freshwater release in the ocean system, which is not compensated elsewhere in the reality. Thus, our experimental design can be viewed both as an improvement of the melting from Greenland in the model as well as a correction towards the observed trends. The latter are indeed underestimated in the model, due to a very crude parameterization of ice sheet dynamics.

\subsubsection{Solid ice discharge processing}

Regarding the iceberg melting flux, it is included as a liquid freshwater flux and spread homogeneously above $40^{\circ} \mathrm{N}$ in the model IPSL-CM6-LR (for the northern hemisphere only) as there is no active iceberg model for this region yet ( $c f$. description of the model, section 1.2.1). To overwrite this crude parametrization in the Melting ensemble, the methodology described below is applied. 
This methodology was chosen for the sake of technical feasibility. As we do not know the amount of solid ice discharge outside of Greenland, we prescribe the same amount of global solid ice discharge above $40^{\circ} \mathrm{N}$ in the Melting ensemble as the one diagnosed in the Historical runs. The improvement in our Melting ensemble is that solid ice discharge is more concentrated around GrIS, in the solid ice forcing zone shown in Figure 1 (left), instead of being equally distributed on the whole oceanic area north of $40^{\circ} \mathrm{N}$. Also, solid ice discharge values around Greenland (Figure 3, purple line) are more realistic. To overwrite local values in the forcing zone, while maintaining the global values close to the historical ones, the steps described below are performed:

1. Above $40^{\circ} \mathrm{N}$ and outside the forcing zone, we impose a constant value obtained by averaging the iceberg discharge value from a historical run over the reference period 1900-1920.

2. In the forcing zone, the iceberg melting fluxes are replaced directly with the reconstructed solid ice component (included as liquid flux) from Figure 3 (purple line), using the spatial redistribution calculated with Altiberg data.

3. Finally, the difference in the forcing zone with control values from step 1 is compensated by subtracting freshwater flux in the rest of $40^{\circ} \mathrm{N}$ to maintain a coherent global value ( $c f$. supplementary Figure S2).

There is indeed no global bias correction, but we perform a trend and a bias correction in the forcing zone around Greenland. These values of iceberg discharge are added to the runoff values of the ocean-ice model NEMO-LIM in the Melting runs.

To summarize the experimental method, in the Melting experiments, we release about 12,466 $\mathrm{km}^{3}$ (cumulated value over the period 1920-2014) more FWF than in the Historical ensemble over 95 years (or $4.2 \mathrm{mSv}$ additionnal freshwater input on average over this period) and we correct the spatial distribution of the solid ice discharge. Such an accumulation of FWF over almost a century may have an impact on the ocean. We evaluate in section 2 the impact on ocean and climate by comparing the Melting ensemble and the Historical ensemble model outputs.

\subsection{Passive tracer experiments}

The spreading of the realistic ice runoff from Greenland is traced in the simulations using a passive tracer. It is released at each time step and each grid cell at the locations of Greenland freshwater sources. Its initial concentration is proportional to the imposed amount of ice runoff component from Greenland only (red line in Figure 3), so grid cells with maximum runoff values are set to 1 . As it is implemented in the model as a passive conservative tracer, it does not affect ocean circulation and its propagation is governed only by physical processes of advection and diffusion. It is transported into the North Atlantic by IPSL-CM6A-LR physical fields, that uses a classical advection-diffusion equation (Madec 2008; Arsouze et al. 2009; Ayache et al. 2016):

$$
\frac{\partial T}{\partial t}=-\nabla \cdot(T U)+S(T)+D^{T}
$$

Where $S(T)$ represents the sources minus sinks, $\nabla \cdot(T U)$ is the three-dimensional advection and $D^{T}$ is the lateral and vertical diffusion of the passive tracer. We run 
off-line simulations over the period 1950-2014 using the monthly velocity fields $(\mathrm{U}, \mathrm{V}, \mathrm{W})$ and the diffusion coefficient (kept constant) from five members of the Melting simulations ( $c f$. section 1.2), following the protocol of (Boucher et al. 2020).

1.5 The observed salinity and temperature data

We use different datasets derived from direct observations to evaluate the simulated trends of surface salinity and temperature from our experiments in the last section of this study (section 3). All the datasets have been interpolated on the eORCA1.2 grid (Deshayes et al., in prep) of our ocean model.

Regarding salinity, the first dataset is the one presented in the work of Friedman et al. (2017). They proposed a gridded North Atlantic Sea Surface Salinity (SSS) compilation from 1896 to 2013, recently updated up to 2016, which reveals a longterm subpolar freshening and low-latitude salinification trends. The SSS time series are binned in 32 boxes that are separated in two regions: one with boxes from $45^{\circ}$ to $62^{\circ} \mathrm{N}$ and the second from $20^{\circ} \mathrm{S}$ to $40^{\circ} \mathrm{N}$. The second salinity dataset is the EN4 dataset, from Good et al. (2013). Data are available monthly from 1900 to the present.

Regarding temperature, we use the version 4 of the Extended Reconstructed Sea Surface Temperature dataset (ERSST), from Huang et al. (2016), which is a global monthly sea surface temperature dataset derived from the International Comprehensive OceanAtmosphere Dataset (ICOADS). This monthly analysis begins in January 1854 up to the present. The other SST dataset in this study is from the Hadley Centre Global Sea Ice and Sea Surface Temperature (HadISST), from Rayner et al. (2003). It is a combination of monthly globally complete fields of SST and sea ice concentration for the period 1871-present. HadISST uses reduced space optimal interpolation applied to SSTs from the Marine Data Bank (mainly ship tracks) and ICOADS through 1981 and a blend of in situ and adjusted satellite-derived SSTs for 1982-onwards. 


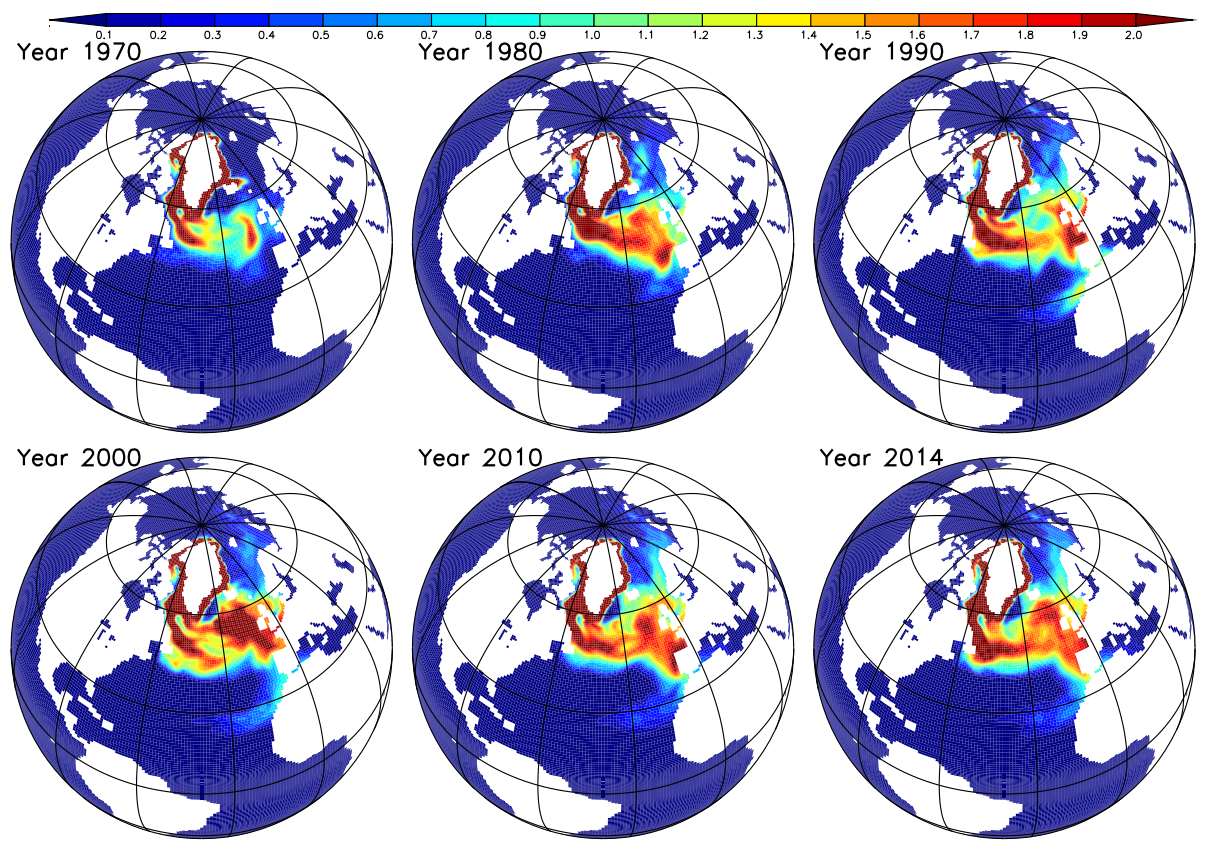

Fig. 5: Ensemble mean of the evolution of passive tracer concentration (normalized units) at the surface from 5-member off-line simulations of passive tracer starting in 1950.

Passive tracer calculations have been performed to illustrate the circulation of the liquid runoff fluxes from GrIS melting over the recent decades ( $c f$. section 1.4). We decide to only focus here on runoff because it is very concentrated in space, while the iceberg term is more diluted. Freshwater fluxes concentrations are plotted as a function of time in Figure 5. Initial concentrations are set between 0 and 1 , so values larger than 1 show a convergence of the fluxes. We can observe a rapid spreading of the freshwater tracer into the Labrador Sea, with a later accumulation along the eastern coast of Europe. Small parts of the Labrador Sea and the Irminger Sea seem to be bypassed by the freshwater. The signal may also have disappeared in these areas because of vertical mixing in these convection zones. We notice that even after 65 years, there is a very weak propagation of the freshwater tracer at the surface in the Nordic or the Subtropical seas, while most of the surface signal remains in the subpolar gyre and around Greenland.

To isolate the signature of the observed melting of GrIS, we present in Figure 6 the anomalous annual SSS and SST diagnosed from the difference between the Melting and Historical ensemble means, over the period 1920-2014. To obtain the areas of significant difference between the ensemble means, we perform a Student's 
t-test (detailed in subsection 1.3), after averaging the members over the time period of the experiment (1920-2014). The same test is used to find regions of significant difference for all the other physical variables considered in this section. Patterns and values obtained by evaluating the differences between the two ensemble means over the last 30 years are quite close to the ones obtained for the whole period of the experiment (not shown). However, statistically significant regions are smaller, which could be due to the fact that the period considered is shorter.

The additional freshwater released in the Melting ensemble creates a large (>1 psu) and significant (90\%) surface freshening in the Baffin Bay that extends south of the subpolar gyre towards the subtropical gyre (Figure 6, top) with far lower amplitude $(<0.2 \mathrm{psu})$. This freshening might also have been amplified by an atmospheric feedback: indeed, Figure 6 (bottom) reveals a cooling of sea surface and this would lead to less evaporation and thus an additionnal freshening of the surface. The spatial spread of the Melting signal is wider than in the tracer experiments, possibly because simulations are longer in the Melting ensemble so the freshening signal has had more time to be distributed. Also all components of the melting are included: liquid and solid, Greenland and surrounding regions. In the Arctic Ocean, we notice a strong positive SSS anomaly ( $>0.3 \mathrm{psu}$ ). Such a signal is difficult to detect in Arctic SSS observations, because there are no SSS data available for a long enough period, but it has been found in previous idealized hosing experiments using six different models where freshwater was released homogeneously around Greenland (Swingedouw et al. 2013). This highlights the robustness of this signal in response to hosing from GrIS melting. This SSS anomaly can be the result of a modification of the North Atlantic circulation: an enhanced Atlantic inflow in subsurface at Fram Strait and in the Barents Sea would lead to an increase of saltier Atlantic water entering the Arctic Ocean, and might be related to the decrease of convection in the subpolar and Nordic Seas (Swingedouw et al. 2013). Although there is no corresponding warming signal in the Arctic surface temperature (see Figure 6, bottom), we found that net heat flux from the ocean to the atmosphere is enhanced by $6 \%$ above $75^{\circ} \mathrm{N}$ over the period (not shown). It is thus possible that the SST signal from the Atlantic inflow water emerging in the Arctic water may have been cooled by the atmosphere, obscuring the temperature signal.

Comparing SST for both ensembles reveals a cooling signal in the subpolar gyre, in the Nordic and Barents Seas and also along the Canary Current in the Melting experiments (Figure 6, bottom). We also notice a very small warmer area east of the Gulf Stream region which could be consistent with a slowed AMOC. Overall, the cooling anomaly amounts to less than $-0.5^{\circ} \mathrm{C}$ over the subpolar gyre, where it is the most widespread, and leaks towards the subtropical gyre with lower values $\left(>-0.15^{\circ} \mathrm{C}\right)$, where it becomes significant at the $90 \%$ level.

In the atmosphere, there is a wide cooling signal (down to $-0.7^{\circ} \mathrm{C}$ ) for the 2-meter temperature north of $55^{\circ} \mathrm{N}$ in the Melting ensemble as compared to the Historical one (Figure 7). This is consistent with the SST pattern shown in Figure 6 (bottom), except that regions with significant difference (90\%) are quite small here. Such a cooling was found in other idealized hosing studies (Swingedouw et al. 2013; Stouffer et al. 2006) and was related to a slowdown of the AMOC. Reduction of northward heat transport and vertical heat transport (due to reduced vertical mixing) may indeed lead to a robust cooling of the North Atlantic oceanic and 
atmospheric temperature (Jackson et al. 2015; Laurian et al. 2009). However global warming could counteract this effect in the long-term (Drijfhout 2015).

Melting - Historical ensemble mean 1920-2014 SSS
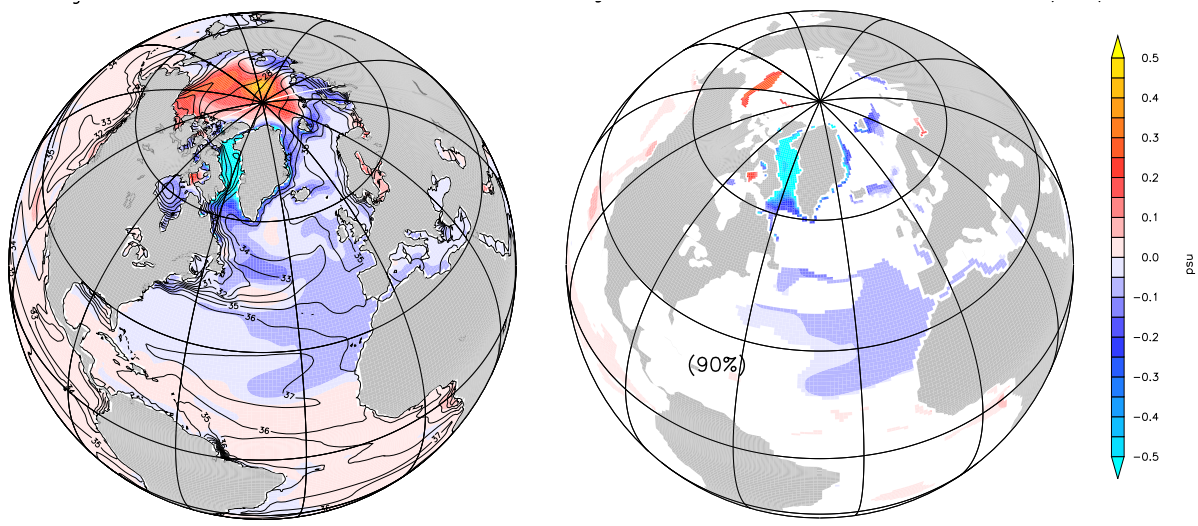

Melting - Historical ensemble mean 1920-2014 SST
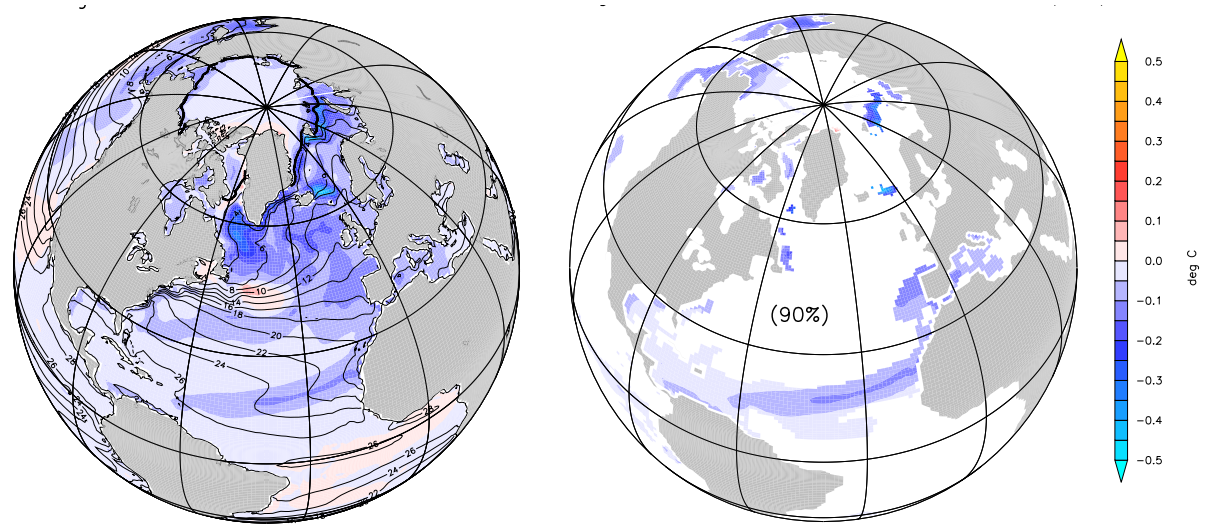

Fig. 6: Shadings are the differences (left figures) and the significant (90\%) differences (right figures) between the Historical and Melting ensemble means for annual SSS (top figures, in psu) and SST (bottom figures, in ${ }^{\circ} \mathrm{C}$ ) averaged over the period 1920-2014. Contour lines are the mean state of the Historical ensemble mean over 1920-2014. 
Melting - Historical ensemble mean 1920-2014 T2M
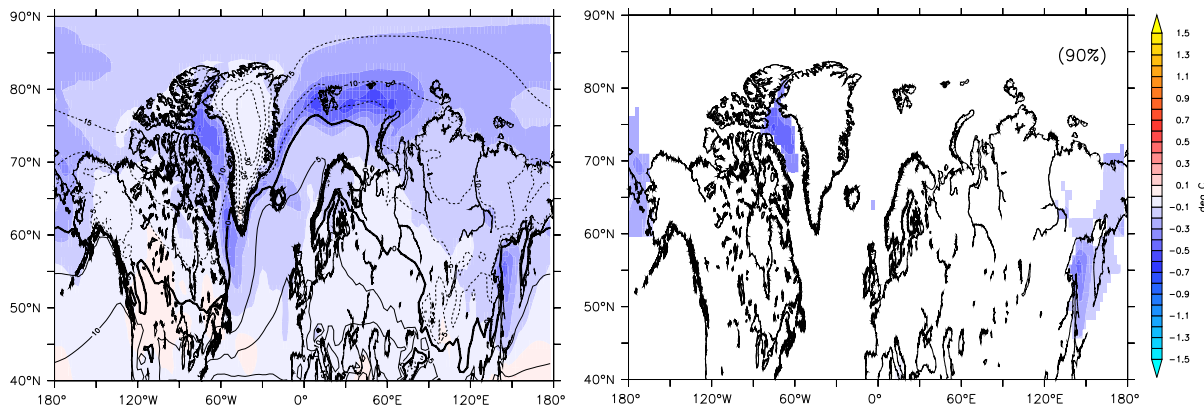

Fig. 7: Colors are the differences (left figure) and the significant (90\%) differences (right figure) between Historical and Melting ensemble means atmospheric 2-m temperature (in ${ }^{\circ} \mathrm{C}$ ) averaged over the period 1920-2014. Contour lines are the mean state of the Historical ensemble mean over 1920-2014.

To evaluate how the GrIS melting signals propagate below the surface, we compare in Figure 8 the two ensemble means averaged over 1920-2014 for the Atlantic zonal mean salinity and potential temperature down to 5500 meters. The surface cooling and freshening signal observed in Figure 6 spreads down to 3000 meters between $55^{\circ} \mathrm{N}$ and $70^{\circ} \mathrm{N}$, with anomalies around $-0.02 \mathrm{psu}$ for zonal mean salinity and $-0.1^{\circ} \mathrm{C}$ for zonal mean temperature. The maximum cooling ($0.2^{\circ} \mathrm{C}$ ) is significant $(90 \%)$ and detected at 1000 meters depth between 60 and $73^{\circ} \mathrm{N}$. A significant $(90 \%)$ freshening is found in the same region, so this can be caused by a modification of the circulation in the Nordic Seas. The maximum freshening (-0.1 psu), probably directly caused by the input of freshwater, lays at the surface at the same latitudes. There is also a non-significant warm and salty signal (about $0.02^{\circ} \mathrm{C}$ and $0.01 \mathrm{psu}$ ) at $45^{\circ} \mathrm{N}$ and at 250 meters depth extending southwards and down to 2000 meters. This may be interpreted as a shift of the Gulf Stream position, which could be consistent with a weakened AMOC (Zhang 2008). The impact of the melting on oceanic deep convection and circulation is investigated in the next subsection. 
Melting - Historical ensemble mean 1920-2014 zonal salinity
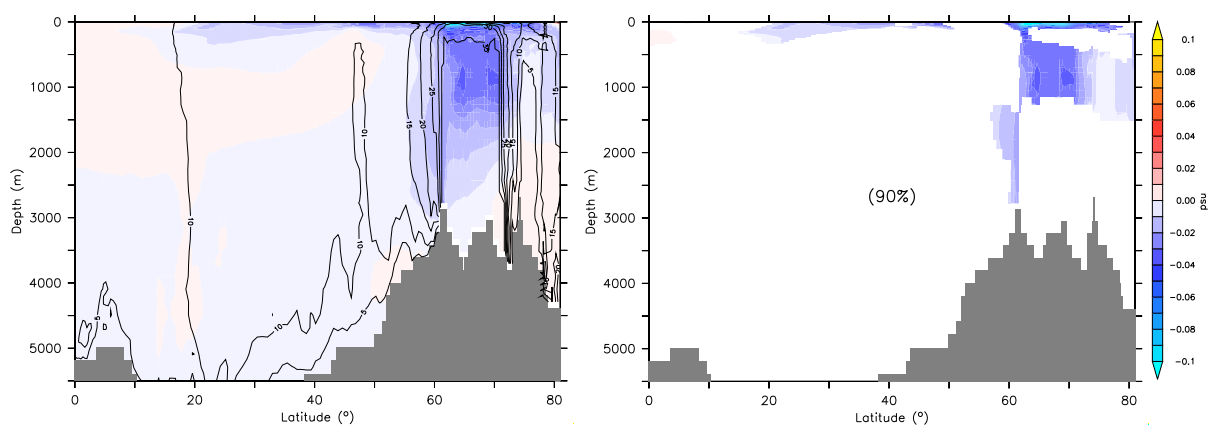

Melting - Historical ensemble mean 1920-2014 potential temperature
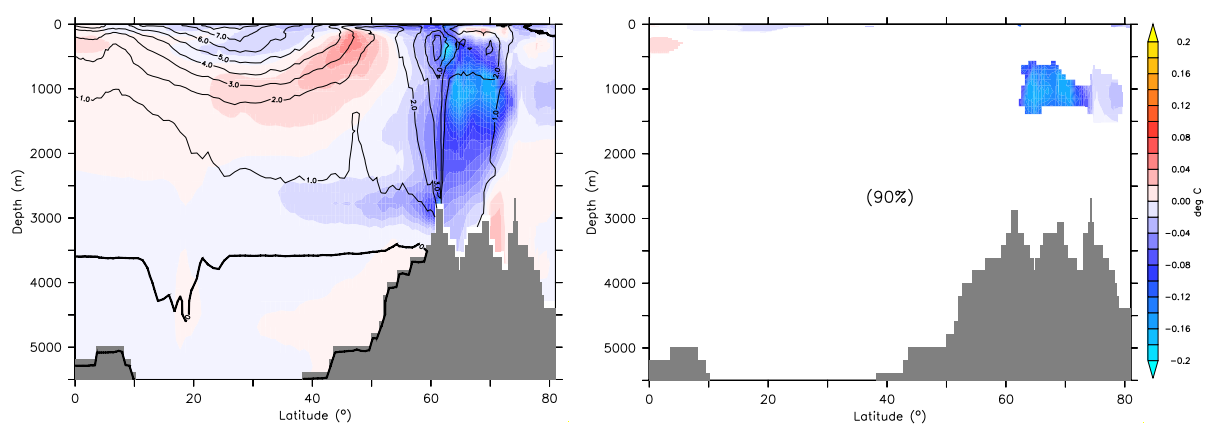

Fig. 8: Shading shows differences (left figures) and significant (90\%) differences (right figures) between Historical and Melting ensemble means for zonal mean over the Atlantic of salinity (top, in psu) potential temperature (bottom, in ${ }^{\circ} C$ ) averaged over the period 1920-2014. Contour lines are the mean state of the Historical ensemble mean over 1920-2014.

\subsection{Impact on convection and large-scale circulation}

Figure 9 describes the difference between the ensemble means in January-FebruaryMarch (JFM) mixed layer depth (MLD) averaged over the whole period of the experiments. We notice that, on the one hand, the convection site in the Irminger Sea is more active in the Melting ensemble than in the Historical one, with a positive difference of JFM MLD by up to 20 meters on average. On the other hand, including the observed GrIS melting leads to a reduction of convective activity in the Labrador and Nordic Seas, with mean differences exceeding 50 meters in a few locations of these seas. In the Historical ensemble convection preferentially occurs in the Labrador and Nordic Seas with MLD exceeding 1000 meters on average the period (not shown).

Convective activity can decrease with surface freshening, as it was observed in the 1970s during the Great Salinity Anomaly for the Labrador Sea (Gelderloos et al. 2012). The primary signature of reduced convection in climate models is reduced surface density: a lower surface density stabilizes the water column and diminishes the number and intensity of convective events in winter. Given the cooling and freshening signals obtained in Figure 6 , it is worth investigating the 
resulting density anomaly at the surface of the ocean. Figure 10 reveals that in the Nordic and the Labrador Sea, the decrease in SSS is not entirely compensated in density by the SST: surface waters in the Melting ensemble are lighter by about $0.1 \mathrm{~kg} / \mathrm{m}^{3}$. This can thus explain the deep convection reduction. Surface density in the Baffin Bay is reduced by up to $1 \mathrm{~kg} / \mathrm{m}^{3}$ because of the large freshwater accumulation in this area.

A lower October-November (ON) MLD is found west of Greenland (Figure 11, left) which together with the surface freshening favors sea ice formation by reducing the heat capacity of the upper ocean (Selyuzhenok et al. 2020). A positive and significant sea ice cover difference between the two ensemble means is indeed found in this region and up to the Barents Sea with values between 2 and $5 \%$ on average over the period 1920-2014 (Figure 11, right). This modification in sea ice formation could in turn trigger convection in the Irminger Sea (Figure 9), consistent with the increase of density in this region (Figure 10). Indeed, more sea ice leads to a cooling of the water along the ice edge which helps to increase density in the upper layer together with the salt rejection of newly formed ice. Also, the Irminger Sea is less affected by the freshwater release trajectories according to our passive tracer experiments (Figure 5 and 6).

\section{Melting - Historical ensemble mean 1920-2014 JFM MLD}

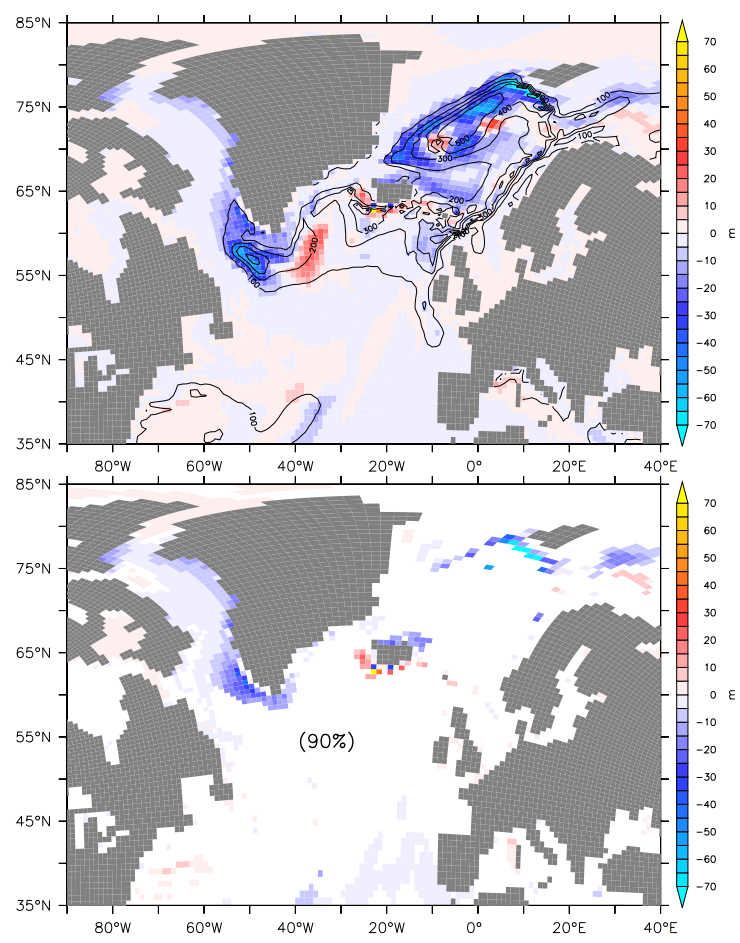

Fig. 9: Shading shows the differences (top figure) and the significant (90\%) differences (bottom figure) between Historical and Melting ensemble means for January-February-March mixedlayer depth (in m) averaged over the period 1920-2014. Contour lines are the mean state of the Historical ensemble mean over 1920-2014. 
Melting - Historical ensemble mean 1920-2014 surface density
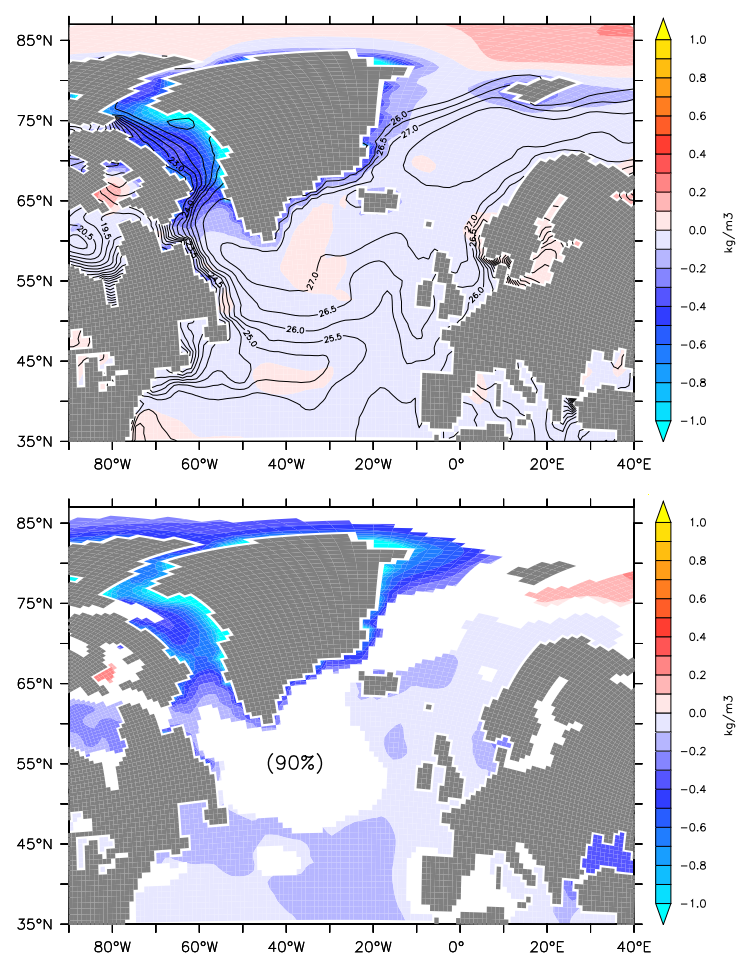

Fig. 10: Shading shows the differences (top figure) and the significant (90\%) differences (bottom figure) between Historical and Melting ensemble means for surface density (in $\mathrm{kg} / \mathrm{m}^{3}$ ) averaged over the period 1920-2014. Contour lines are the mean state of the Historical ensemble mean over 1920-2014. 

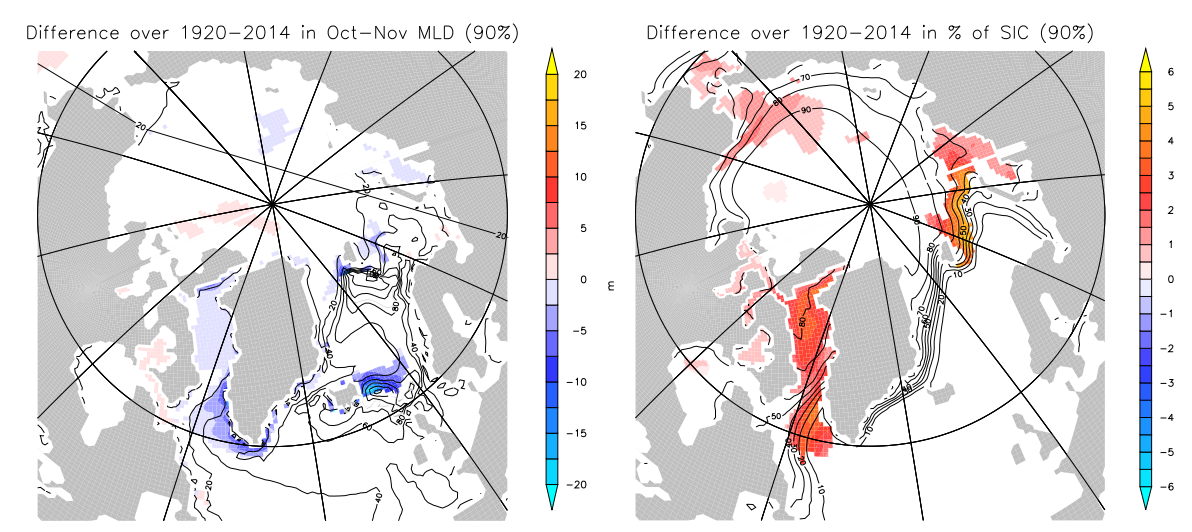

Fig. 11: Significant differences (90\%) between Historical and Melting ensemble means in October-November sea ice cover (left, in \%) and MLD (right, in m) averaged over the period 1920-2014. Contour lines are the mean state of the Historical ensemble mean over 1920-2014.

The impact of the decrease in convective activity in the Labrador and Nordic Seas can be found on the North Atlantic large-scale circulation: comparing the Atlantic meridional overturning stream-function of the ensemble means over the experimental period shows a general decrease of up to $0.4 \mathrm{~Sv}$ around $40^{\circ} \mathrm{N}$ latitude (Figure 12). The slowdown lies between 0.3 and $0.4 \mathrm{~Sv}$ in the first 2000 meters from $30^{\circ} \mathrm{S}$ to $50^{\circ} \mathrm{N}$. We looked at several periods, including the $1980-2014$ period, and the difference between the two ensembles was not higher than the difference over the whole experiments period (1920-2014). 

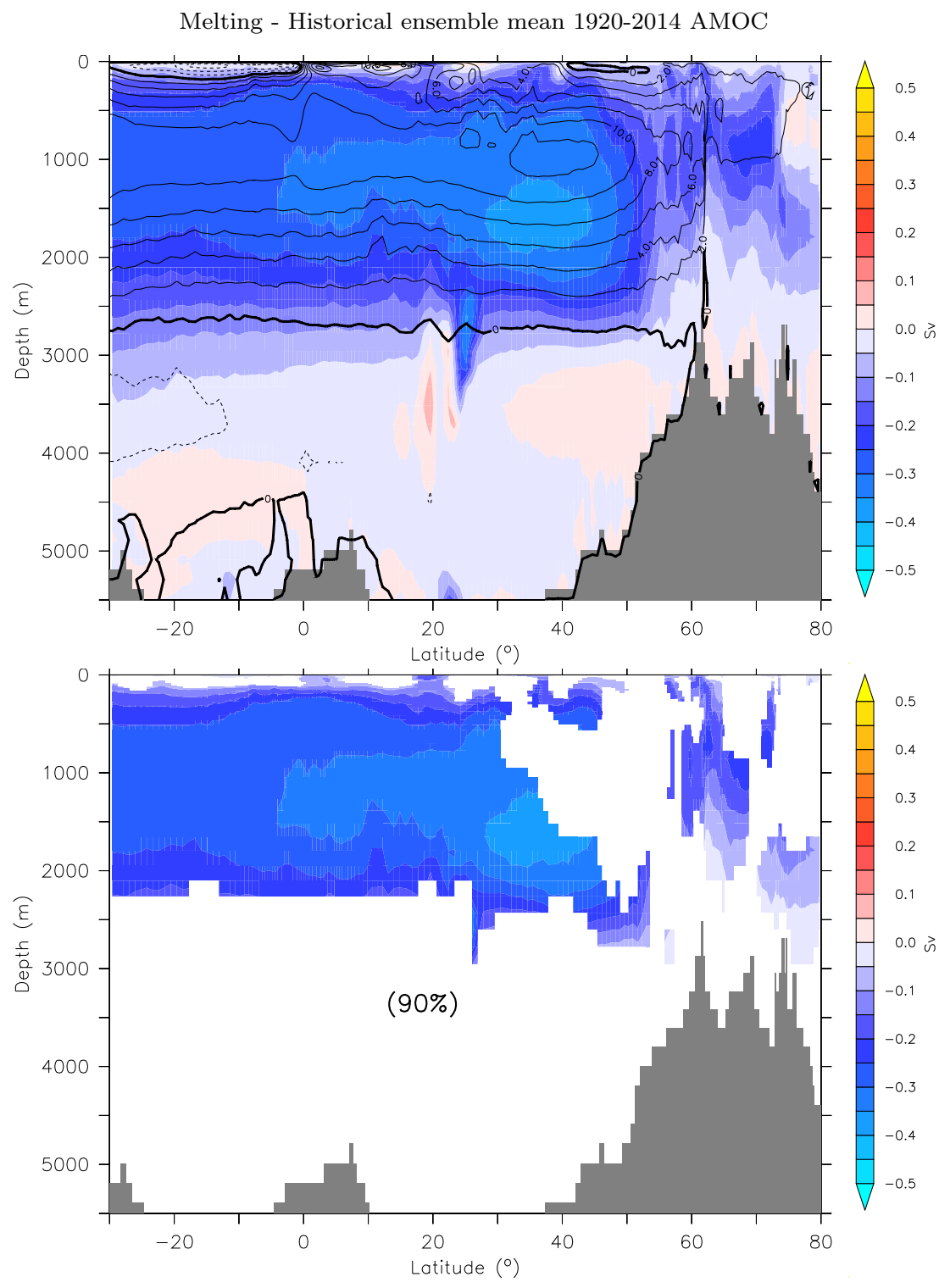

Fig. 12: Colors are the differences (top figure) and the significant (90\%) differences (bottom figure) between Historical and Melting ensemble means of the Atlantic meridional overturning stream-function (in Sv) averaged over the period 1920-2014. Contour lines are the mean state of the Historical ensemble mean over 1920-2014.

We evaluate the difference between the two ensemble means, which measures the forced signal from the freshwater release ( $c f$. section 1.2.2), of the maximum $\mathrm{AMOC}$ at $26^{\circ} \mathrm{N}$ to be about $0.32 \pm 0.35 \mathrm{~Sv}$ on average over the $1920-2014$ period. It is weaker further north $\left(0.26 \pm 0.37 \mathrm{~Sv}\right.$ for the maximum $\mathrm{AMOC}$ at $\left.48^{\circ} \mathrm{N}\right)$ and it is $0.33 \pm 0.4 \mathrm{~Sv}$ for the maximum AMOC between $30^{\circ} \mathrm{S}$ and $60^{\circ} \mathrm{N}$, on average over the 
1920-2014 period. To compute the uncertainty intervals, the standard deviation of the differences in AMOC maximum at $26^{\circ} \mathrm{N}, 48^{\circ} \mathrm{N}$, and between $30^{\circ} \mathrm{S}$ and $60^{\circ} \mathrm{N}$ between the two ensembles are calculated after averaging the members over the time of the experiment (1920-2014).

The time series of the three AMOC indices for both ensembles are shown in Figure S3. The standard deviations of the indices are calculated for each ensemble after averaging the members over 1920-2014, in order to obtain an estimation of the internal variability. We obtain comparable values for the two ensembles: for the maximum AMOC, on average over the whole period, the standard deviation of the Melting ensemble is $0.29 \mathrm{~Sv}$, while it is $0.42 \mathrm{~Sv}$ for the Historical ensemble. A larger Melting ensemble could thus help to correctly estimate the forced signal from the freshwater release which is here, for this century-long average, of the same order of magnitude as the internal variability.

Figure 13 shows the Kernel-based estimations of the distribution of the timeaveraged members for the maximum AMOC at $26^{\circ} \mathrm{N}$. The maximum of the distributions is the maximum likelihood i.e. the value that is most likely obtained with larger ensembles, keeping in mind that these statistics were only obtained with ten members, so the uncertainty remains quite large. For the maximum AMOC at $26^{\circ} \mathrm{N}$, the maximum of the distribution is lower by $0.55 \mathrm{~Sv}$ in the Melting ensemble as compared to the Historical one $\left(0.41 \mathrm{~Sv}\right.$ at $48^{\circ} \mathrm{N}$ and 0.49 between $30^{\circ} \mathrm{S}$ and $\left.60^{\circ} \mathrm{N}\right)$. The AMOC weakening is therefore coherent over the whole basin and may become a little higher with a larger ensemble. The dispersion between the members within the ensembles is further investigated in section 3 , where we evaluate the century-long linear trends of the ensemble means and individual members for both SSS and SST and compare them to available observations.

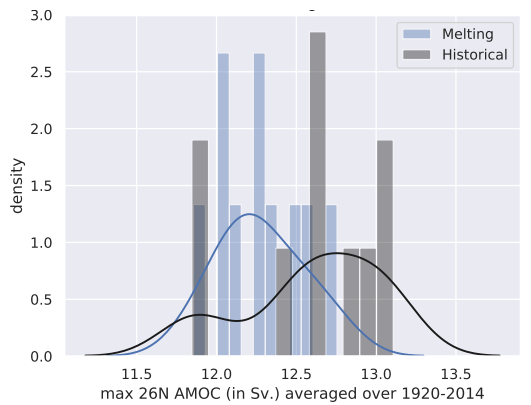

Fig. 13: Histograms of the Maximum at $26^{\circ} \mathrm{N}$ of the AMOC for the members of the Melting (blue) and Historical (grey) ensembles, averaged over 1920-2014. Solid-lines are the kernelbased estimations of the probability density functions.

\section{Comparison of long-term trends and variations with observations}

Surface temperature and salinity multi-decadal trends and anomalies are compared to available observations in order to asses the long-term impact of adding a realistic Greenland and surroundings melting in the IPSL-CM6A-LR model. Analysis of the individual members of the Melting and Historical ensembles is provided. 
3.1 Salinity trends and variations

The recent study of Friedman et al. (2017) reveals a significant negative trend in SSS in the SPG over the period 1896-2013. This trend might be related to climate change, as it is suggested for the increase of SSS in the tropical area (Du et al. 2015). This could be a signal of an intensified hydrological cycle. We compare the reconstructed SSS linear trends from Friedman et al. (2017) and EN4 (Good et al. 2013), presented in section 1.5, to linear trends of annual mean SSS of the Historical and Melting ensembles in the subpolar gyre region (Figure 14). The chosen area in Figure 14 (top) is a part of the NATL region described in Friedman et al. (2017) and in section 1.5. Data above $65^{\circ} \mathrm{N}$ were excluded in order to focus on the SPG region but results are not sensitive to the details of the region (not shown). In order to compare our model outputs to this observed trend, we apply the protocol of the study of Friedman et al. (2017) to evaluate annual means: December to November SSS are averaged and a 1-2-1 temporal filter is applied. The anomalies are calculated with respect to the 1920-2014 period.

The trends have opposite signs in the two observational dataset (Figure 14) and are significantly different at the $95 \%$ level. The Melting and Historical trends also have different signs and are significantly different at the $90 \%$ level. Over the whole period, the Historical ensemble mean trend is significantly higher than the Friedman et al. (2017) observation-based estimate and closer to EN4 data. The SSS trend of the Melting ensemble mean is closer to the estimate from Friedman et al. (2017) than to EN4 data. It seems that the inclusion of the melting may have lead this ensemble towards the observation-based estimate from Friedman et al. (2017).

In the study of Reverdin et al. (2018), the authors argued that the observationbased estimates from Friedman et al. (2017) in the subpolar gyre might be more reliable than EN4 data for the early twentieth century. It indeed uses a larger observational database, especially before the 1950s, because of the inclusion of some in situ data from research vessels and merchant ships that are not taken into account in EN4. Under the assumption that Friedman et al. (2017) better represents the long-term trends, due to additional data, we can suggest that the Melting ensemble mean trend is closer to the observational data trend than the Historical ensemble mean one. 

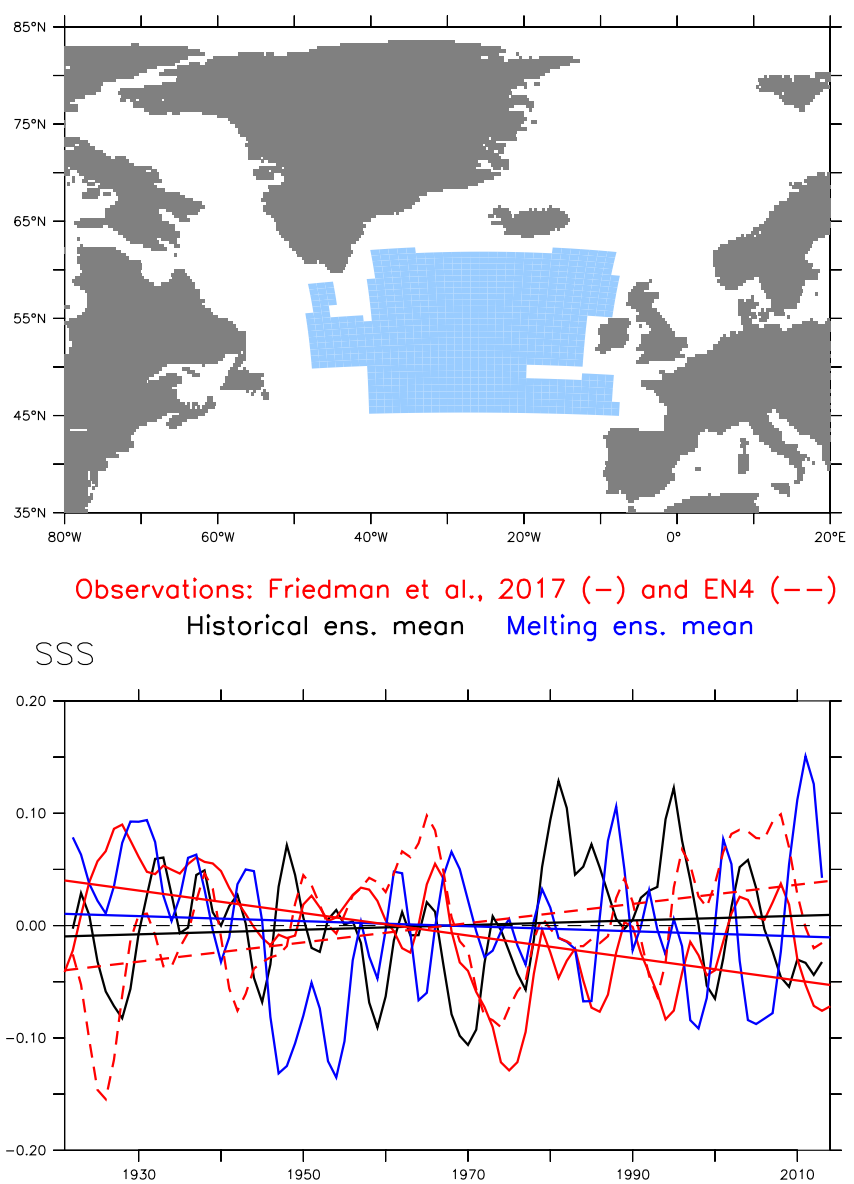

Fig. 14: SSS anomalies (in psu), with respect to 1920-2014, and linear trends in the subpolar region (blue region in top panel) for the Historical (black) and Melting (blue) ensemble means. Red lines are the SSS observations: anomalies, with respect to 1920-2014, and trends from Friedman et al. (2017) (continuous line) and EN4 from Good et al. (2013) (dashed line).

To evaluate the spread among the trends of both ensembles, we present the slopes of the 95-year linear trends of every member in the histogram of Figure 15. We compare these slopes to the one of the observation trend from Friedman et al. (2017).

We notice that six out of ten Melting members have a trend which is closer to the observed trend of Friedman et al. (2017) than their Historical twins (members with the same starting dates). Five members from the Melting ensemble are able to display a negative trend while only three members from the Historical ensemble do. The last two bars represent the mean and variance of the slopes obtained for the individual members, showing that the variance is twice as large in the Melting ensemble as in the Historical one. This raises the question for the need for a larger ensemble to correctly evaluate the improvement of the long-term trend. This also highlights the considerable spread due to internal variability, which is clearly more 
important than the forced signal due to GrIS melting. The latter is estimated by evaluating the difference between the Historical and the Melting ensemble means (first black and blue bars in Figure 15). The ratio of the forced signal from GrIS melting and the standard deviation in the Historical simulations gives a small signal to noise ratio of 0.15 for the SSS trends, highlighting the potential very large role of internal variability in this model to explain the observed trends.

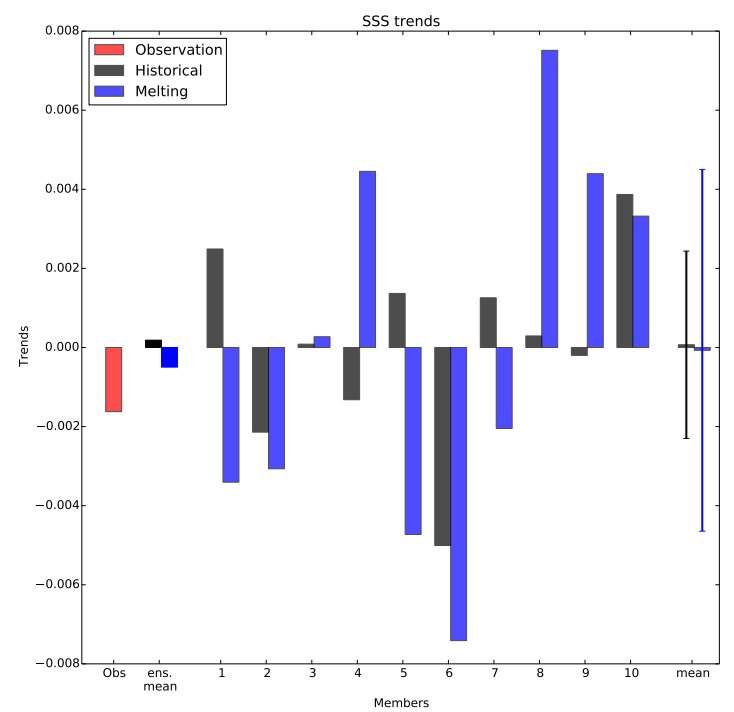

Fig. 15: SSS trends for the ten members of the Historical ensemble (black), the Melting experiments (blue) and the observations from Friedman et al. (2017) (red) in the subpolar region (Figure 14, top). The second column represents the trends of the ensemble means, while the last one shows the ensemble means of the trends of the different members, with the associated error bar (two standard deviations).

We now consider the interannual variations of SSS anomalies in the subpolar region. For this purpose we use the Root-Mean-Square-Error (RMSE) metric which allows to evaluate the whole error with respect to observations and not only the long-term linear trend. This metric provides information for both bias in variance and correlation ( $c f$. supplementary subsection 6.4 and detailed formula in Taylor 2001). As we look at RMSE of anomalies, the mean bias is not accounted for.

RMSE of detrended SSS anomalies with respect to observations from Friedman et al. (2017) are evaluated for the ten members of the Melting and Historical ensembles and results are presented in Figure 16. Even if the Melting ensemble mean displays a slightly smaller RMSE than the Historical one, only four out of ten of the Melting members are closer to the observations than their Historical twins. Also, the ensemble mean RMSE are not significantly different.

These results show that the inclusion of the melting only slightly improves the SSS variations as compared to the available observations in this region over the whole period 1920-2014. We can conclude that, with our model, either a larger ensemble or a longer period are needed to draw strong conclusions on the impact 
of Greenland melting on the surface salinity long-term trend and variability in the subpolar gyre region. A reduction of uncertainties in the observational data is also necessary. Our two ensembles are hard to distinguish and this first study does not supply evidence that GrIS melting have a strong impact on SSS variations in this region.

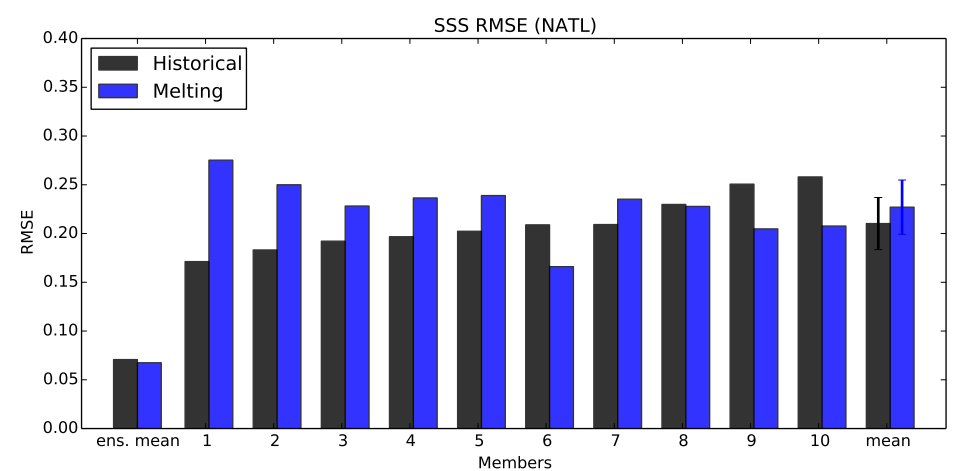

Fig. 16: RMSE of the detrended SSS with respect to observations from Friedman et al. (2017) in the subpolar region (Figure 14, top) for the ten members of the Historical (black) and Melting (blue) ensembles. The first column represents the RMSE of the ensemble means, while the last one shows ensemble means of the RMSE of the different members, with the associated errors bars (two standard deviations)

\subsection{Temperature trends and variations}

Simulated sea surface temperature are compared with observations in the subpolar region over the same period (1920-2014) (Figure 17, top). SST anomalies (with respect to 1920-2014) and trends from both ensembles, ERSST data from Huang et al. (2016) and HadISST data from Rayner et al. (2003) (presented in section 1.5) are showed in Figure 17 (bottom). We notice that both ensemble means exhibit a positive trend, while observation-based estimates from ERSST and HadISST show a slightly negative or slightly positive trend respectively, both of which being not significantly different from zero. In our model, the inclusion of the melting is bringing the signal closer to the observations in this region, even though the difference between the trends is very small and not significant at the $95 \%$ level but only at the $90 \%$ level. 

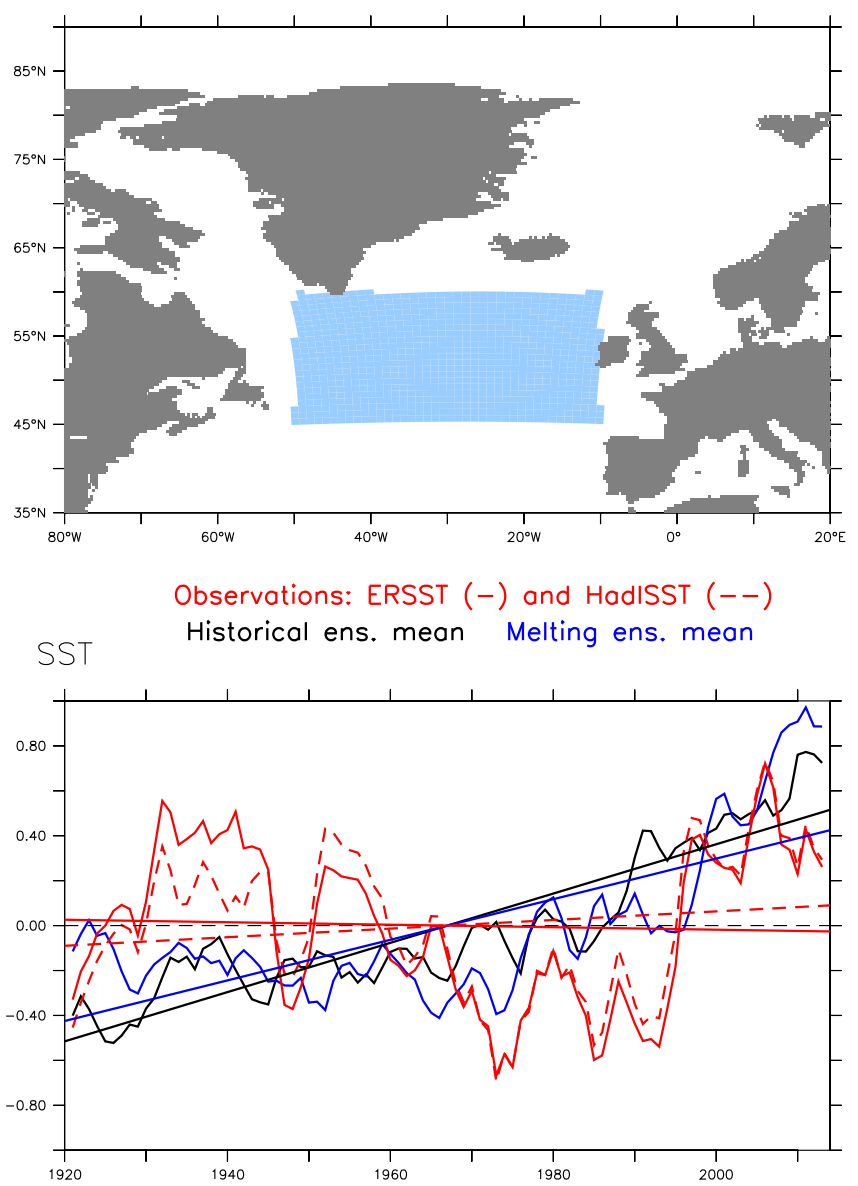

Fig. 17: SST anomalies (in ${ }^{\circ} \mathrm{C}$ ), with respect to $1920-2014$, and trends in the subpolar gyre region (blue region in the top panel) for the Historical (black) and Melting (blue) ensemble means. Red lines are the SST observations: anomalies, with respect to 1920-2014, and trends from ERSST from Huang et al. (2016) (continuous lines) and HADISST from Rayner et al. (2003) (dashed lines).

The SST trends computed for the individual members of both ensembles are compared to the observed one from ERSST in the histogram of Figure 18. Results using HadISST are not different since both observational data are very close. Six out of ten Melting members display a SST trend closer to the observations than their Historical twins. Three members do show a negative trend, one from the Historical ensemble and two from the Melting one. This means that forcing from GrIS melting is helping to get closer to the observations but the internal variability in the model is sufficient to be able to reproduce the observed SST trend. Indeed, the signal to noise ratio, here evaluated as the ratio of forced GrIS melting response (difference of the ensemble means) and the mean standard deviation of the historical simulations, is here estimated to be 0.1 , which shows that the contribution of GrIS melting to the observed trend remains small. 


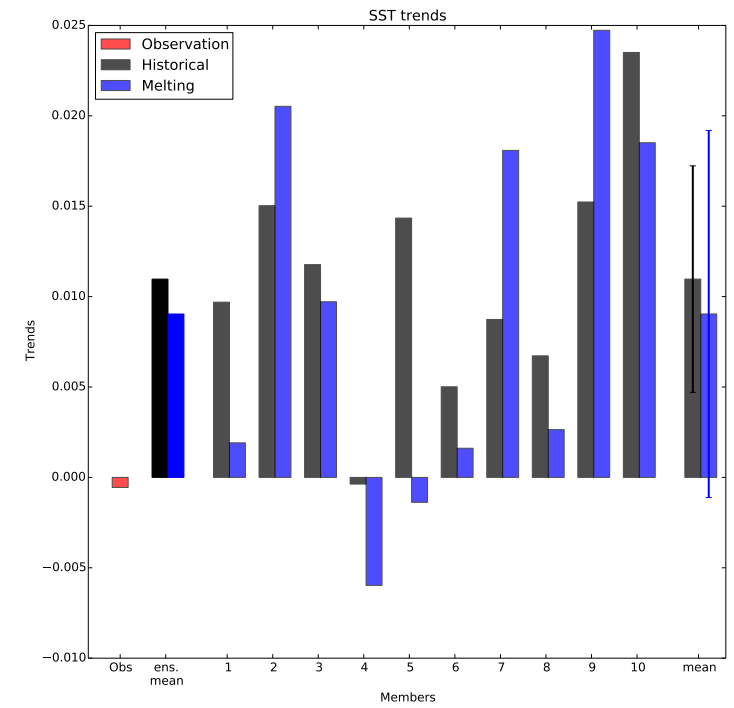

Fig. 18: SST trends for the ten members of the Historical ensemble (black), the Melting experiments (blue) and the observations from ERSST (Huang et al. 2016) (red) in the subpolar region (Figure 17, top). The second column represents the trends of the ensemble means, while the last one shows the ensemble means of the trends of the different members, with the associated errors bars (two standard deviations).

The RMSE of detrended SST with respect to observations is evaluated for the individual members of the Historical and Melting ensembles (Figure 19) over the whole period 1920-2014. For the subpolar region, seven out of ten Melting members display a lower SST RMSE than their Historical twins. The ensemble means RMSE are different with only a $70 \%$ level of confidence, which shows again that if the inclusion of the GrIS melting seems to improve the error made with the observations in this region, the results are not very robust and a larger ensemble could help to build stronger conclusions. We conclude that there are some signs showing that the inclusion of a realistic melting brings this model closer to the observed SST in the subpolar region, in terms of long-term trend and variability, even though the signal-to-noise ratio and levels of confidence remain low and internal variability is more likely to explain the observed trends. 


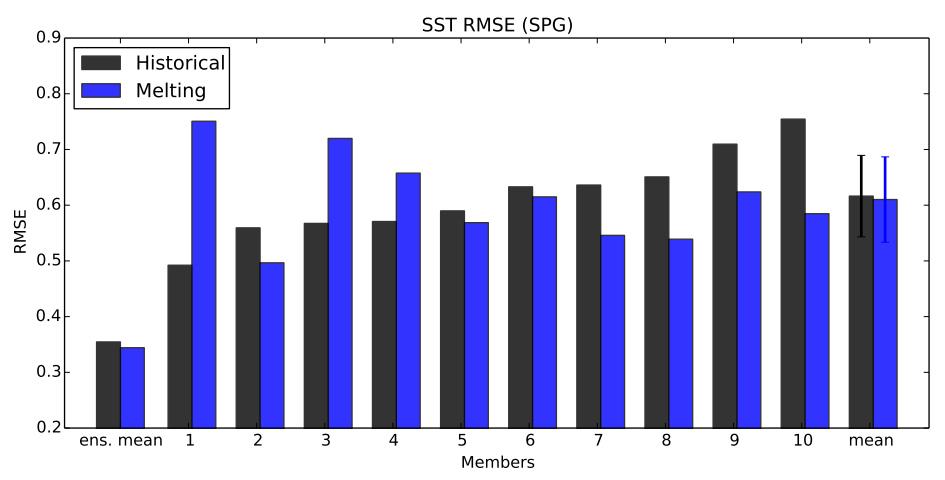

Fig. 19: RMSE of detrended SST with respect to ERSST (Huang et al. 2016) in the subpolar gyre region (Figure 17, top) of the ten members of the Historical (black) and the Melting (blue) ensembles. The first column represents the RMSE of the ensemble mean, while the last one is ensemble mean of the RMSE of the different members, with the associated error bar (two standard deviations).

\section{Discussion and conclusion}

In this study, we have reconstructed a complete set of freshwater fluxes around the GrIS into the ocean, based on Bamber et al. (2018) and Box and Colgan (2013) estimates. It includes monthly values of runoff and icebergs, from Greenland and surrounding regions, over the period $1840-2016$ on a $1^{\circ}$ resolution grid for the ocean. We have forced a global coupled climate model with this realistic input of freshwater due to the melting of GrIS for the period 1920-2014. We have compared a ten-member ensemble of historical simulations including this realistic input of freshwater due to the melting, against the ten-member ensemble of historical simulations starting from the same initial conditions but without this realistic melting.

Comparison of the ensemble means enables to identify in our model the oceanic and climatic consequences of the increasing trend in GrIS melting observed since 1920. We have found a cooling of the subpolar gyre that spreads toward the supbtropical gyre. This fingerprint can also be found in SSS with the same sign. In addition, the Arctic exhibits a strong surface salinification, consistent with other idealized hosing experiments (Swingedouw et al. 2013). In response to the melting, the oceanic convection furthermore decreases in the Labrador and Nordic Seas, while it increases in the Irminger Sea. Along with the modifications in convection, we detect a possible reduction of the AMOC at $26^{\circ} \mathrm{N}$ of $0.32 \pm 0.35 \mathrm{~Sv}$, from 1920 to 2014 , as compared to historical simulations.

A recent study (Caesar et al. 2018) estimated that the AMOC may have slowed down by $3 \pm 1 \mathrm{~Sv}$ in the recent decades. This value should not be taken per se, as the uncertainty might be larger than suggested in the former study, but we will use this first estimate to put our results and those from other models in a quantitative perspective. In the large ensemble (30 members) of IPSL-CM6A-LR historical simulations, the externally forced signal of AMOC weakening at $26^{\circ} \mathrm{N}$ obtained through a comparison of periods 2005-2014 and 1870-1900 - is very close 
to zero $(0.05 \pm 0.82 \mathrm{~Sv})$. Only a few members exhibit a large weakening, almost up to $2 \mathrm{~Sv}$, which is therefore the result of internal variability. In our experiments, including realistic Greenland melting is allowing one Melting member to reach a weakening of $2.5 \mathrm{~Sv}$ for the maximum AMOC at $26^{\circ} \mathrm{N}$ using the same periods for the calculation. Such a weakening is within the values of the reconstructed trend from Caesar et al. (2018), even though it remains quite sensitive to the reference periods used for the computation and our estimation is not calculated with the same method as Caesar et al. (2018). The latter indeed used AMOC fingerprints based on SST, while in our experiments, we use direct measure of AMOC intensity. If our model estimates, using ten members, are correct, the forced signal from radiative forcing is close to zero over the historical era and the forced signal from Greenland melting is $-0.32 \pm 0.35 \mathrm{~Sv}$ of AMOC weakening at $26^{\circ} \mathrm{N}$ over $1920-2014$. This would indicate that Greenland melting is responsible for about $10 \%$ of the weakening estimate obtained by Caesar et al. (2018), while the external radiative forcing does not play a role, and the rest of the weakening would then be largely explained by internal variability.

Nevertheless, it is possible that IPSL-CM6A-LR underestimates the weakening of the AMOC due to external forcing. Indeed in chapter 6 of SROCC report, Collins et al. (2019) showed that CMIP5 climate projections exhibit a weakening of $\mathrm{AMOC}$ at $26^{\circ} \mathrm{N}$ of $1.4 \pm 1.4 \mathrm{~Sv}$ for present day (2006-2015) in comparison with preindustrial era (1850-1900). This result is based on CMIP5 models which do not take into account the melting (either from runoff, basal melting or icebergs) from the GrIS (cf. Section 6.7.1.2 of Pörtner et al. (2019)). This may lead to an underestimation of the freshwater fluxes, as it is for IPSL-CM6A-LR (see Figure 4 ), due to a poor representation of the land ice processes. Thus, from the CMIP5 estimate of $1.4 \pm 1.4 \mathrm{~Sv}$, about half of the reconstructed weakening of the AMOC from Caesar et al. (2018) ( $3 \pm 1 \mathrm{~Sv}$ ) can be explained by external forcings. The spread nevertheless remains large and the weakening appears to be lower in CMIP6 models, as discussed in Menary et al. (2020).

To summarize, based on our forced IPSL-CM6A-LR ensemble of simulations, we argue that internal variability might be the best candidate to explain the possible AMOC weakening over the last decades with about only $10 \%$ due to Greenland ice sheet melting and a negligible role from direct response to external forcing. Nevertheless, this result is model dependent and some CMIP5 models show a substantial AMOC weakening over the historical era, without including GrIS melting. The ensemble mean of CMIP5 does show that external forcing might explain up to about half of the AMOC weakening estimate from Caesar et al. (2018). It should also be kept in mind that the observed weakening itself remains disputable, since only indirect measurements are available for a sufficiently long period to assess trends. We thus conclude that the on-going melting of GrIS might have played a limited role in the potential recent AMOC weakening, while external forcing within CMIP5 models, or internal variability within IPSL-CM6A-LR model, are able to explain a large amount of such a weakening.

The impact of observed GrIS melting on multi-decadal variability has not been evaluated up to now. There has been a few hypotheses stating that the on-going melting might explain some of the cooling signal observed in the North Atlantic (Rahmstorf et al. 2015; Yang et al. 2016), but no proper attribution. Multidecadal SST trends are here closer to observations but only for six out of ten members. These results indicate that including a realistic Greenland melting may help ob- 
taining more realistic SST trends with respect to observations in the subpolar gyre. However, SST trends of the ensemble means remain quite close as they are only significantly different with a $90 \%$ level of confidence. It was difficult to analyze the impact on the long-term trend due to uncertainties related to observations.

In our experiment, comparison with several observational datasets reveals a reduced sea surface temperature RMSE in the subpolar gyre region as compared to observations for seven out of ten members of the Melting ensemble. Regarding surface salinity, the error is reduced for only four out of ten members of the Melting ensemble. A larger ensemble may help increasing the level of confidence of the signals since the amount of freshwater added in the Melting experiments is relatively modest. Overall, we found some signs that the inclusion of Greenland Melting is bringing the model ensemble closer to the observation, although the two ensembles remain hardly distinguishable. Therefore, our study does not give enough evidence to support the hypothesis raised by Rahmstorf et al. (2015) and Yang et al. (2016) that relates AMOC weakening over the twentieth century to a decrease in salinity of North Atlantic waters due to increasing melting of GrIS.

The possible reduction of surface temperature bias with GrIS melting could have implications for decadal prediction, for which an accurate estimate of the initial ocean state plays a key role (Cassou et al. 2018). The melting product that we deliver here, starting in 1920 and based on Bamber et al. (2018) and Box and Colgan (2013) estimates, adapted to an ocean GCM grid, is an important tool to go in that direction.

While the use of a multi-member ensemble of climate simulations forced for a long period with realistic freshwater fluxes, including the large increase in the 1920 s, is the main novelty of the present study, its principal limitation concerns the relatively low spatial resolution of the IPSL-CM6-LR ocean grid. Indeed, it has been shown by Gillard et al. (2016) that narrow boundary currents, which are poorly resolved here, are important for freshwater transport and distribution. Ideally, at least a $1 / 10^{\circ}$ resolution in the ocean might be necessary to properly resolve key mesoscale processes. However Jackson et al. (2020) showed that climate models using higher resolutions still entail strong uncertainty and may show stronger response to $\mathrm{CO}_{2}$ forcing in terms of AMOC weakening. Given the limited benefits of switching from $1^{\circ}$ to a $1 / 4^{\circ}$ resolution ocean grid (Menary et al. 2015) and the computational cost of current climate models, which hampers the possibility to run such ensembles of simulations on higher resolutions, the $1^{\circ}$ ocean resolution appears to be a reasonable compromise. Moreover, our results highlight that more than ten members are necessary to properly isolate the signal of observed GrIS melting from internal variability, and such an ensemble is already quite computationnally expensive.

Acknowledgements This work was granted access to the HPC resources of TGCC under the allocation No. 2016-017403. The authors thank the platform group users of the IPSL. 


\section{Declarations}

\subsection{Funding}

This research benefited from Blue-Action project: European Union's Horizon 2020 research and innovation program, grant number 727852 .

\subsection{Conflicts of interest/Competing interests}

Not applicable

5.3 Availability of data and material

Available on request

\subsection{Code availability}

Available on request

\section{References}

Arsouze T, Dutay JC, Lacan F, Jeandel C (2009) Reconstructing the Nd oceanic cycle using a coupled dynamical- Biogeochemical model. Biogeosciences 6, DOI:10.5194/ bgd-6-5549-2009

Aumont O, Bopp L (2006) Globalizing results from ocean in situ iron fertilization studies. Global Biogeochemical Cycles 20(2), DOI : 10.1029/2005GB002591

Ayache M, Dutay JC, Arsouze T, Révillon S, Beuvier J, Jeandel C (2016) High-resolution neodymium characterization along the Mediterranean margins and modelling of $\varepsilon_{N d}$ distribution in the Mediterranean basins. Biogeosciences 13:52595276

Bamber J, van den Broeke M, Ettema J, Lenaerts J, Rignot E (2012) Recent large increases in freshwater fluxes from Greenland into the North Atlantic. Geophysical Research Letters 39(19), DOI : $10.1029 / 2012$ GL052552

Bamber JL, Tedstone AJ, King MD, Howat IM, Enderlin EM, van den Broeke MR, Noel B (2018) Land Ice Freshwater Budget of the Arctic and North Atlantic Oceans: 1. Data, Methods, and Results. Journal of Geophysical Research: Oceans 123(3):1827-1837, DOI: 10.1002/2017JC013605

Böning CW, Behrens E, Biastoch A, Getzlaff K, Bamber JL (2016) Emerging impact of Greenland meltwater on deepwater formation in the North Atlantic Ocean. Nature Geoscience 9(7):523-527, DOI : 10.1038/ngeo 2740

Boucher O, Servonnat J, Albright AL, Aumont O, Balkanski Y, Bastrikov V, Bekki S, Bonnet R, Bony S, Bopp L, Braconnot P, Brockmann P, Cadule P, Caubel A, Cheruy F, Codron F, Cozic A, Cugnet D, D'Andrea F, Davini P, de Lavergne C, Denvil S, Deshayes J, Devilliers M, Ducharne A, Dufresne JL, Dupont E, th C, Fairhead L, Falletti L, Flavoni S, Foujols MA, Gardoll S, Gastineau G, Ghattas J, Grandpeix JY, Guenet B, Guez E Lionel, Guilyardi E, Guimberteau M, Hauglustaine D, Hourdin F, Idelkadi A, Joussaume S, Kageyama M, Khodri M, Krinner G, Lebas N, Levavasseur G, Lvy C, Li L, Lott F, Lurton T, Luyssaert S, Madec G, Madeleine JB, Maignan F, Marchand M, Marti O, Mellul L, Meurdesoif Y, Mignot J, Musat I, Ottl C, Peylin P, Planton Y, Polcher J, Rio C, Rochetin N, Rousset C, Sepulchre P, Sima A, Swingedouw D, Thiblemont R, Traore AK, Vancoppenolle M, Vial J, Vialard J, Viovy N, Vuichard N (2020) Presentation and Evaluation of the IPSL-CM6A-LR Climate Model. Journal of Advances in Modeling Earth Systems 12(7):e2019MS002010, DOI : 10.1029/2019MS002010 
Box JE, Colgan W (2013) Greenland Ice Sheet Mass Balance Reconstruction. Part III: Marine Ice Loss and Total Mass Balance (18402010). Journal of Climate 26(18):6990-7002, DOI : 10.1175/JCLI-D-12-00546.1

van den Broeke MR, Enderlin EM, Howat IM, Kuipers Munneke P, Noël BPY, van de Berg WJ, van Meijgaard E, Wouters B (2016) On the recent contribution of the Greenland ice sheet to sea level change. The Cryosphere 10(5):1933-1946, DOI :10.5194/tc-10-1933-2016

Buckley MW, Marshall J (2016) Observations, inferences, and mechanisms of the Atlantic Meridional Overturning Circulation: A review. Reviews of Geophysics 54(1):5-63, DOI: 10.1002/2015RG000493

Caesar L, Rahmstorf S, Robinson A, Feulner G, Saba V (2018) Observed fingerprint of a weakening Atlantic Ocean overturning circulation. Nature 556:191-196, DOI:10.1038/ s41586-018-0006-5

Carmack EC, Yamamoto-Kawai M, Haine TWN, Bacon S, Bluhm BA, Lique C, Melling H, Polyakov IV, Straneo F, Timmermans ML, Williams WJ (2016) Freshwater and its role in the Arctic Marine System: Sources, disposition, storage, export, and physical and biogeochemical consequences in the Arctic and global oceans. Journal of Geophysical Research: Biogeosciences 121(3):675-717, DOI : 10.1002/2015JG003140

Cassou C, Kushnir Y, Hawkins E, Pirani A, Kucharski F, Kang IS, Caltabiano N (2018) Decadal climate variability and predictability: Challenges and opportunities. Bulletin of the American Meteorological Society 99(3):479-490, DOI:10.1175/BAMS-D-16-0286.1

Chylek P, Dubey MK, Lesins G (2006) Greenland warming of 19201930 and 19952005 . Geophysical Research Letters 33(11), DOI : 10.1029/2006GL026510

Collins M, Sutherland M, Bouwer L, S-M C, Frölicher T, Jacot Des Combes H, Koll Roxy M, Losada I, McInnes K, Ratter B, Rivera-Arriaga E, Susanto R, Swingedouw D, Tibig L (2019) Extremes, abrupt changes and managing risk. IPCC Special Report on the Ocean and Cryosphere in a Changing Climate, Chapter 6

Drijfhout S (2015) Competition between global warming and an abrupt collapse of the AMOC in Earths energy imbalance. Scientific Reports 5:14877, DOI : 10.1038/srep14877

Drijfhout S, van Oldenborgh GJ, Cimatoribus A (2012) Is a Decline of AMOC Causing the Warming Hole above the North Atlantic in Observed and Modeled Warming Patterns? Journal of Climate 25(24):8373-8379, DOI : 10.1175/JCLI-D-12-00490.1

Du Y, Zhang Y, Feng M, Wang T, Zhang N, Wijffels S (2015) Decadal trends of the upper ocean salinity in the tropical Indo-Pacific since mid-1990s. Scientific Reports 5:16050, DOI : $10.1038 /$ srep 16050

Dukhovskoy DS, Myers PG, Platov G, Timmermans ML, Curry B, Proshutinsky A, Bamber JL, Chassignet E, Hu X, Lee CM, Somavilla R (2016) Greenland freshwater pathways in the sub-Arctic Seas from model experiments with passive tracers. Journal of Geophysical Research: Oceans 121(1):877-907, DOI:10.1002/2015JC011290

Dukhovskoy DS, Yashayaev I, Proshutinsky A, Bamber JL, Bashmachnikov IL, Chassignet EP, Lee CM, Tedstone AJ (2019) Role of Greenland Freshwater Anomaly in the Recent Freshening of the Subpolar North Atlantic. Journal of Geophysical Research: Oceans 124(5):3333-3360, DOI : 10.1029/2018JC014686

Fettweis X, Box JE, Agosta C, Amory C, Kittel C, Lang C, van As D, Machguth H, Gallée H (2017) Reconstructions of the 1900-2015 Greenland ice sheet surface mass balance using the regional climate MAR model. The Cryosphere 11(2):1015-1033, DOI: 10.5194/tc-11-1015-2017

Friedman AR, Reverdin G, Khodri M, Gastineau G (2017) A new record of Atlantic sea surface salinity from 1896 to 2013 reveals the signatures of climate variability and long-term trends. Geophysical Research Letters 44(4):1866-1876, DOI : 10.1002/2017GL072582

Gelderloos R, Straneo F, Katsman CA (2012) Mechanisms behind the Temporary Shutdown of Deep Convection in the Labrador Sea: Lessons from the Great Salinity Anomaly Years 196871. Journal of Climate 25(19):6743-6755, DOI:10.1175/JCLI-D-11-00549.1

Gervais M, Shaman J, Kushnir Y (2018) Mechanisms Governing the Development of the North Atlantic Warming Hole in the CESM-LE Future Climate Simulations. Journal of Climate 31(15):5927-5946, DOI : 10.1175/JCLI-D-17-0635.1

Gillard LC, Hu X, Myers PG, Bamber JL (2016) Meltwater pathways from marine terminating glaciers of the Greenland ice sheet. Geophysical Research Letters 43(20):10,873-10,882, DOI : $10.1002 / 2016$ GL070969

Good SA, Martin MJ, Rayner NA (2013) EN4: Quality controlled ocean temperature and salinity profiles and monthly objective analyses with uncertainty estimates. Journal of 
Geophysical Research: Oceans 118(12):6704-6716, DOI:10.1002/2013JC009067

Hourdin F, Grandpeix JY, Rio C, Bony S, Jam A, Cheruy F, Rochetin N, Fairhead L, Idelkadi A, Musat I, Dufresne JL, Lahellec A, Lefebvre MP, Roehrig R (2013) LMDZ5B: The atmospheric component of the IPSL climate model with revisited parameterizations for clouds and convection. Climate Dynamics 40(9):2193-2222, DOI : 10.1007/s00382-012-1343-y

Hourdin F, Rio C, Grandpeix JY, Madeleine JB, Cheruy F, Rochetin N, Jam A, Musat I, Idelkadi A, Fairhead L, Foujols MA, Mellul L, Traore AK, Dufresne JL, Boucher O, Lefebvre MP, Millour E, Vignon E, Jouhaud J, Diallo FB, Lott F, Gastineau G, Caubel A, Meurdesoif Y, Ghattas J (2020) LMDZ6A: The Atmospheric Component of the IPSL Climate Model With Improved and Better Tuned Physics. Journal of Advances in Modeling Earth Systems 12(7):e2019MS001892, DOI : 10.1029/2019MS001892

Huang B, Thorne PW, Smith TM, Liu W, Lawrimore J, Banzon VF, Zhang HM, Peterson TC, Menne M (2016) Further Exploring and Quantifying Uncertainties for Extended Reconstructed Sea Surface Temperature (ERSST) Version 4 (v4). Journal of Climate 29(9):31193142, DOI: $10.1175 /$ JCLI-D-15-0430.1

Jackson L, Kahana R, Graham T, Ringer M, Woollings T, Mecking J, Wood R (2015) Global and European climate impacts of a slowdown of the AMOC in a high resolution GCM. Climate Dynamics 45:1-18, DOI:10.1007/s00382-015-2540-2

Jackson L, Peterson KA, Roberts CD, Wood R (2016) Recent slowing of Atlantic overturning circulation as a recovery from earlier strengthening. Nature Geoscience 19:518522

Jackson LC, Roberts MJ, Hewitt HT, Iovino D, Koenigk T, Meccia VL, Roberts CD, RuprichRobert Y, Wood RA (2020) Impact of ocean resolution and mean state on the rate of AMOC weakening. Climate Dynamics 55:1711-1732, DOI : 10.1007/s00382-020-05345-9

Kostov Y, Armour KC, Marshall J (2014) Impact of the Atlantic meridional overturning circulation on ocean heat storage and transient climate change. Geophysical Research Letters 41(6):2108-2116

Laurian A, Drijfhout SS, Hazeleger W, van Dorland R (2009) Global surface cooling: The atmospheric fast feedback response to a collapse of the thermohaline circulation. Geophysical Research Letters 36(20), DOI:10.1029/2009GL040938

Lenaerts JTM, Le Bars D, van Kampenhout L, Vizcaino M, Enderlin EM, van den Broeke MR (2015) Representing Greenland ice sheet freshwater fluxes in climate models. Geophysical Research Letters 42(15):6373-6381, DOI : 10.1002/2015GL064738

Lurton T, Balkanski Y, Bastrikov V, Bekki S, Bopp L, Braconnot P, Brockmann P, Cadule P, Contoux C, Cozic A, Cugnet D, Dufresne JL, th C, Foujols MA, Ghattas J, Hauglustaine D, Hu RM, Kageyama M, Khodri M, Lebas N, Levavasseur G, Marchand M, Ottl C, Peylin P, Sima A, Szopa S, Thiblemont R, Vuichard N, Boucher O (2020) Implementation of the CMIP6 Forcing Data in the IPSL-CM6A-LR Model. Journal of Advances in Modeling Earth Systems 12(4):e2019MS001940, DOI:10.1029/2019MS001940

Madec G (2008) NEMO ocean engine. Note du Pôle de modélisation, Institut Pierre-Simon Laplace (IPSL), France, No 27, ISSN No 1288-1619

Marsh R, Desbruyères D, Bamber JL, de Cuevas BA, Coward AC, Aksenov Y (2010) Shortterm impacts of enhanced Greenland freshwater fluxes in an eddy-permitting ocean model. Ocean Science 6(3):749-760, DOI:10.5194/os-6-749-2010

Marsh R, Ivchenko VO, Skliris N, Alderson S, Bigg GR, Madec G, Blaker AT, Aksenov Y, Sinha B, Coward AC, Le Sommer J, Merino N, Zalesny VB (2015) NEMOICB (v1.0): interactive icebergs in the NEMO ocean model globally configured at eddy-permitting resolution. Geoscientific Model Development 8(5):1547-1562, DOI : 10.5194/gmd-8-1547-2015

Marshall J, Scott JR, Armour KC, Campin JM, Kelley M, Romanou A (2015) The ocean's role in the transient response of climate to abrupt greenhouse gas forcing. Climate Dynamics 44(7-8):2287-2299, DOI : 10.1007/s00382-014-2308-0

Marti O, Braconnot P, Dufresne JL, Bellier J, Benshila R, Bony S, Brockmann P, Cadule P, Caubel A, Codron F, de Noblet N, Denvil S, Fairhead L, Fichefet T, Foujols MA, Friedlingstein P, Goosse H, Grandpeix J, Guilyardi E, Talandier C (2010) Key features of the IPSL ocean atmosphere model and its sensitivity to atmospheric resolution. Climate Dynamics 34, DOI : 10.1007/S00382-009-0640-6

McCarthy G, Haigh I, Hirschi J, Grist J, Smeed D (2015a) Ocean impact on decadal Atlantic climate variability revealed by sea-level observations. Nature 521:508

McCarthy G, Smeed D, Johns W, Frajka-Williams E, Moat B, Rayner D, Baringer M, Meinen C, Collins J, Bryden H (2015b) Measuring the Atlantic Meridional Overturning Circulation at $26^{\circ} \mathrm{N}$. Progress in Oceanography $130: 91-111$, DOI $: 10.1016 / j$. pocean.2014.10.006 
Menary MB, Hodson DLR, Robson JI, Sutton RT, Wood RA, Hunt JA (2015) Exploring the impact of CMIP5 model biases on the simulation of North Atlantic decadal variability. Geophysical Research Letters 42(14):5926-5934, DOI : 10.1002/2015GL064360

Menary MB, Robson J, Allan RP, Booth BBB, Cassou C, Gastineau G, Gregory J, Hodson D, Jones C, Mignot J, Ringer M, Sutton R, Wilcox L, Zhang R (2020) Aerosolforced amoc changes in cmip6 historical simulations. Geophysical Research Letters 47(14):e2020GL088166, DOI : 10.1029/2020GL088166

Morlighem M, Williams CN, Rignot E, An L, Arndt JE, Bamber JL, Catania G, Chauch N, Dowdeswell JA, Dorschel B, Fenty I, Hogan K, Howat I, Hubbard A, Jakobsson M, Jordan TM, Kjeldsen KK, Millan R, Mayer L, Mouginot J, Nol BPY, O'Cofaigh C, Palmer S, Rysgaard S, Seroussi H, Siegert MJ, Slabon P, Straneo F, vandenBroeke MR, Weinrebe W, Wood M, Zinglersen KB (2017) BedMachine v3: Complete Bed Topography and Ocean Bathymetry Mapping of Greenland From Multibeam Echo Sounding Combined With Mass Conservation. Geophysical Research Letters 44(21):11,051-11,061, DOI : 10.1002/2017GL074954

Noël B, van de Berg WJ, van Wessem JM, van Meijgaard E, van As D, Lenaerts JTM, Lhermitte S, Kuipers Munneke P, Smeets CJPP, van Ulft LH, van de Wal RSW, van den Broeke MR (2018) Modelling the climate and surface mass balance of polar ice sheets using RACMO2, Part 1: Greenland (19582016). The Cryosphere 12:811-831

Pardaens A, Vellinga M, Wu P, Ingleby B (2008) Large-Scale Atlantic Salinity Changes over the Last Half-Century: A ModelObservation Comparison. Journal of Climate 21(8):1698-1720, DOI : $10.1175 / 2007$ JCLI1988.1

Pörtner HO, Roberts D, Masson-Delmotte V, Zhai P, Tignor M, Poloczanska E, Mintenbeck K, Nicolai M, Okem A, Petzold J, Rama B, Weyer N (2019) IPCC Special Report on the Ocean and Cryosphere in a Changing Climate. Tech. rep., IPCC: Summary for Policymakers.

Radić V, Hock R (2014) Glaciers in the Earth's Hydrological Cycle: Assessments of Glacier Mass and Runoff Changes on Global and Regional Scales. Surveys in Geophysics 35(3):813837, DOI : $10.1007 / \mathrm{s} 10712-013-9262-y$

Rahmstorf S, Box J, Feulner G, Mann M, Robinson A, Rutherford S, Schaffernicht E (2015) Exceptional twentieth-Century slowdown in Atlantic Ocean overturning circulation. Nature Climate Change 5, DOI:10.1038/nclimate2554

Rayner NA, Parker DE, Horton EB, Folland CK, Alexander LV, Rowell DP, Kent EC, Kaplan A (2003) Global analyses of sea surface temperature, sea ice, and night marine air temperature since the late nineteenth century. Journal of Geophysical Research: Atmospheres 108(D14), DOI : 10.1029/2002JD002670

Reverdin G, Valdimarsson H, Alory G, Diverres D, Bringas F, Goni G, Heilmann L, Chafik L, Szekely T, Friedman AR (2018) North atlantic subpolar gyre along predetermined ship tracks since 1993: a monthly data set of surface temperature, salinity, and density. Earth System Science Data 10(3):1403-1415

Ribes A, Zwiers FW, Azas JM, Naveau P (2017) A new statistical approach to climate change detection and attribution. Climate Dynamics 48:367-386, DOI:10.1007/ s00382-016-3079-6

Rignot E, Kanagaratnam P (2006) Changes in the Velocity Structure of the Greenland Ice Sheet. Science 311(5763):986-990, DOI:10.1126/science.1121381

Robson J, Ortega P, Sutton R (2016) A reversal of climatic trends in the North Atlantic since 2005. Nature Geoscience 9:513

Romanou A, Marshall J, Kelley M, Scott J (2017) Role of the ocean's AMOC in setting the uptake efficiency of transient tracers. Geophysical Research Letters 44(11):5590-5598, DOI : 10.1002/2017GL072972

Rousset C, Vancoppenolle M, Madec G, Fichefet T, Flavoni S, Barthélemy A, Benshila R, Chanut J, Levy C, Masson S, Vivier F (2015) The Louvain-La-Neuve sea ice model LIM3.6: global and regional capabilities. Geoscientific Model Development 8(10):2991-3005, DOI : 10.5194/gmd-8-2991-2015

Saenko OA, Yang D, Myers PG (2017) Response of the North Atlantic dynamic sea level and circulation to Greenland meltwater and climate change in an eddy-permitting ocean model. Climate Dynamics 49:2895-2910, DOI : 10.1007/s00382-016-3495-7

Sánchez Goñi M, Bakker P, Desprat S, Carlson A, Van Meerbeeck C, Peyron O, Naughton F, Fletcher W, Eynaud F, Rossignol L, Renssen H (2012) European climate optimum and enhanced Greenland melt during the Last Interglacial. Geology 40:627-630, DOI :10.1130/ G32908.1 
Selyuzhenok V, Bashmachnikov I, Ricker R, Vesman A, Bobylev L (2020) Sea ice volume variability and water temperature in the greenland sea. The Cryosphere 14(2):477-495, DOI : 10.5194/tc-14-477-2020, URL https://tc.copernicus.org/articles/14/477/2020/

Sgubin G, Swingedouw D, Drijfhout S, Mary Y, Bennabi A (2017) Abrupt cooling over the North Atlantic in modern climate models. Nature Communications 8(14375), DOI: 10 . 1038/ncomms 14375

Stouffer RJ, Yin J, Gregory JM, Dixon KW, Spelman MJ, Hurlin W, Weaver AJ, Eby M, Flato GM, Hasumi H, Hu A, Jungclaus JH, Kamenkovich IV, Levermann A, Montoya M, Murakami S, Nawrath S, Oka A, Peltier WR, Robitaille DY, Sokolov A, Vettoretti G, Weber SL (2006) Investigating the Causes of the Response of the Thermohaline Circulation to Past and Future Climate Changes. Journal of Climate 19(8):1365-1387, DOI : 10.1175/ JCLI3689. 1

Swingedouw D, Braconnot P, Delcluse P, Guilyardi E, Marti O (2007) Quantifying the AMOC feedbacks during a 2xCO2 stabilization experiment with land-ice melting. Climate Dynamics 29:521-534, DOI : 10.1007/s00382-007-0250-0

Swingedouw D, Mignot J, Braconnot P, Mosquet E, Kageyama M, Alkama R (2009) Impact of Freshwater Release in the North Atlantic under Different Climate Conditions in an OAGCM. Journal of Climate 22(23):6377-6403, DOI:10.1175/2009JCLI3028.1

Swingedouw D, Rodehacke C, Behrens E, Menary M, Olsen S, Gao Y, Mikolajewicz U, Mignot J, Biastoch A (2013) Decadal fingerprints of freshwater discharge around Greenland in a multi-model ensemble. Climate Dynamics 41:695-720

Swingedouw D, Rodehacke CB, Olsen SM, Menary M, Gao YQ, Mikolajewicz U, Mignot J (2015) On the reduced sensitivity of the Atlantic overturning to Greenland ice sheet melting in projections: a multi-model assessment. Climate Dynamics 44:3261-3279, DOI: $10.1007 / \mathrm{s} 00382-014-2270-\mathrm{x}$

Taylor KE (2001) Summarizing multiple aspects of model performance in a single diagram. Journal of Geophysical Research: Atmospheres 106(D7):7183-7192, DOI:10.1029/ 2000JD900719

Thornalley DJR, Oppo DW, Ortega P, Robson JI, Brierley CM, Davis R, Hall IR, MoffaSanchez P, Rose NL, Spooner PT, Yashayaev I, Keigwin LD (2018) Anomalously weak Labrador Sea convection and Atlantic overturning during the past 150 years. Nature 556:227-230, DOI : 10.1038/s41586-018-0007-4

Tournadre J, Bouhier N, Girard-Ardhuin F, Rémy F (2015) Antarctic icebergs distributions 1992-2014. Journal of Geophysical Research: Oceans 121(1):327-349, DOI : 10.1002/ 2015JC011178

Wunsch C (2002) What Is the Thermohaline Circulation? Science 298(5596):1179-1181, DOI: 10.1126/science. 1079329

Yang Q, Dixon TH, Myers PG, Bonin J, Chambers D, van den Broeke MR, Ribergaard MH, J M (2016) Recent increases in Arctic freshwater flux affects Labrador Sea convection and Atlantic overturning circulation. Nat Commun 7(10525), DOI:10.1038/ncomms 10525

Yashayaev I, Loder J (2016) Further Intensification of Deep Convection in the Labrador Sea in 2016: Intensified 2016 Labrador Sea Convection. Geophysical Research Letters 44, DOI : 10.1002/2016GL071668

Zhang R (2008) Coherent surface-subsurface fingerprint of the Atlantic Meridional Overturning Circulation. Geophys Res Lett 35, DOI : 10.1029/2008GL035463 
The Figure S1 shows the annual global fluxes from Bamber et al. (2018) interpolated on the eORCA1.2 grid (Deshayes et al., in prep). The nearest neighbour algorithm used for the interpolation is conservative. However, the total amount is about $6 \%$ lower than the raw data of Bamber et al. (2018) because the resolution between the grids are very different, and several ocean cells from the original data at lower resolution appeared to be land in the eORCA1.2 grid and were therefore not considered. Doing so, we avoid the risk of prescribing a too high amount of freshwater in some of the grid cells of the coarse grid.

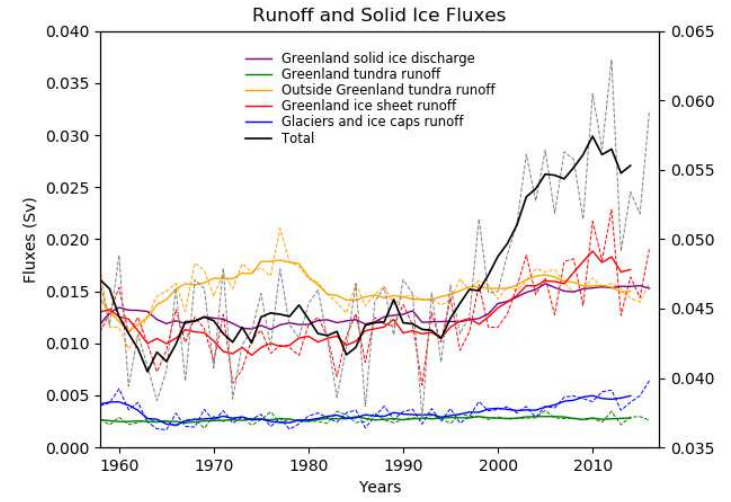

Fig. S1: Freshwater fluxes (in Sv) from Greenland ice sheet and glaciers and ice caps outside of Greenland from Bamber et al. (2018). Solid lines are 5-years running means, dashed lines are the mean annual values. The total flux from all sources is shown by the solid black line plotted against the right-hand $\mathrm{Y}$ axis.

6.2 Methodology for the inclusion of the solid ice discharge fluxes into the model

The Figure S2 illustrates the methodology used for the inclusion of the solid ice component (icebergs) in the climate model. The calving values included into the model are the solid ice component (purple line in Figure 3), in the pink zone of Figure S2 (top). Compensation of the FWF is done in the light blue zone of Figure S2 (top). 

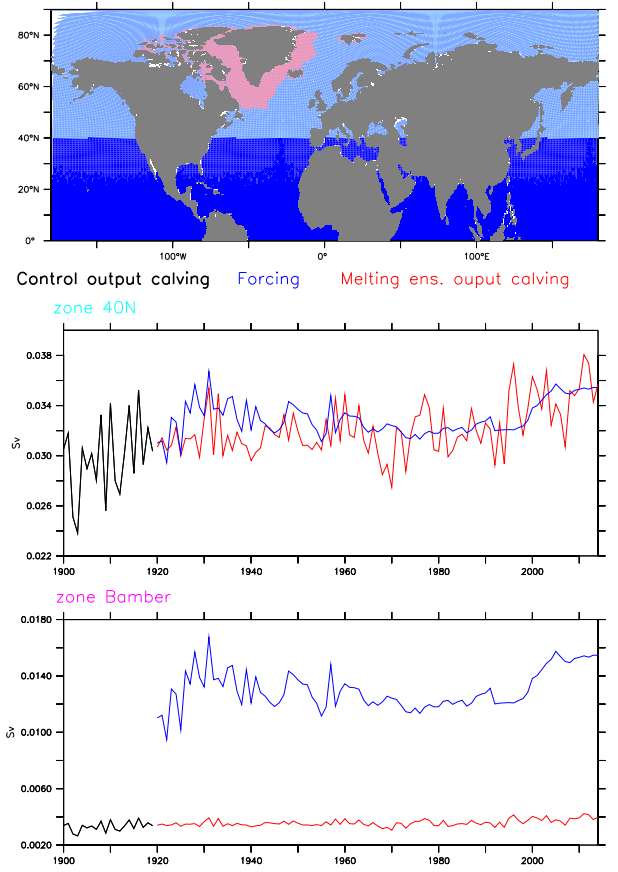

Fig. S2: Top figure shows two areas: the forcing area (pink, cf. Figure 1) and the North of $40^{\circ}$ latitude (blue and pink). Middle figure is a comparison of mean annual values (in Sv) of calving fluxes (icebergs) from an Historical run (black line) over the years 1900-1920, the disabled output calving in our Melting experiments (red line) from 1920 to 2016 and the calving values applied in our Melting experiments (blue line) in the $40^{\circ} \mathrm{N}$ area. Bottom figure compares these values in the forcing zone.

Figure S3 shows the time series of three AMOC indices, for the Melting and Historical ensembles. The Melting ensemble envelope is also compared to the envelope of the large ensemble of 30 members of Historical runs available with the IPSLCM6A-LR model, denoted as "the Large Historical ensemble" (dashed black lines in Figure S3), and which ensemble strandard deviation amounts $1.20 \mathrm{~Sv}$. We observe that the hosing members are within the distribution of the Large Historical ensemble. 

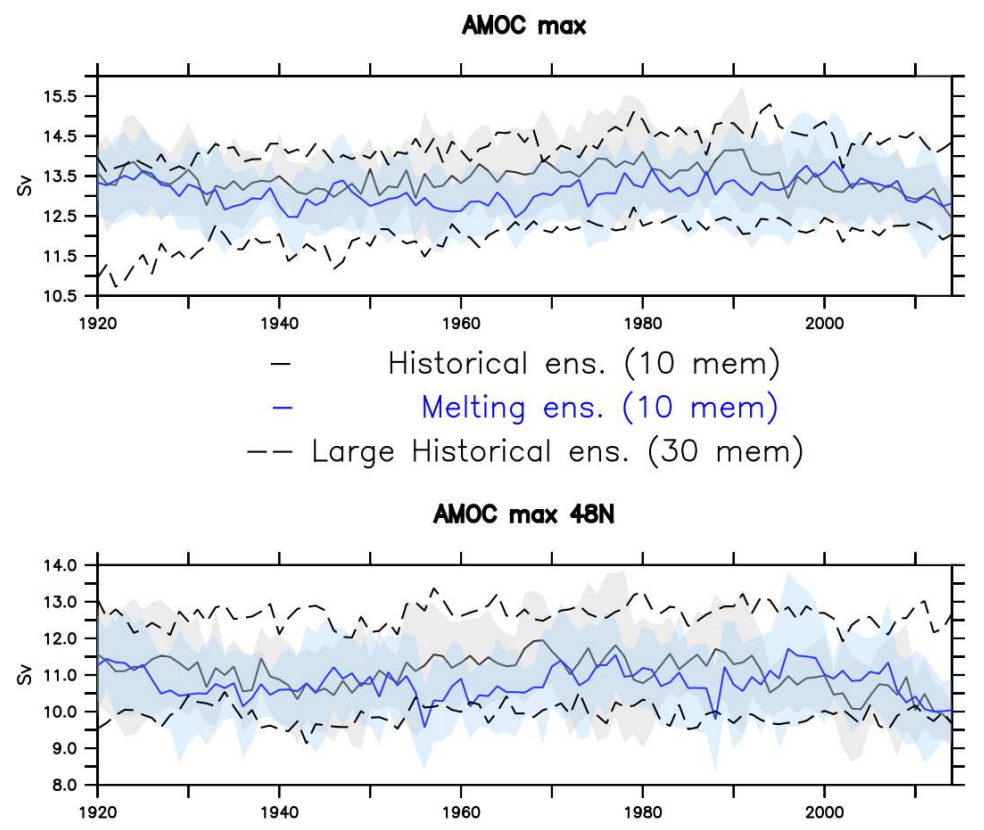

AMOC max 26N

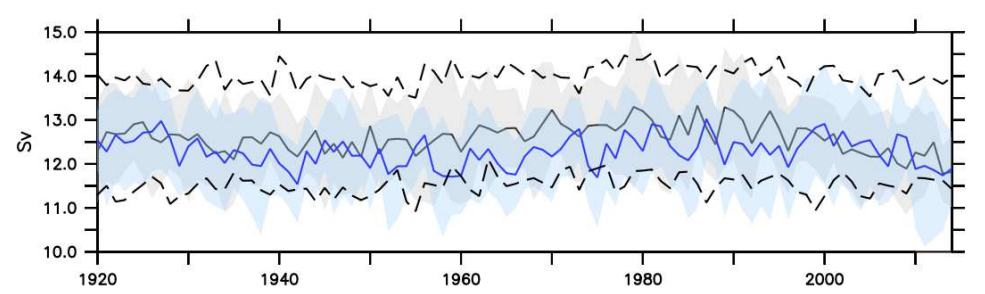

Fig. S3: Time series of the Melting (blue line) and Historical (grey line) ensemble means of the maximum between $30^{\circ} \mathrm{S}$ and $60^{\circ} \mathrm{N}$ (top), at $26^{\circ} \mathrm{N}$ (middle) and at $48^{\circ} \mathrm{N}$ (bottom) of the AMOC, from 1920 to 2014. Shadings represent the $1-\sigma$ uncertainty bands of Melting (blue) and Historical (grey) ensemble. Dash black lines are the 1- $\sigma$ uncertainty bands of the Large Historical ensemble of 30 members. 


$$
\begin{aligned}
\operatorname{var}(x) & =\frac{1}{n} \sum_{i=1}^{n}\left(x_{i}-\bar{x}\right)^{2}=\sigma_{x}^{2} \\
\operatorname{cov}(x, y) & =\frac{1}{n} \sum_{i=1}^{n}\left(x_{i}-\bar{x}\right)\left(y_{i}-\bar{y}\right) \\
\operatorname{corr}(x, y) & =\frac{\operatorname{cov}(x, y)}{\sigma_{x} \sigma_{y}}
\end{aligned}
$$

$$
\begin{aligned}
M S E & =\frac{1}{n} \sum_{i=1}^{n}\left(x_{i}-y_{i}\right)^{2} \\
& =\frac{1}{n} \sum_{i=1}^{n}\left(x_{i}-\bar{x}+\bar{x}-y_{i}+\bar{y}-\bar{y}\right)^{2} \\
& =\frac{1}{n} \sum_{i=1}^{n}\left(\left(x_{i}-\bar{x}\right)-\left(y_{i}-\bar{y}\right)+(\bar{x}-\bar{y})\right)^{2} \\
& =\frac{1}{n} \sum_{i=1}^{n}\left[\left(\left(x_{i}-\bar{x}\right)-\left(y_{i}-\bar{y}\right)\right)^{2}+(\bar{x}-\bar{y})^{2}+2(\bar{x}-\bar{y})\left(\left(x_{i}-\bar{x}\right)-\left(y_{i}-\bar{y}\right)\right)\right] \\
& =\frac{1}{n} \sum_{i=1}^{n}\left[\left(x_{i}-\bar{x}\right)^{2}+\left(y_{i}-\bar{y}\right)^{2}-2\left(x_{i}-\bar{x}\right)\left(y_{i}-\bar{y}\right)+(\bar{x}-\bar{y})^{2}\right]+\underbrace{\frac{1}{n} \sum_{i=1}^{n}\left[2(\bar{x}-\bar{y})\left(\left(x_{i}-\bar{x}\right)-\left(y_{i}-\bar{y}\right)\right)\right]}_{=0} \\
& =\frac{1}{n} \sum_{i=1}^{n}\left(x_{i}-\bar{x}\right)^{2}+\frac{1}{n} \sum_{i=1}^{n}\left(y_{i}-\bar{y}\right)^{2}-\frac{1}{n} \sum_{i=1}^{n}\left[2\left(x_{i}-\bar{x}\right)\left(y_{i}-\bar{y}\right)+(\bar{x}-\bar{y})^{2}\right] \\
M S E & =\underbrace{\operatorname{var}(x)+\operatorname{var}(y)-2 \operatorname{cov}(x, y)}_{\operatorname{MSE} E_{c}=\operatorname{centered} \operatorname{MSE}}+\underbrace{(\bar{x}-\bar{y})^{2}}_{\text {overall bias }}
\end{aligned}
$$

Therefore:

$$
\frac{M S E_{c}}{\sigma_{x} \sigma_{y}}=\frac{\sigma_{x}}{\sigma_{y}}+\frac{\sigma_{y}}{\sigma_{x}}-2 \operatorname{corr}(x, y)
$$

Note: in our study, we are using anomalies so the overall bias is zero and $M S E=M S E_{c}$. Also, the RMSE is defined as the root of the MSE:

1206 $R M S E=\sqrt{M S E}$ 


\section{Figures}
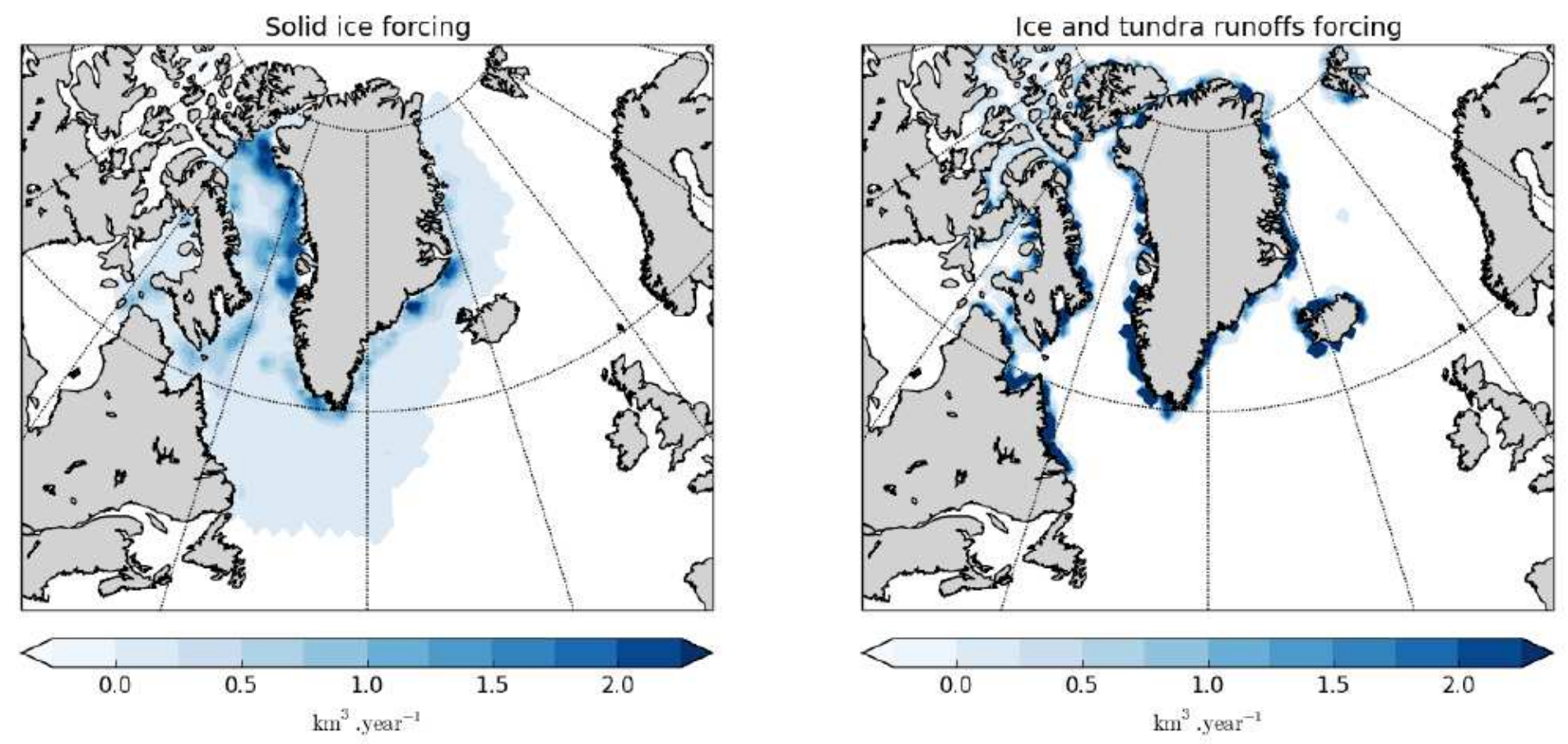

\section{Figure 1}

Time averaged (1920-2014) spatial distribution of icebergs (left) and runoff (right) freshwater uxes (in km3.yr-1) Note: The designations employed and the presentation of the material on this map do not imply the expression of any opinion whatsoever on the part of Research Square concerning the legal status of any country, territory, city or area or of its authorities, or concerning the delimitation of its frontiers or boundaries. This map has been provided by the authors. 


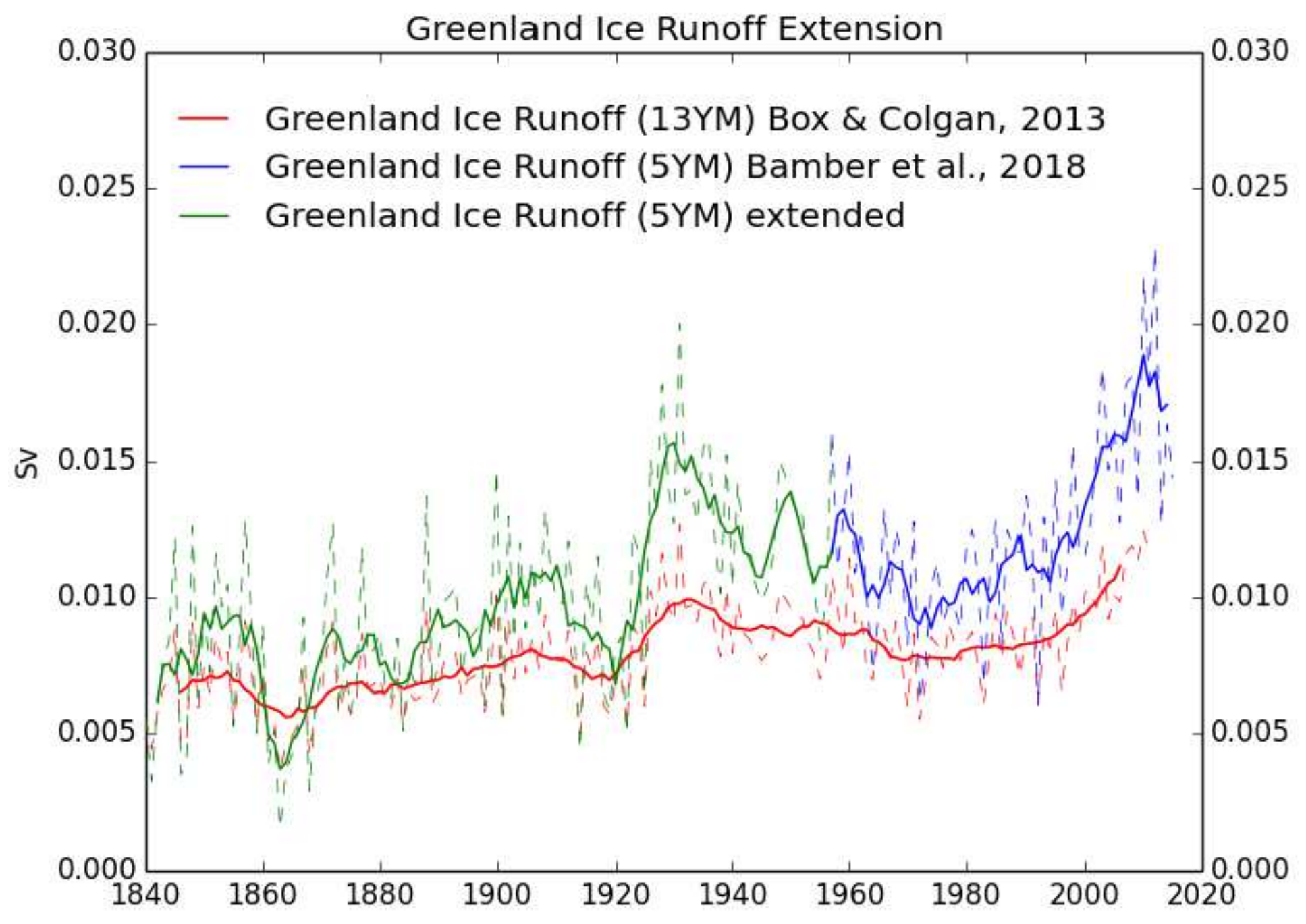

Figure 2

Spatial annual sum of Greenland Ice Runoff (in Sv) for Raw (in blue, with a 5-year running mean) and Extended (in green, with a 5-year running mean) freshwater uxes from Bamber et al. (2018) and Box and Colgan (2013) (in red, with a 13-year running mean). 


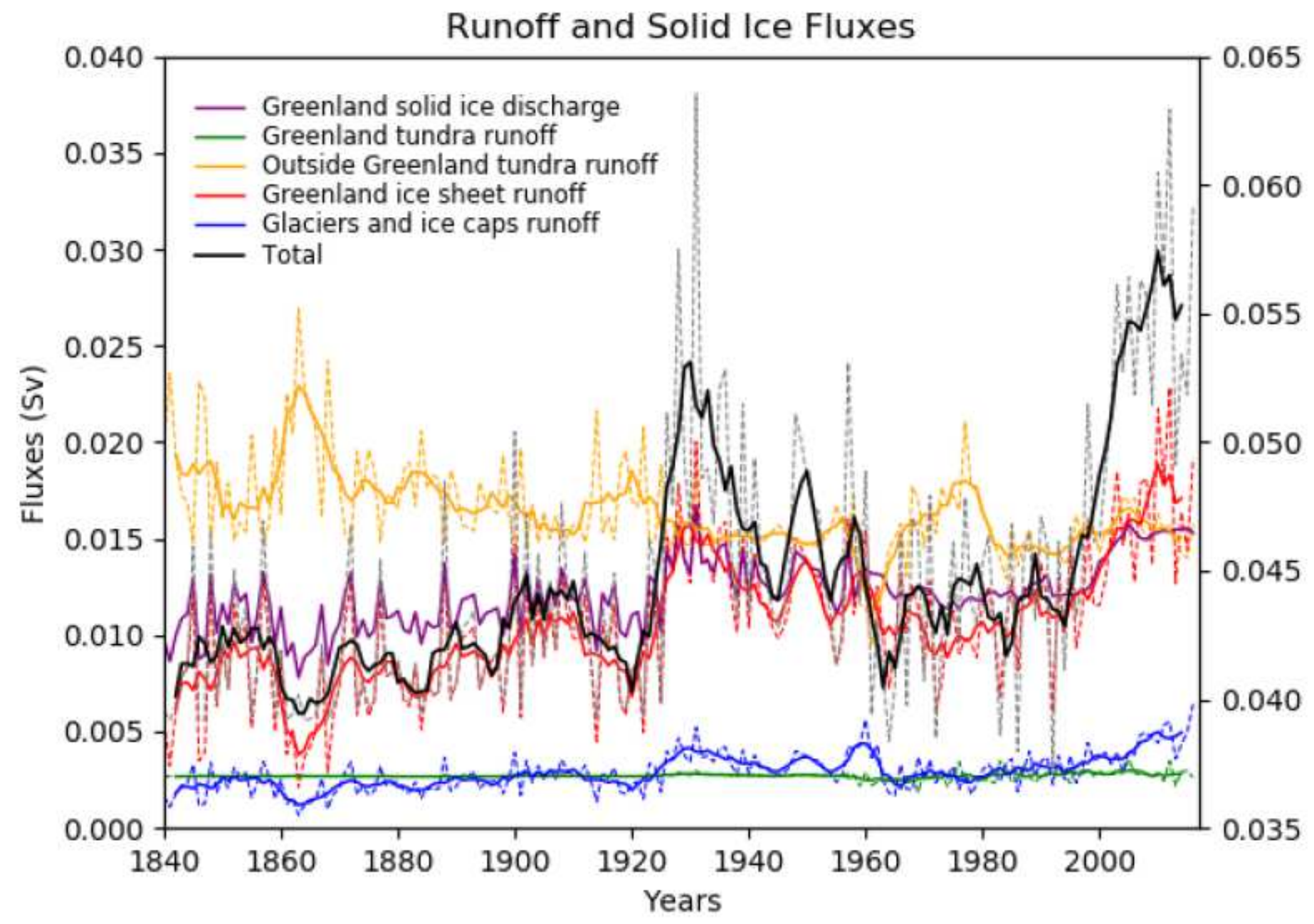

Figure 3

Final dataset: initial and extended annual uxes (in Sv) from Bamber et al. (2018), using a linear regression over the 1958-2012 ice runoff from Box and Colgan (2013) (GIR). Solid lines are 5-year running means, dashed lines are the mean annual values. The total ux from all sources is shown by the solid black line plotted against the right-hand $Y$ axis (in Sv). 


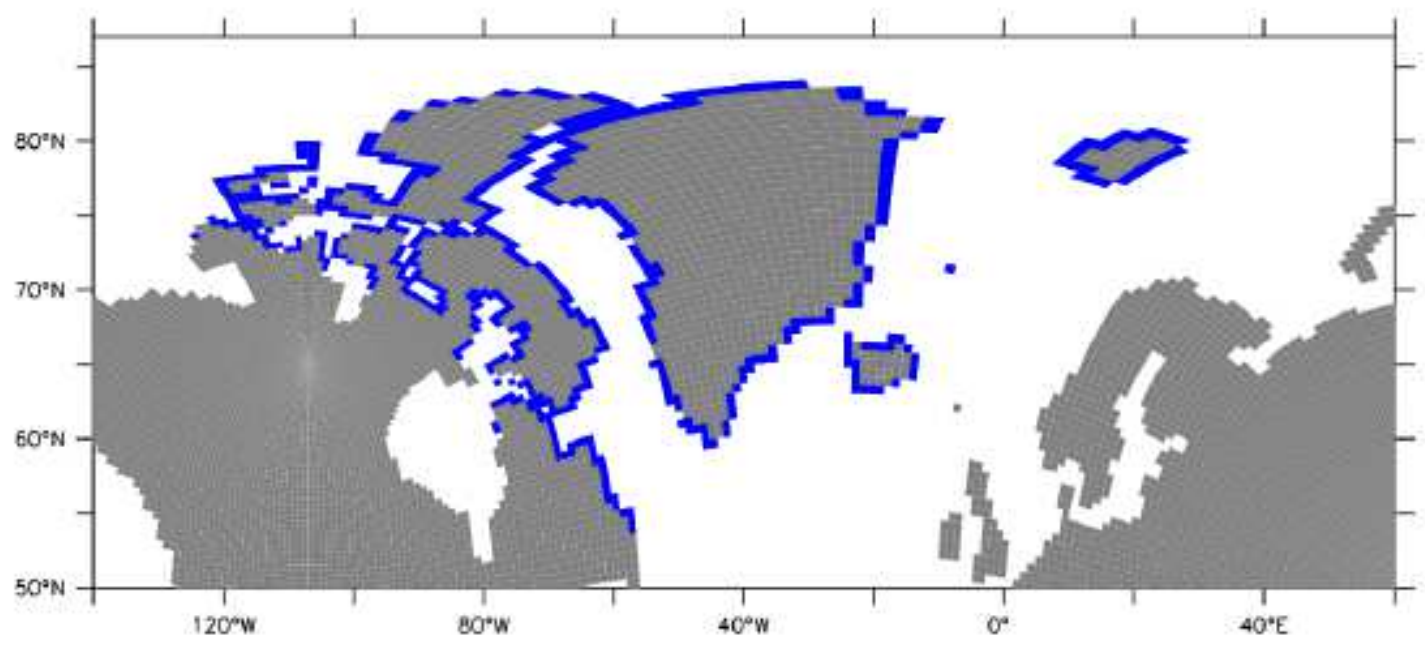

Forcing zone

Historical ens. mean runoff Melting ens. mean runoff

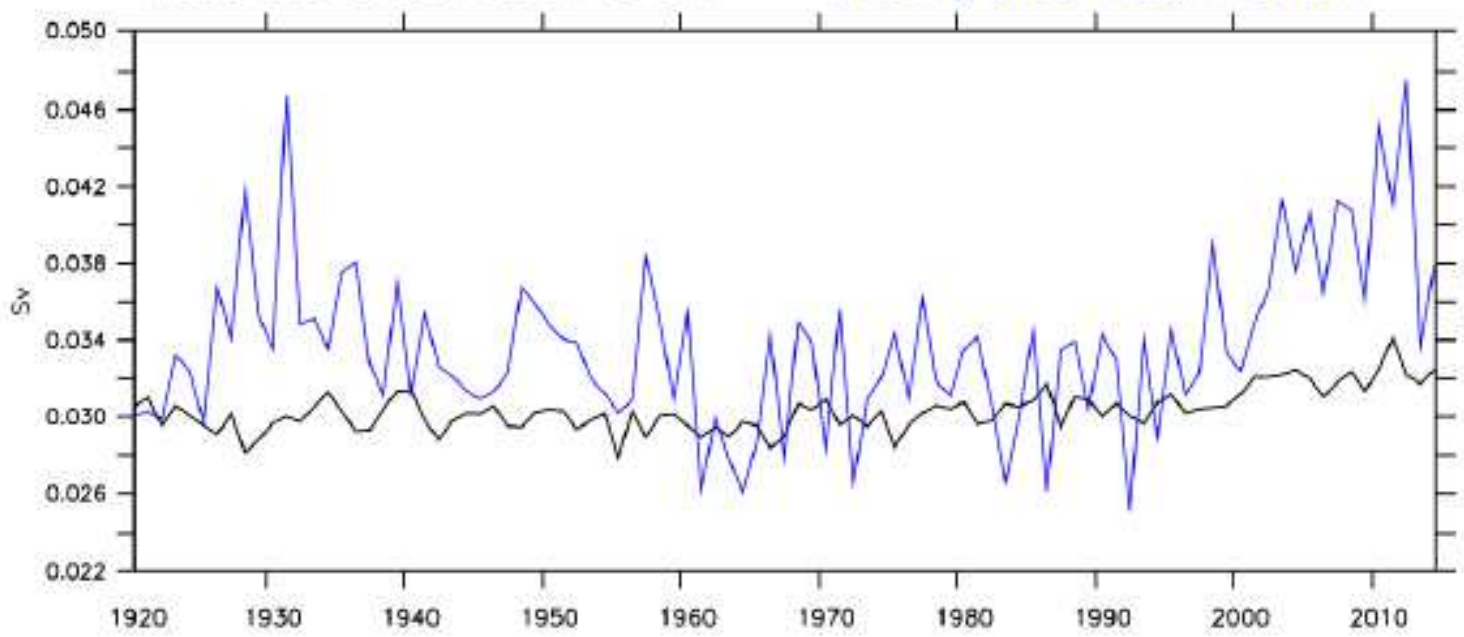

\section{Figure 4}

Top panel shows the area around Greenland (denoted as "forcing zone", in blue) where runoff are replaced in the model. Bottom panel shows the mean annual runoff values (in Sv) in the two ensembles cumulated in the forcing zone: prescribed uxes in the Melting ensemble (blue line) and computed uxes in the Historical ensemble (black line). Note: The designations employed and the presentation of the material on this map do not imply the expression of any opinion whatsoever on the part of Research Square concerning the legal status of any country, territory, city or area or of its authorities, or concerning the delimitation of its frontiers or boundaries. This map has been provided by the authors. 

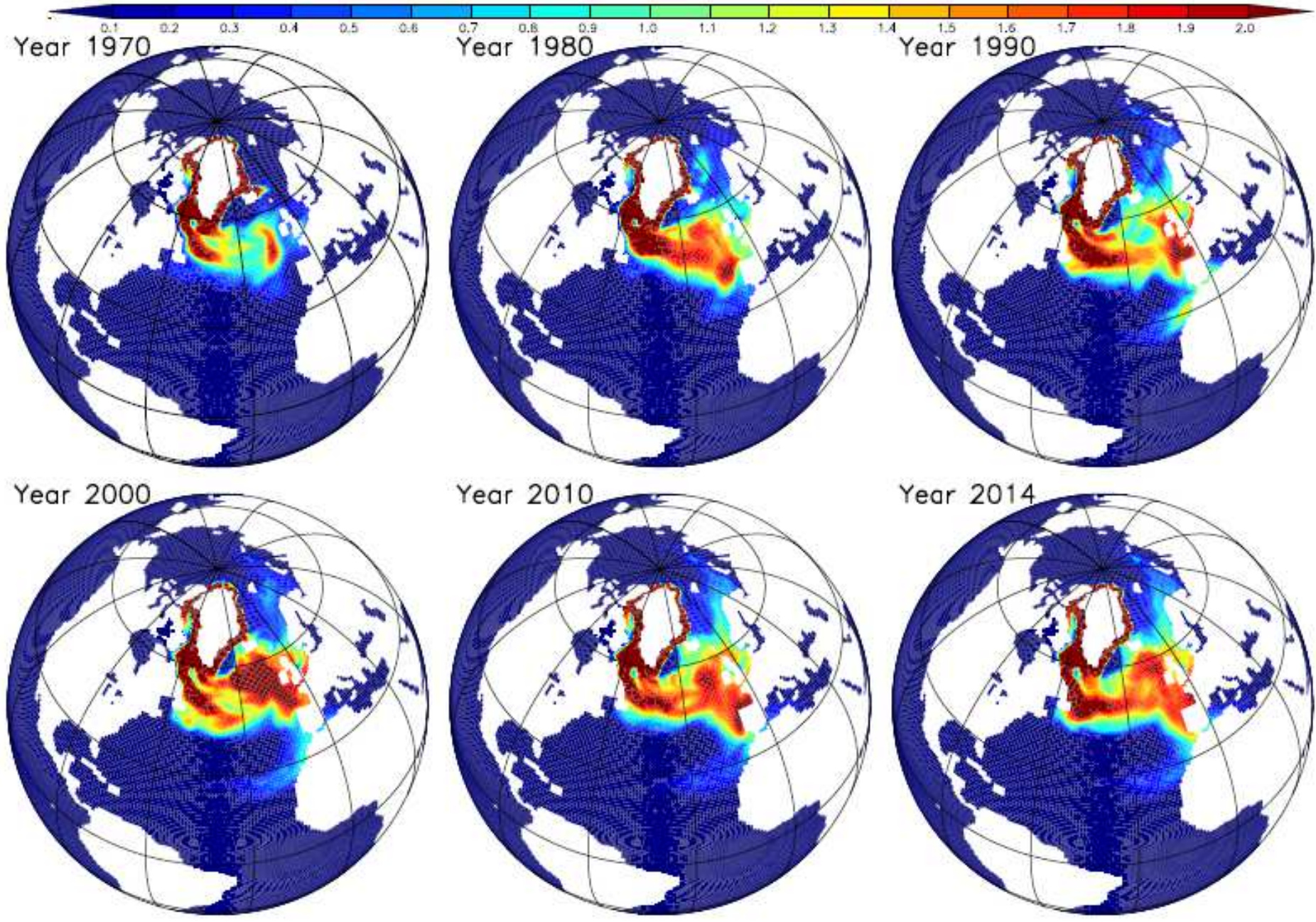

Figure 5

Ensemble mean of the evolution of passive tracer concentration (normalized units) at the surface from 5member off-line simulations of passive tracer starting in 1950. Note: The designations employed and the presentation of the material on this map do not imply the expression of any opinion whatsoever on the part of Research Square concerning the legal status of any country, territory, city or area or of its authorities, or concerning the delimitation of its frontiers or boundaries. This map has been provided by the authors. 

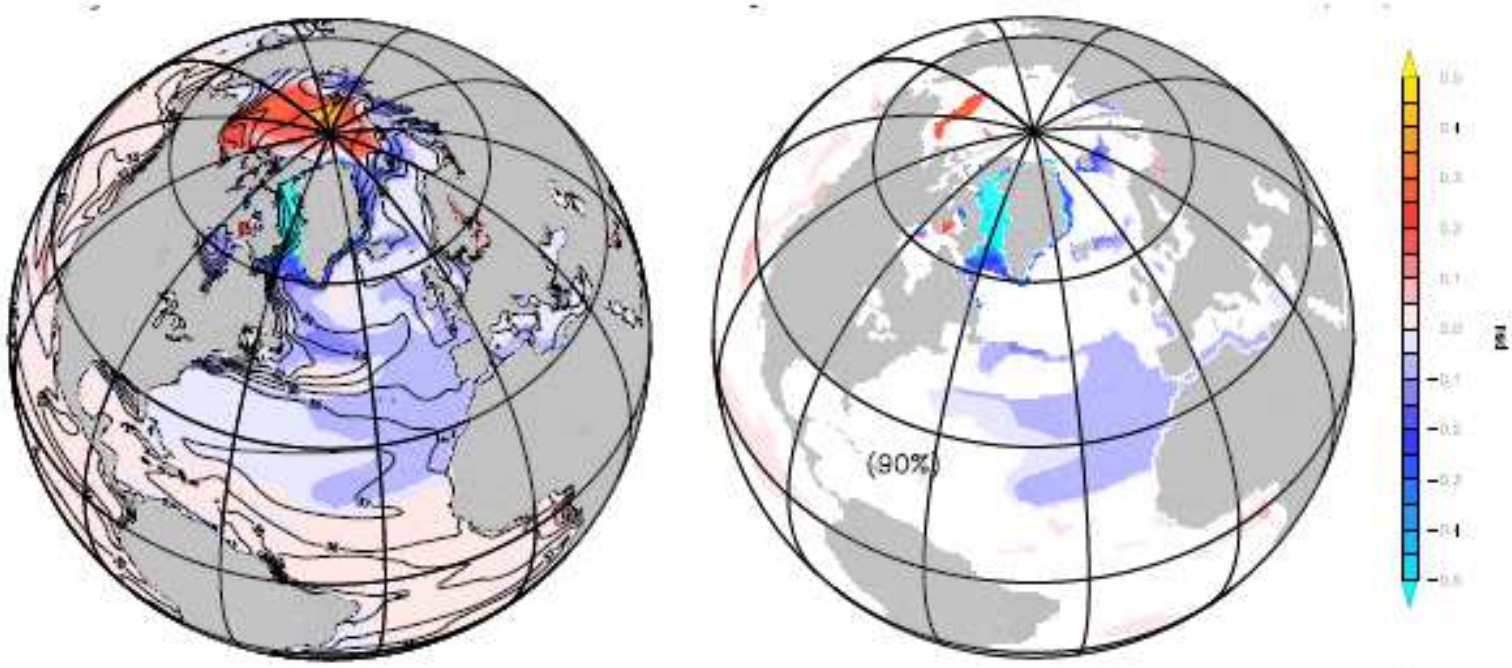

Melting - Historical ensemble mean 1920-2014 SST
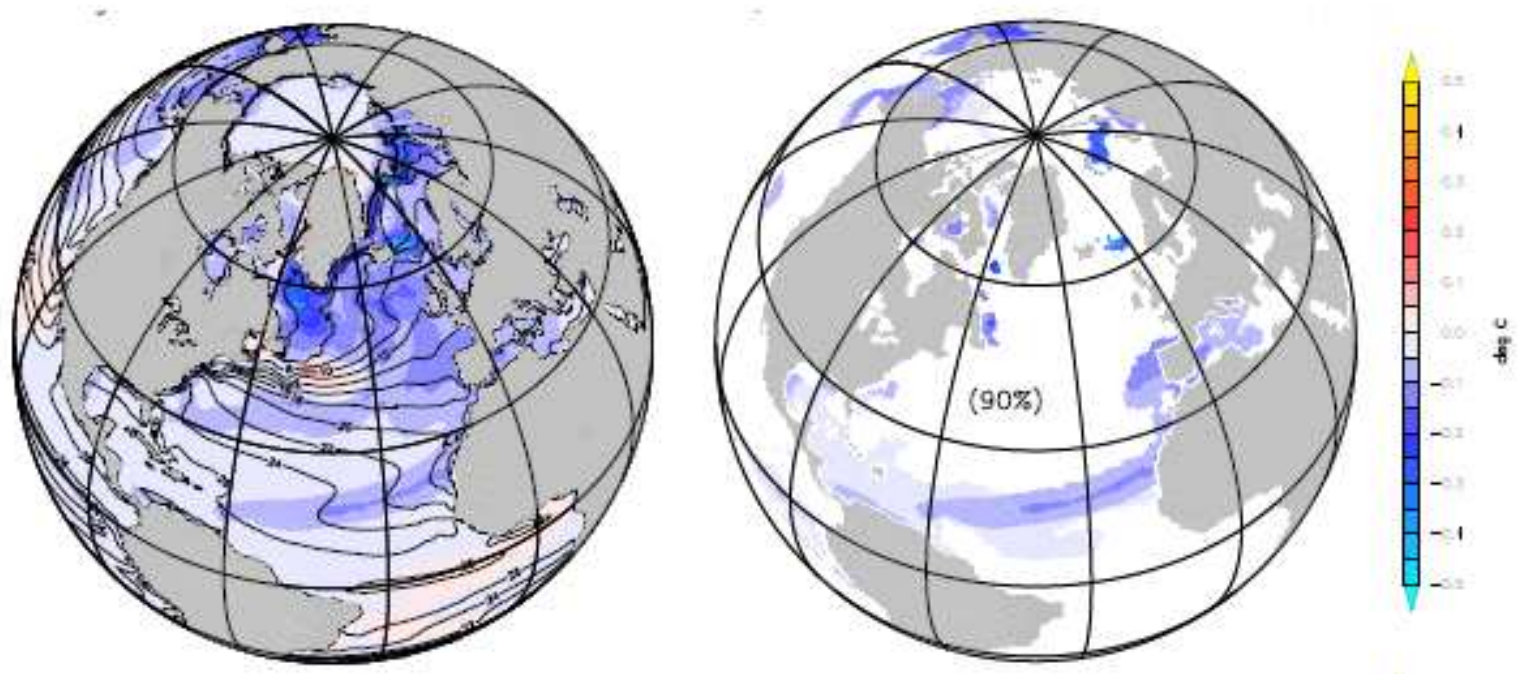

Figure 6

Shadings are the differences (left gures) and the signicant (90\%) differences (right gures) between the Historical and Melting ensemble means for annual SSS (top gures, in psu) and SST (bottom gures, in oC) averaged over the period 1920-2014. Contour lines are the mean state of the Historical ensemble mean over 1920-2014. Note: The designations employed and the presentation of the material on this map do not imply the expression of any opinion whatsoever on the part of Research Square concerning the legal status of any country, territory, city or area or of its authorities, or concerning the delimitation of its frontiers or boundaries. This map has been provided by the authors. 

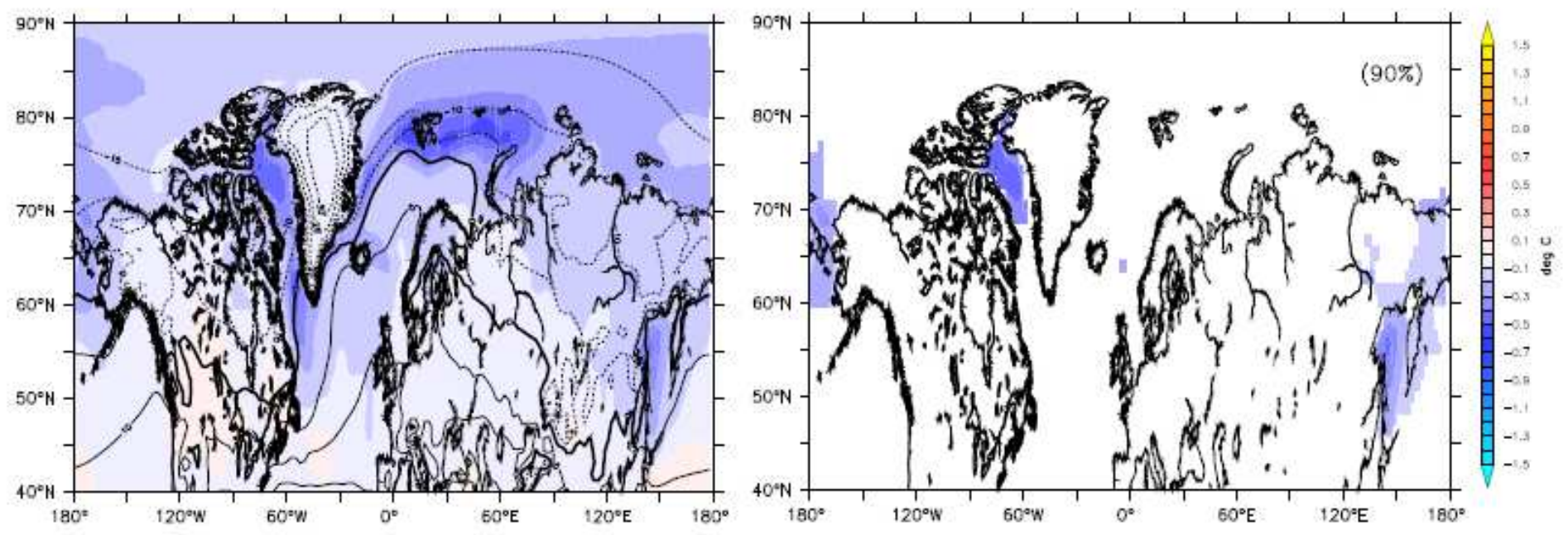

Figure 7

Colors are the differences (left gure) and the signicant (90\%) differences (right gure) between Historical and Melting ensemble means atmospheric 2-m temperature (in oC) averaged over the period 1920-2014. Contour lines are the mean state of the Historical ensemble mean over 1920-2014. Note: The designations employed and the presentation of the material on this map do not imply the expression of any opinion whatsoever on the part of Research Square concerning the legal status of any country, territory, city or area or of its authorities, or concerning the delimitation of its frontiers or boundaries. This map has been provided by the authors. 
Melting - Historical ensemble mean 1920-2014 zonal salinity
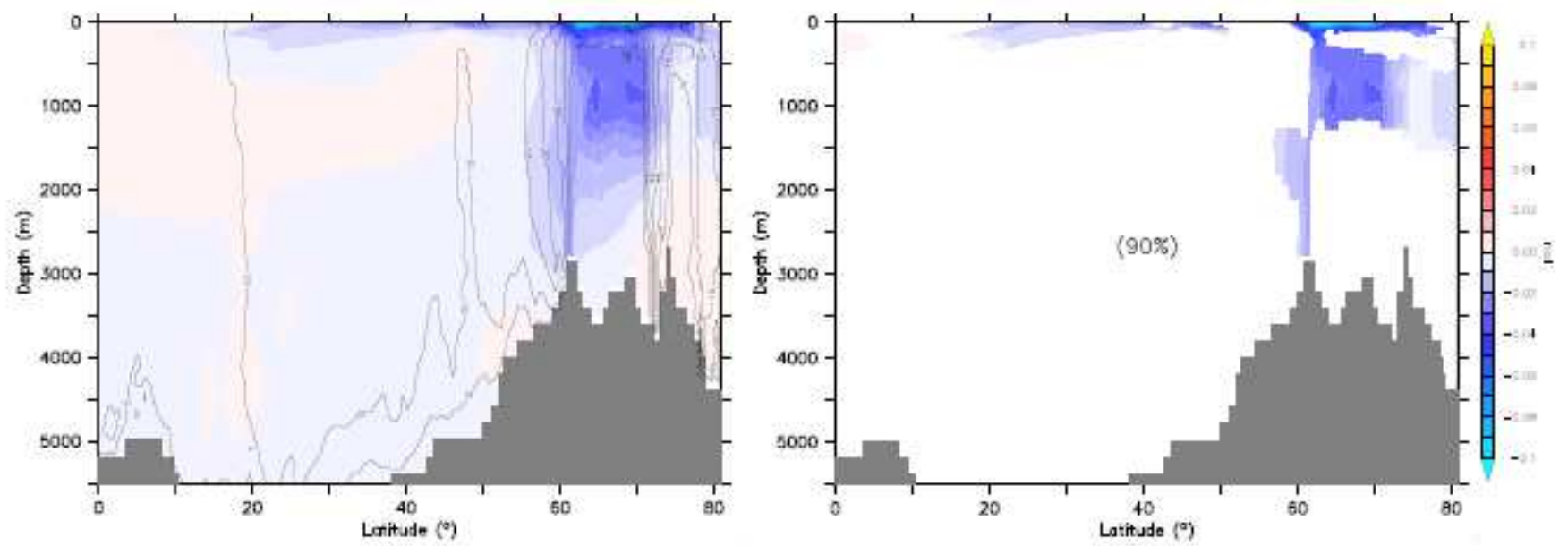

Melting - Historical ensemble mean 1920-2014 potential temperature
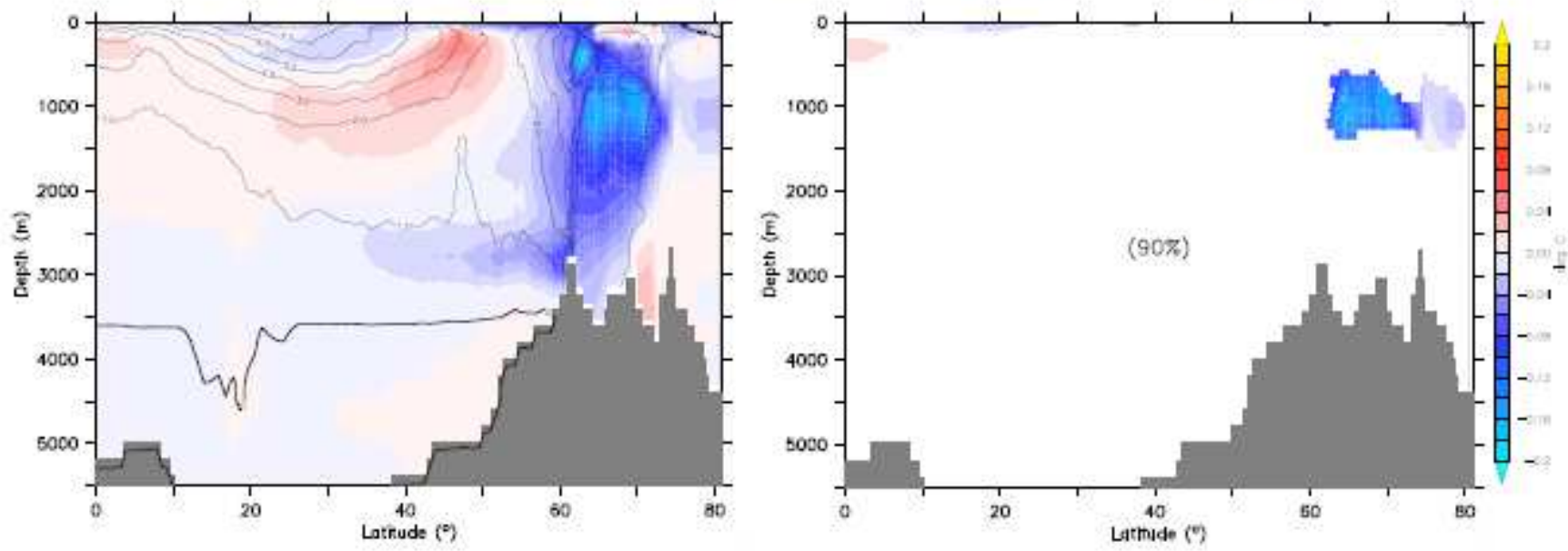

\section{Figure 8}

Shading shows differences (left gures) and significant (90\%) differences (right gures) between Historical and Melting ensemble means for zonal mean over the Atlantic of salinity (top, in psu) potential temperature (bottom, in oC) averaged over the period 1920-2014. Contour lines are the mean state of the Historical ensemble mean over 1920-2014. Note: The designations employed and the presentation of the material on this map do not imply the expression of any opinion whatsoever on the part of Research Square concerning the legal status of any country, territory, city or area or of its authorities, or concerning the delimitation of its frontiers or boundaries. This map has been provided by the authors. 
Melting - Historical ensemble mean 1920-2014 JFM MLD

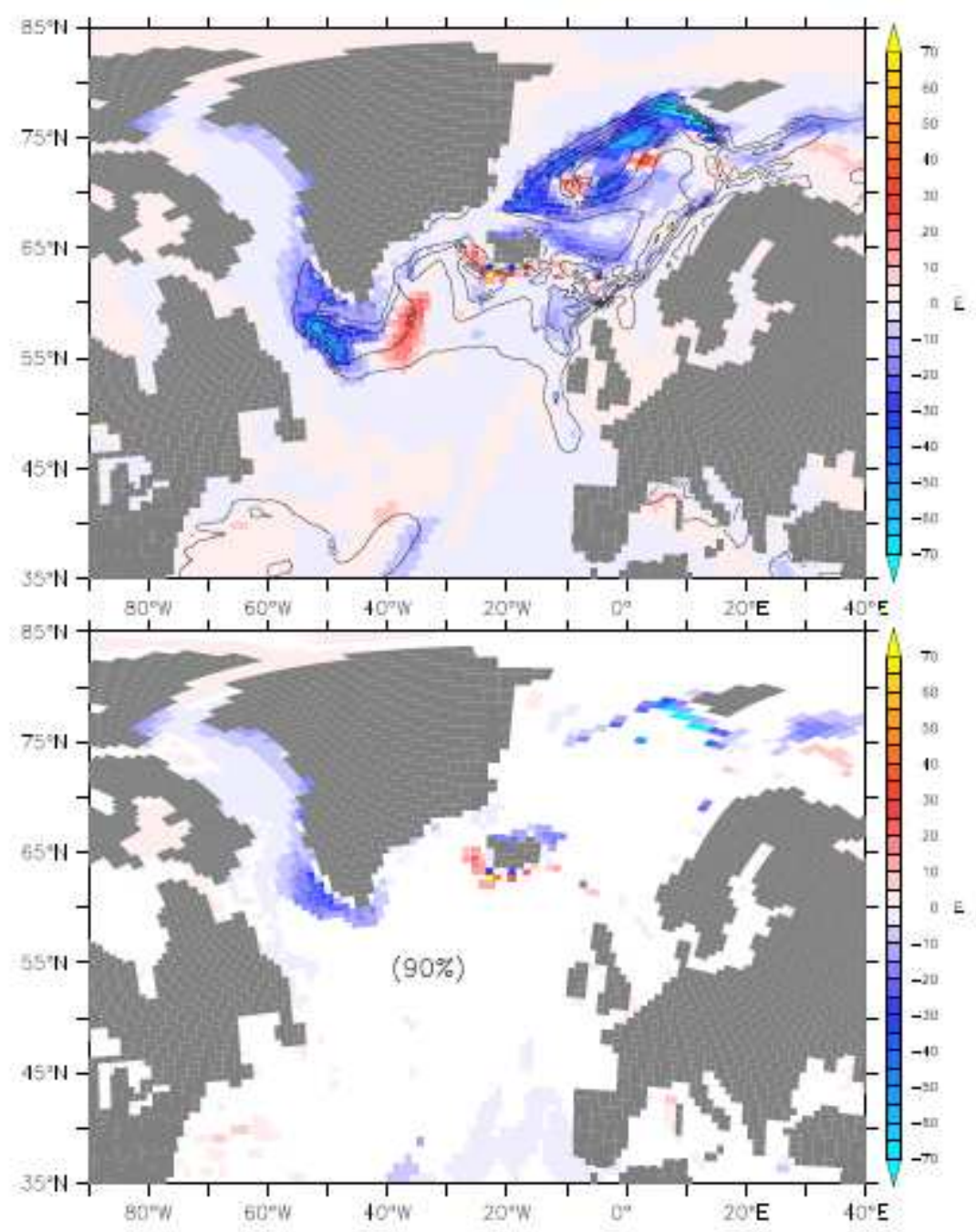

\section{Figure 9}

Shading shows the differences (top gure) and the signicant (90\%) differences (bottom gure) between Historical and Melting ensemble means for January-February-March mixedlayer depth (in $\mathrm{m}$ ) averaged over the period 1920-2014. Contour lines are the mean state of the Historical ensemble mean over 19202014. Note: The designations employed and the presentation of the material on this map do not imply the expression of any opinion whatsoever on the part of Research Square concerning the legal status of any country, territory, city or area or of its authorities, or concerning the delimitation of its frontiers or boundaries. This map has been provided by the authors. 
Melting - Historical ensemble mean 1920-2014 surface density
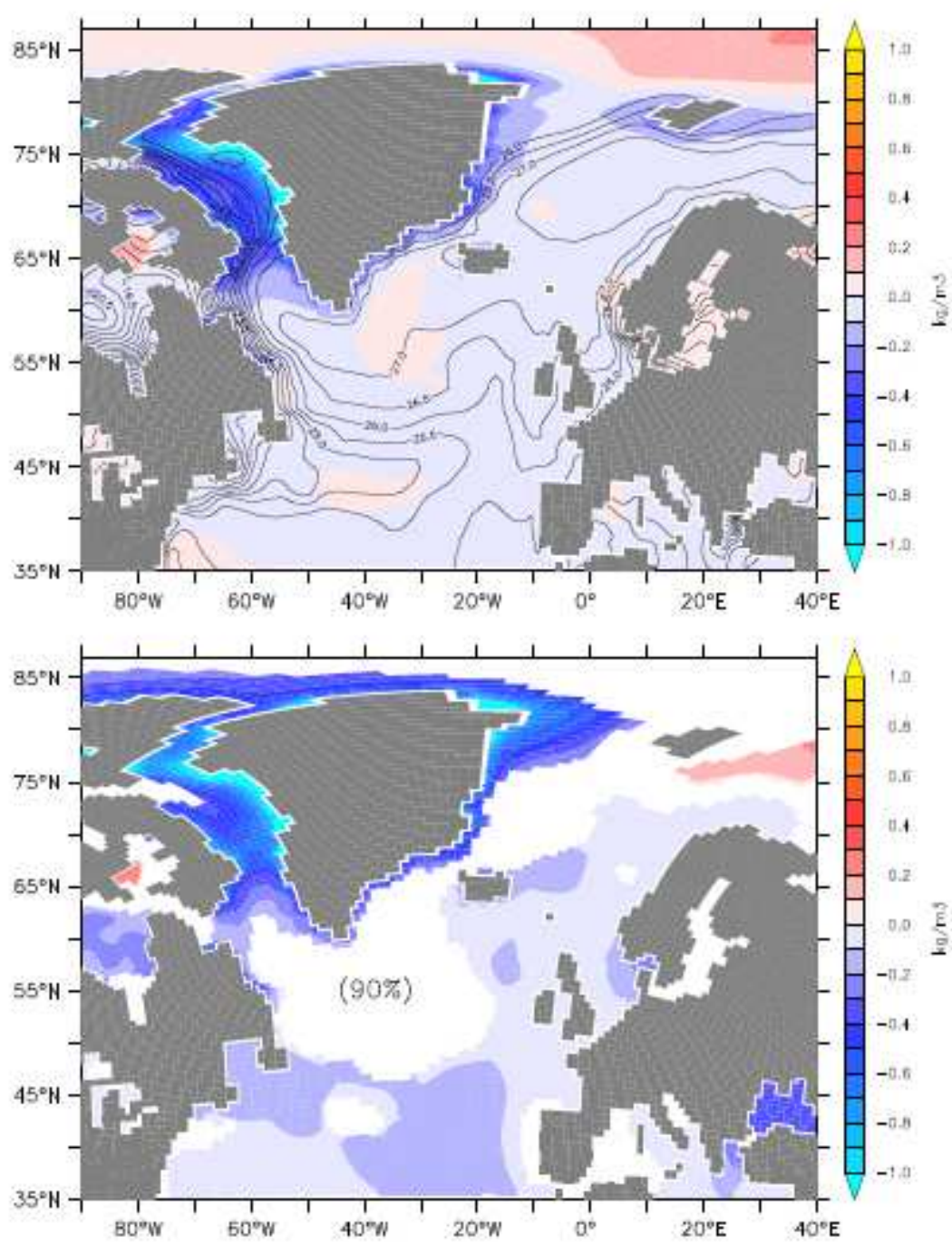

\section{Figure 10}

Shading shows the differences (top gure) and the signicant (90\%) differences (bottom gure) between Historical and Melting ensemble means for surface density (in kg/m3) averaged over the period 19202014. Contour lines are the mean state of the Historical ensemble mean over 1920-2014. Note: The designations employed and the presentation of the material on this map do not imply the expression of any opinion whatsoever on the part of Research Square concerning the legal status of any country, territory, city or area or of its authorities, or concerning the delimitation of its frontiers or boundaries. This map has been provided by the authors. 

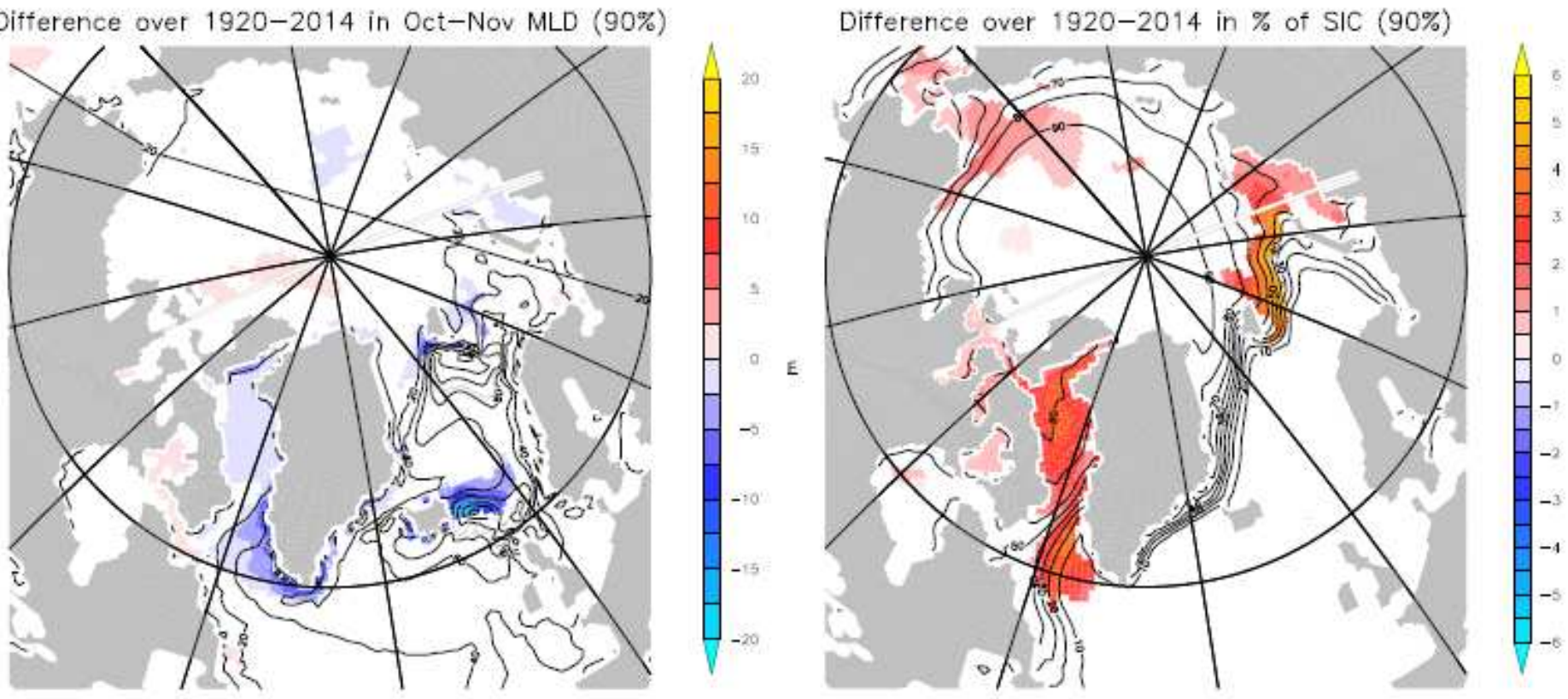

Figure 11

Signicant differences (90\%) between Historical and Melting ensemble means in October-November sea ice cover (left, in \%) and MLD (right, in $\mathrm{m}$ ) averaged over the period 1920-2014. Contour lines are the mean state of the Historical ensemble mean over 1920-2014. Note: The designations employed and the presentation of the material on this map do not imply the expression of any opinion whatsoever on the part of Research Square concerning the legal status of any country, territory, city or area or of its authorities, or concerning the delimitation of its frontiers or boundaries. This map has been provided by the authors. 


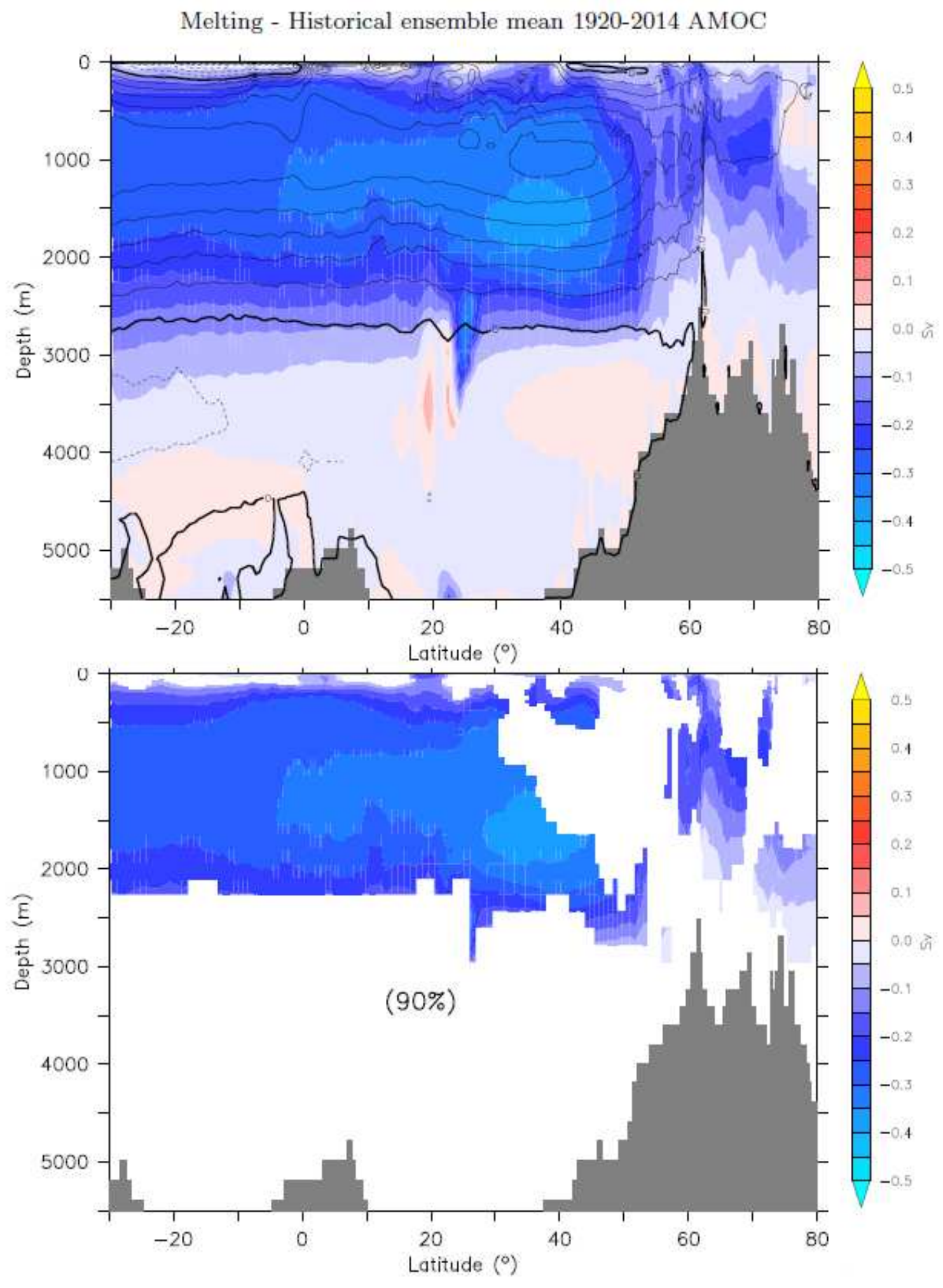

Figure 12

Colors are the differences (top gure) and the signicant (90\%) differences (bottom gure) between Historical and Melting ensemble means of the Atlantic meridional overturning stream-function (in Sv) averaged over the period 1920-2014. Contour lines are the mean state of the Historical ensemble mean over 19202014 


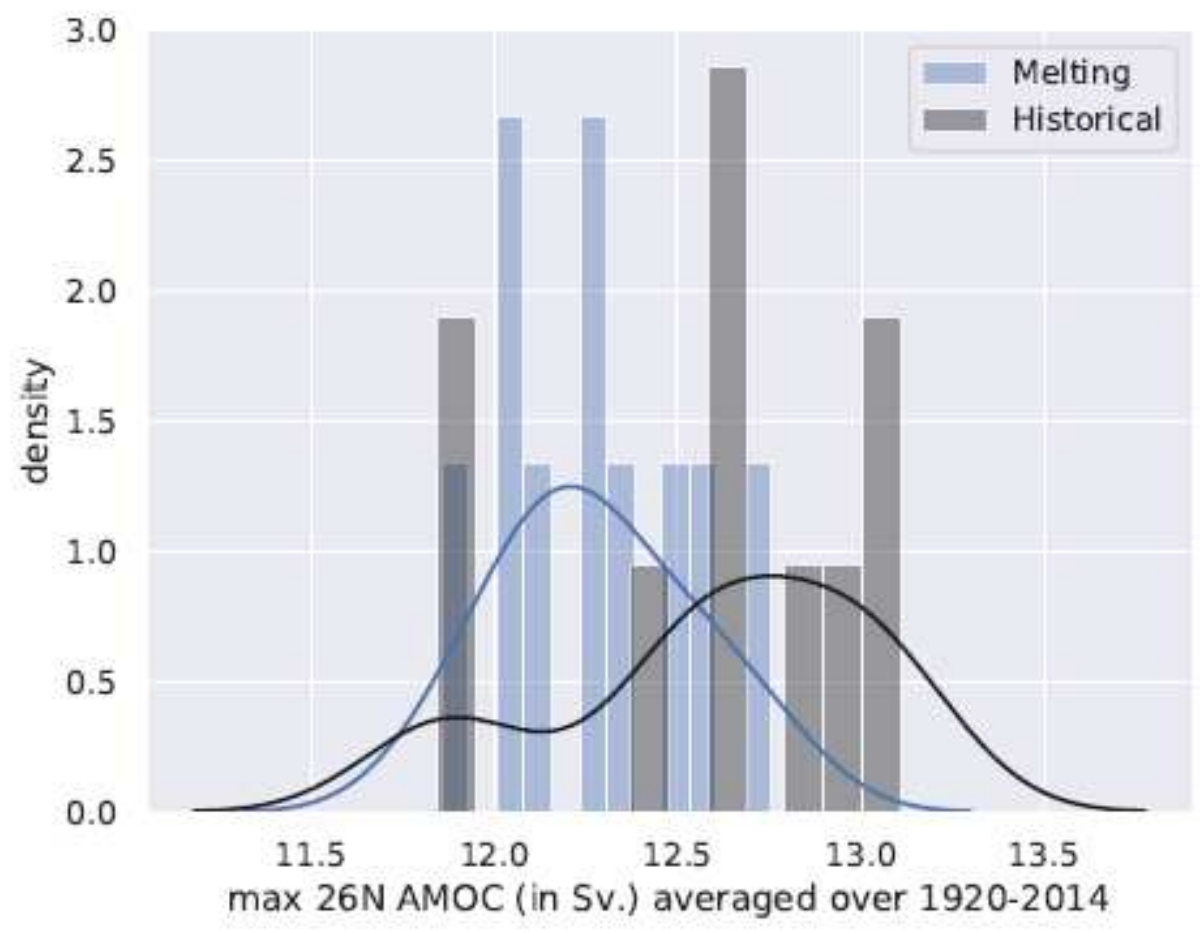

Figure 13

Histograms of the Maximum at $26 \mathrm{~N}$ of the AMOC for the members of the Melting (blue) and Historical (grey) ensembles, averaged over 1920-2014. Solid-lines are the kernelbased estimations of the probability density functions. 


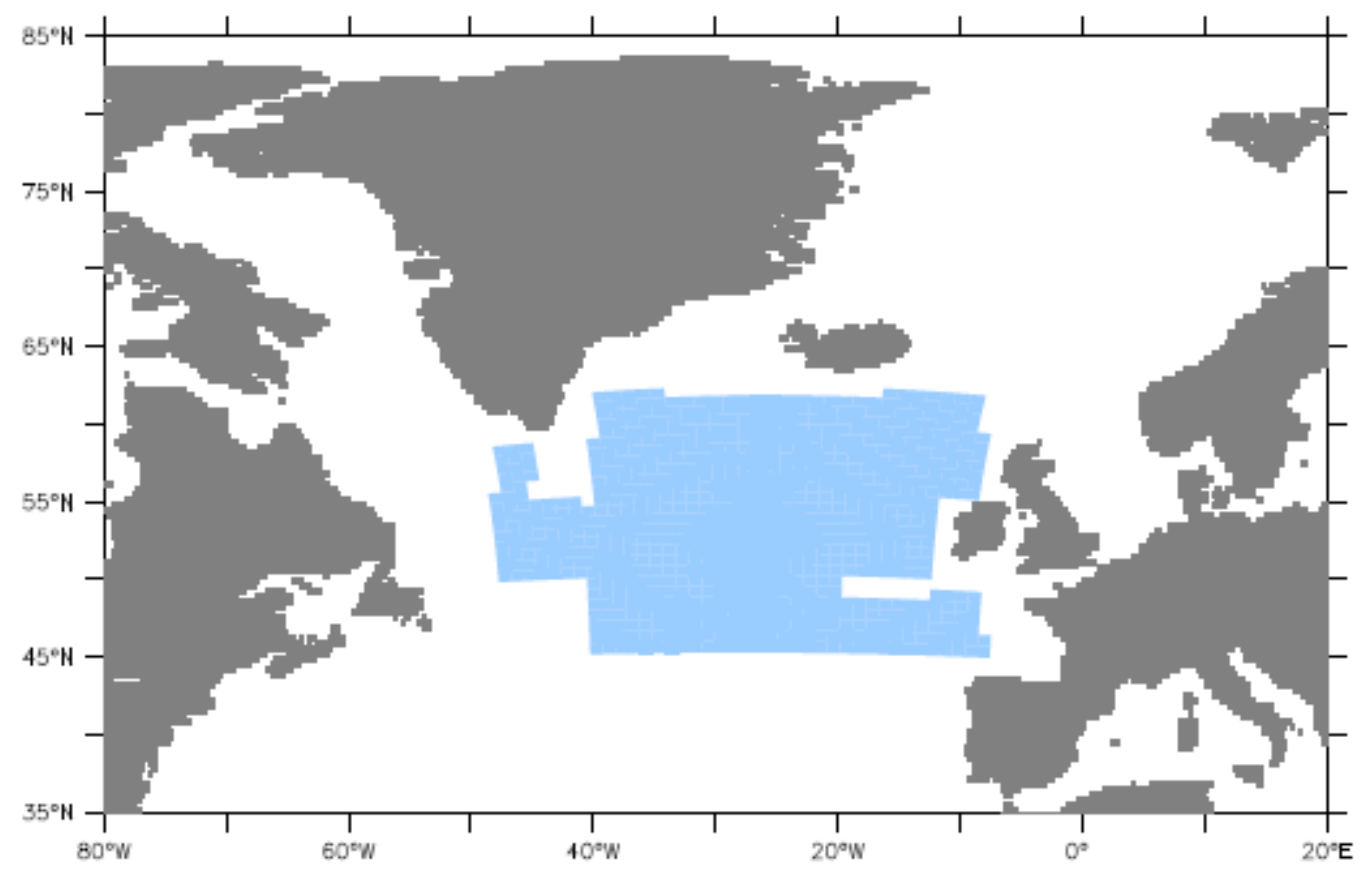

Observations: Friedman et al., 2017 (-) and EN4 (--) Historical ens. mean Melting ens. mean

\section{SSS}

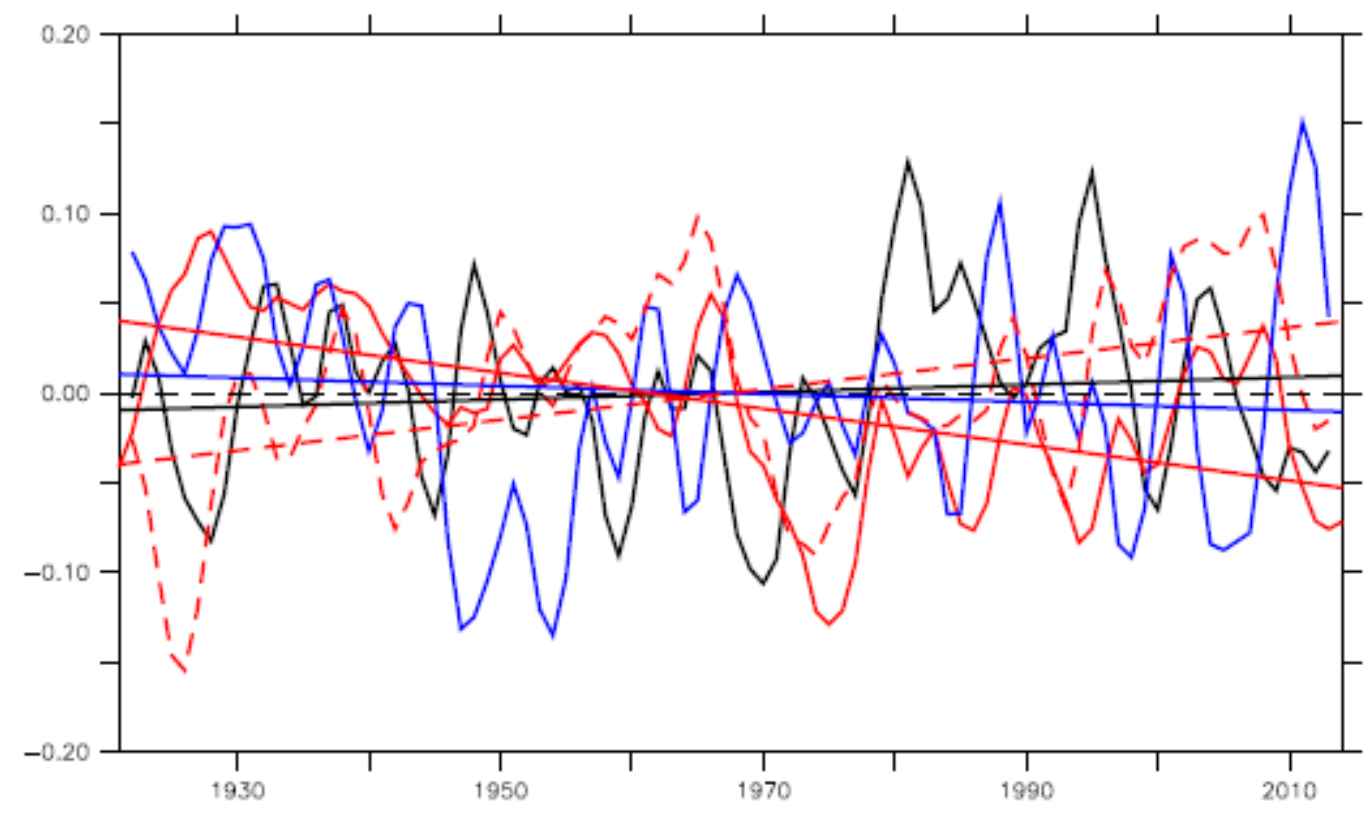

Figure 14

SSS anomalies (in psu), with respect to 1920-2014, and linear trends in the subpolar region (blue region in top panel) for the Historical (black) and Melting (blue) ensemble means. Red lines are the SSS observations: anomalies, with respect to 1920-2014, and trends from Friedman et al. (2017) (continuous line) and EN4 from Good et al. (2013) (dashed line). Note: The designations employed and the presentation of the material on this map do not imply the expression of any opinion whatsoever on the part of Research Square concerning the legal status of any country, territory, city or area or of its 
authorities, or concerning the delimitation of its frontiers or boundaries. This map has been provided by the authors.

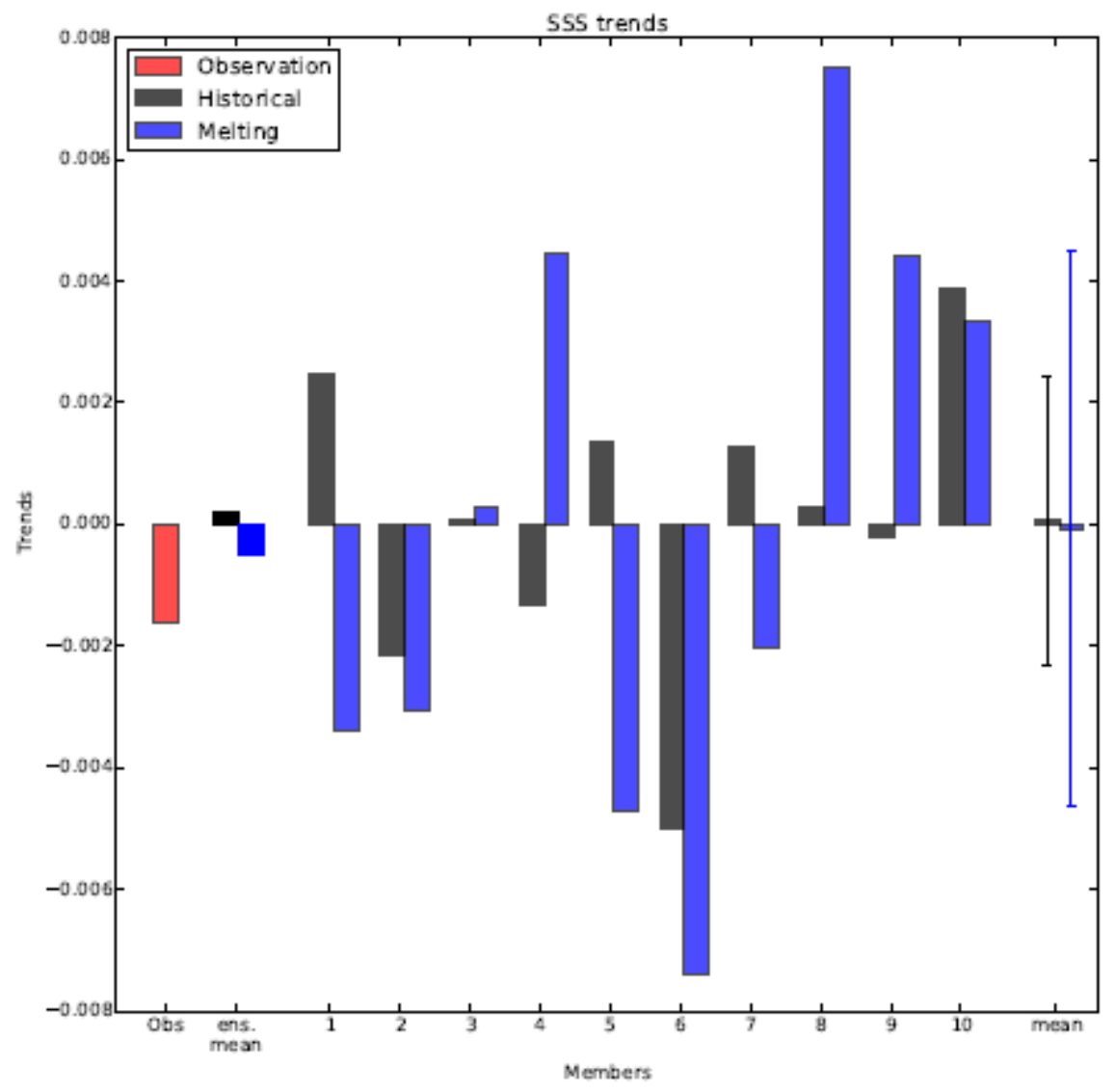

Figure 15

SSS trends for the ten members of the Historical ensemble (black), the Melting experiments (blue) and the observations from Friedman et al. (2017) (red) in the subpolar region (Figure 14, top). The second column represents the trends of the ensemble means, while the last one shows the ensemble means of the trends of the di囚erent members, with the associated error bar (two standard deviations). 


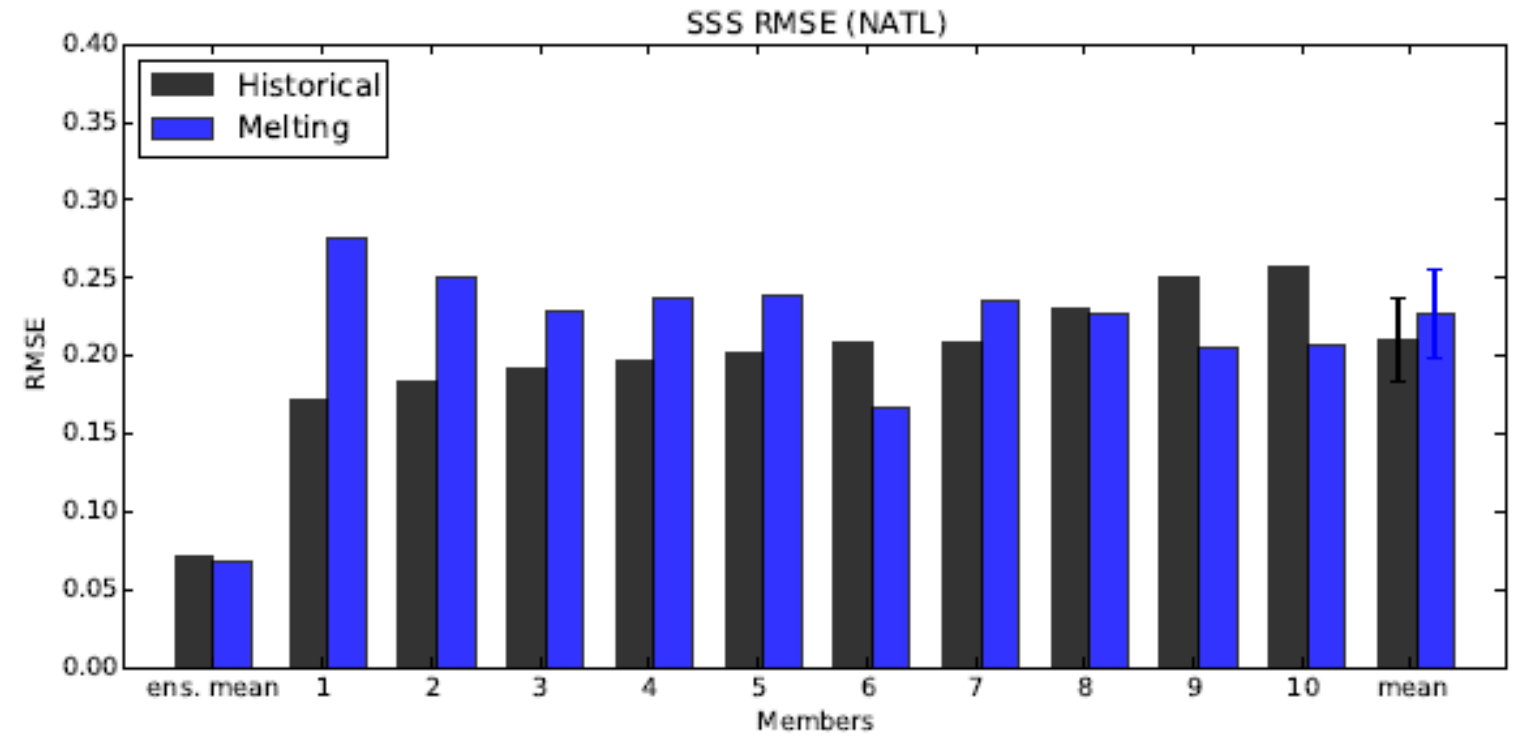

Figure 16

RMSE of the detrended SSS with respect to observations from Friedman et al. (2017) in the subpolar region (Figure 14, top) for the ten members of the Historical (black) and Melting (blue) ensembles. The rst column represents the RMSE of the ensemble means, while the last one shows ensemble means of the RMSE of the different members, with the associated errors bars (two standard deviations) 


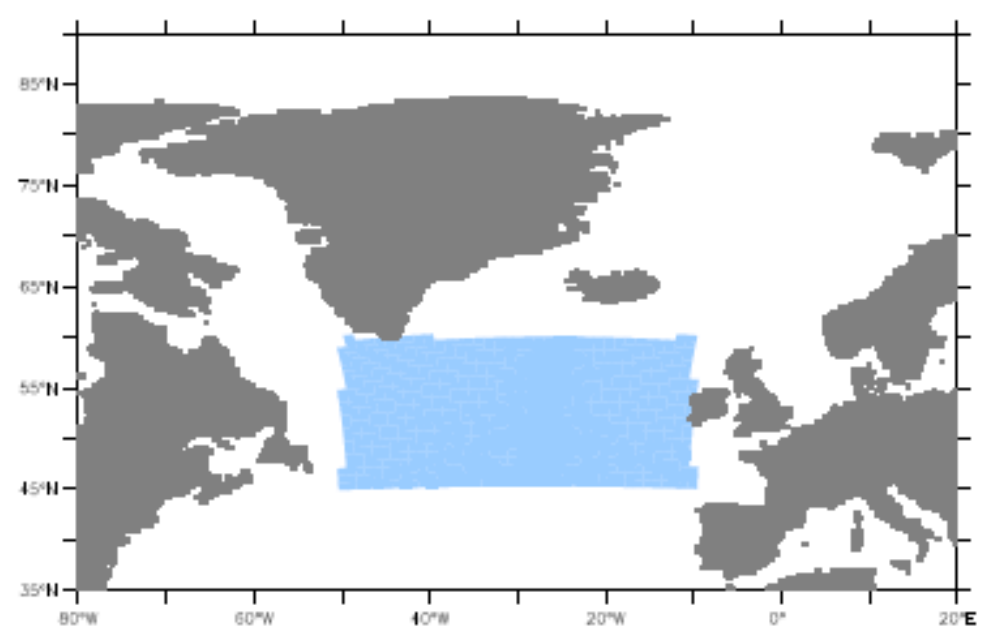

Observations: ERSST (-) and HadISST (--)

SST

Historical ens. mean Melting ens. mean

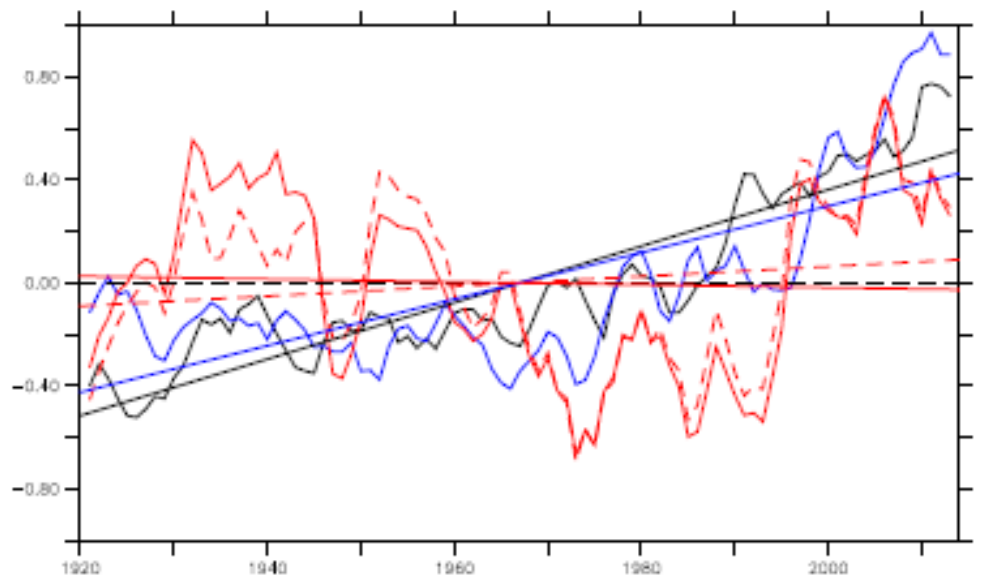

Figure 17

SST anomalies (in oC), with respect to 1920-2014, and trends in the subpolar gyre region (blue region in the top panel) for the Historical (black) and Melting (blue) ensemble means. Red lines are the SST observations: anomalies, with respect to 1920-2014, and trends from ERSST from Huang et al. (2016) (continuous lines) and HADISST from Rayner et al. (2003) (dashed lines). Note: The designations employed and the presentation of the material on this map do not imply the expression of any opinion whatsoever on the part of Research Square concerning the legal status of any country, territory, city or area or of its authorities, or concerning the delimitation of its frontiers or boundaries. This map has been provided by the authors. 


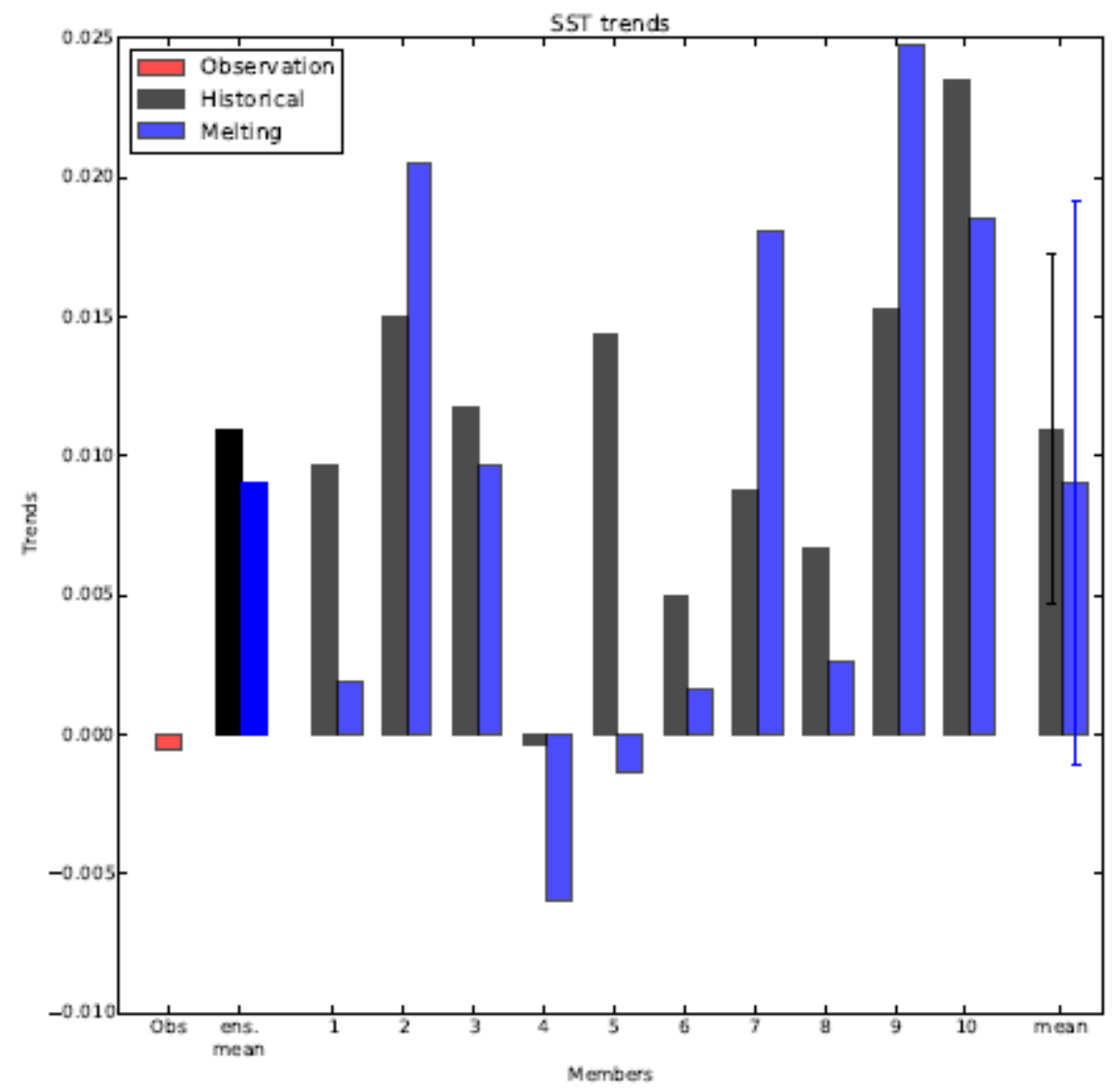

Figure 18

SST trends for the ten members of the Historical ensemble (black), the Melting experiments (blue) and the observations from ERSST (Huang et al. 2016) (red) in the subpolar region (Figure 17, top). The second column represents the trends of the ensemble means, while the last one shows the ensemble means of the trends of the different members, with the associated errors bars (two standard deviations).

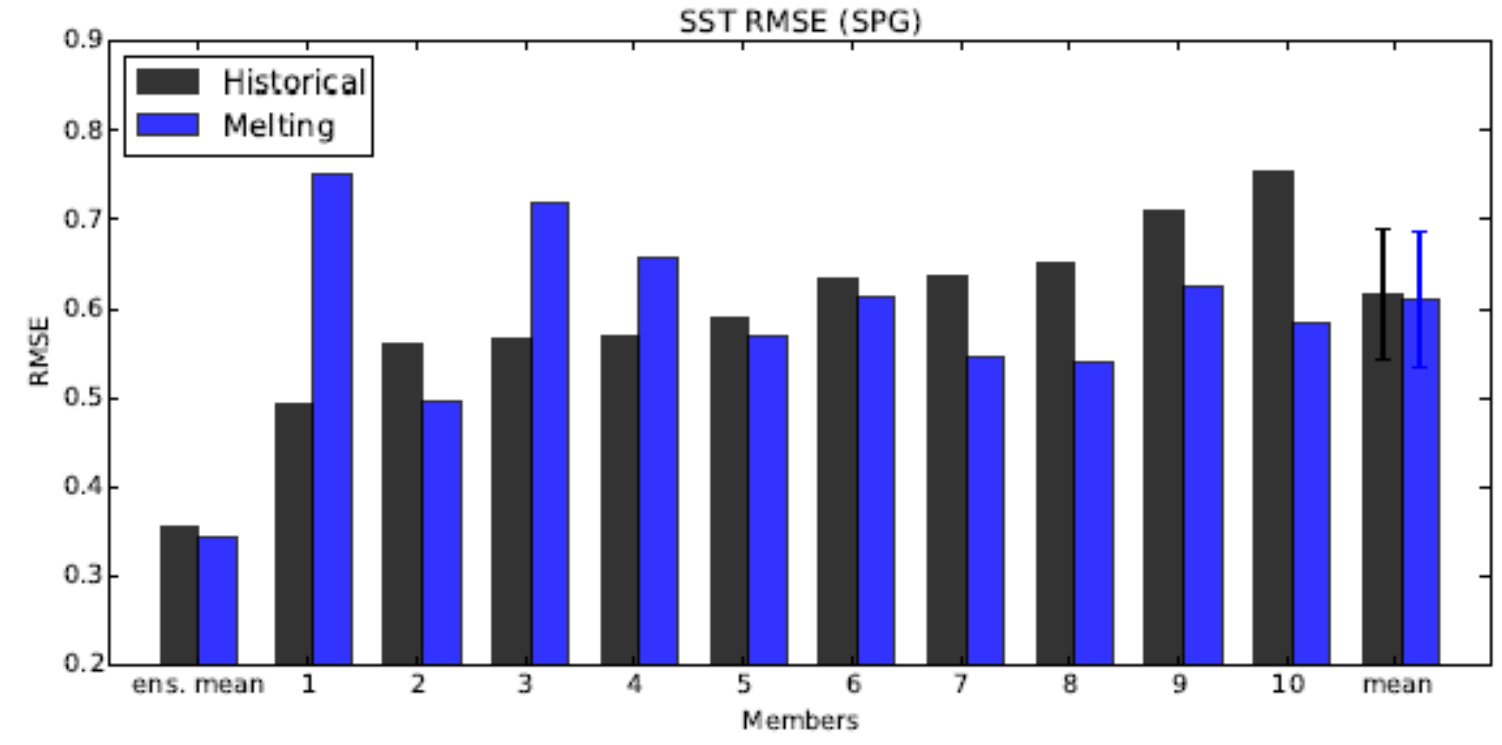

Figure 19 
RMSE of detrended SST with respect to ERSST (Huang et al. 2016) in the subpolar gyre region (Figure 17, top) of the ten members of the Historical (black) and the Melting (blue) ensembles. The rst column represents the RMSE of the ensemble mean, while the last one is ensemble mean of the RMSE of the different members, with the associated error bar (two standard deviations). 